جامعة طنطا

كلية التجارة

\title{
الآليات التى انتهجتها الحكومة المصرية فى برامج الحماية الاجتماعية \\ لإحتواء أزمة كورونا وتحقيق أهداف التنمية المستدامة
}

\author{
إعداد : \\ د/ آمال ضيف بسيونى \\ المعهز العالى للإدارة وتكنولوجيا المعلومات بكفر الثيخ \\ بحث مقدم الى : n \\ المؤتمر العلمى الخامس بكلية التجارة بعوان : \\ أثثر أزمة كورونا على الاقتصاد القومى المقترحات والحلول

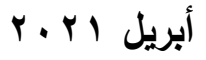




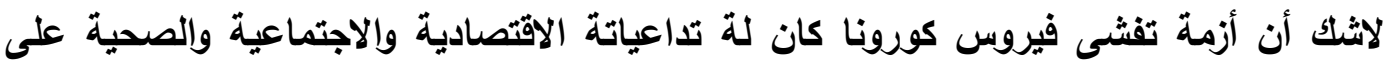

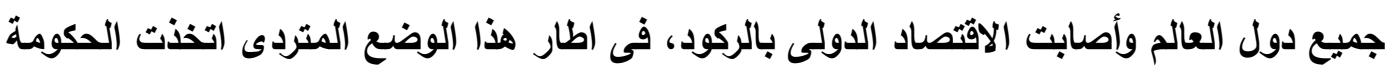

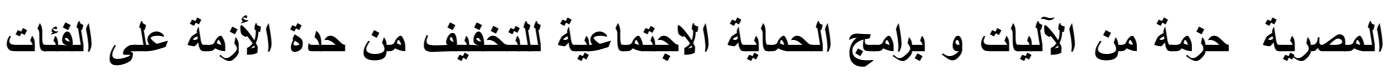

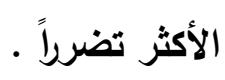

لتحقيق ذلك يناقش البحث أريعة محاور أساسية المحور الأول: تداعيات جائحة فيروس كورونا

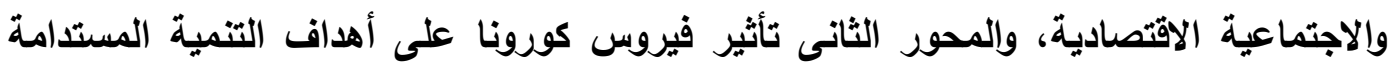

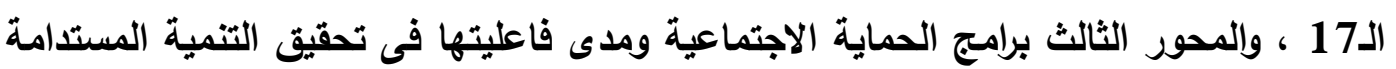

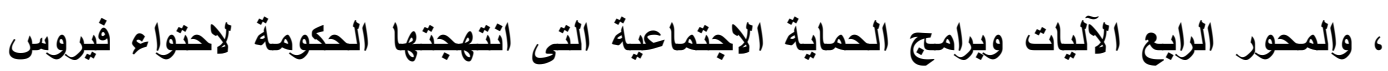
كورونا اتضح من نتائج الداسة أن أزمة كورونا كان لها تداعياتها السلبية الاقتصادية والاجتماعية ليس

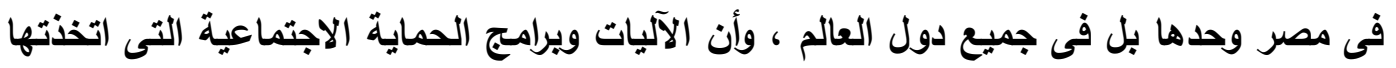

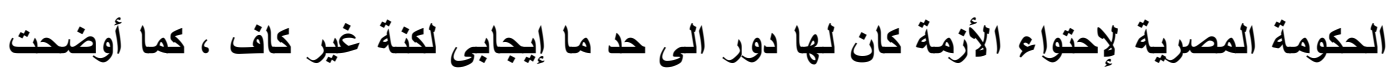

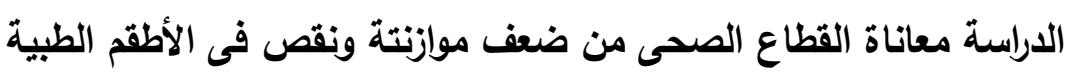

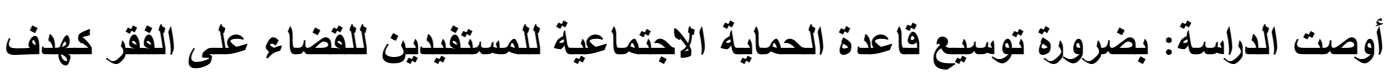

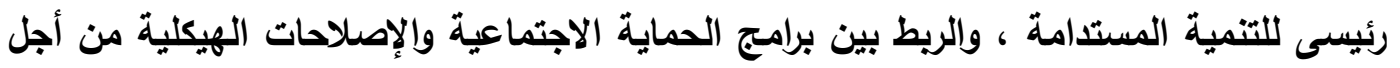

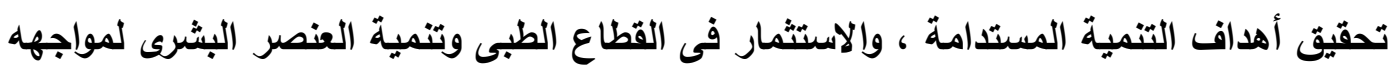
أى أزمات مستقبلية أهنية الكلمات الافتتاحية : أزمة كورونا - الحماية الاجتماعية - التتمية المستدامة - المجتمع المدنى - روئية مستقبلية 


\section{Abstract:}

There is no doubt that the crisis of the Coronavirus outbreak had its economic, social and health repercussions on all countries of the world and hit the international economy into recession. In the context of this deteriorating situation, the Egyptian government took a package of mechanisms and social protection programs to alleviate the severity of the crisis on the most affected groups.

To achieve this, the research discusses four main axes, the first axis: the social and economic repercussions of the Coronavirus pandemic, the second axis the impact of the Corona virus on the 17 sustainable development goals, the third axis the social protection programs and their effectiveness in achieving sustainable development, and the fourth axis the mechanisms and social protection programs that the government has adopted to contain

It became clear from the results of the study that the Corona crisis had negative economic and social repercussions not only in Egypt, but in all countries of the world, and that the mechanisms and social protection programs that the Egyptian government had taken to contain the crisis had an effective role, but it was not sufficient, as the study showed that the health sector suffered from weakness Balancing and shortage of medical teams.

The study recommended the necessity of expanding the base of social protection for the beneficiaries to eliminate poverty as a main goal of sustainable development, linking social protection programs and structural reforms in order to achieve sustainable development goals, investing in the medical sector and developing the human element to face any future crises.

Keywords:

Corona Crisis, Social Protection, Sustainable Development, Civil Society, Future Vision. 
فى ضوء المتغيرات التى مر بها العالم منذ ظهور فيروس كورونا المستجد (COVID - (19)

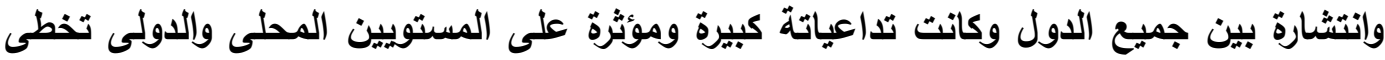
المعارف والحداثة والتكنولوجيا والأنظمة الصحية فى دول العالم المتقدم ، نثر الرعب فى أورويا

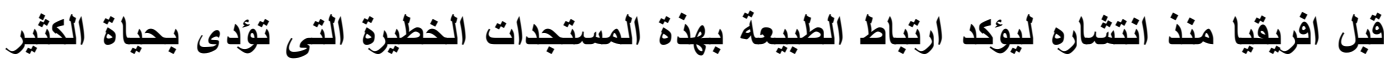

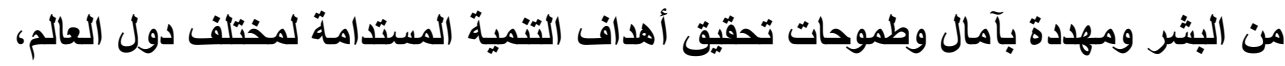
فقد أوضحت أزمة كورونا عن أهمية الهدف الثالث من أهداف التنمية المستدامة والمعنى

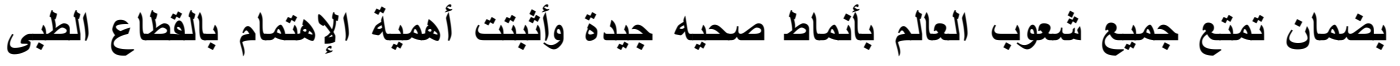

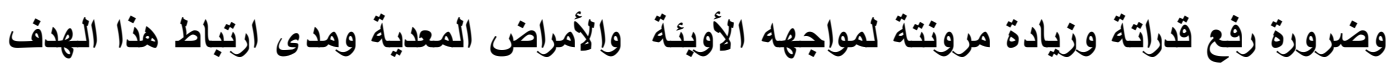
وغاياتة بأهداف أخرى متعددة من أهداف التنمية المستدامة كما اثبتت جائحة كورونا كواندا أهمية

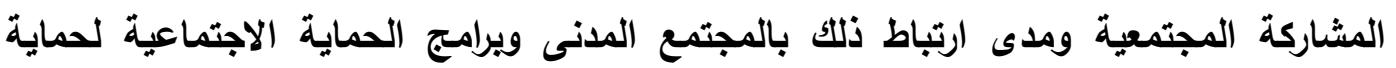
الفئات الأكثر تضراً من هذا الوياء . طبقا لتقرير التنمية المستدامة 2020 الصادر عن هيئة الأمم المتحدة فان الوياء سيقلص

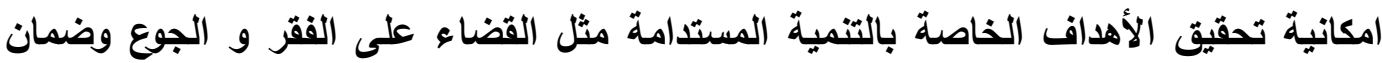

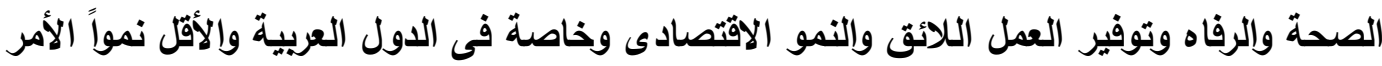
الذى يزيد من صعوية تحقيق خطة التنمية " وطبقا لتقديرات منظمة العمل الدولية فإن 81 \% من القوة العاملة العالمية متأثرة بالاغلاق

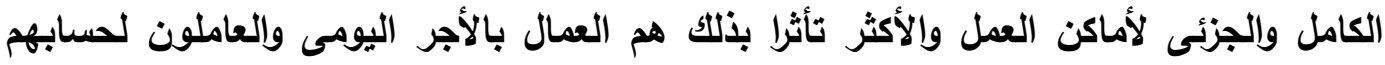

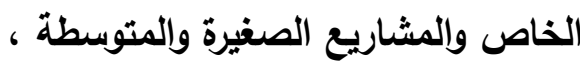
تلك الاوضاع مجتمعة جعت النظم السياسية فى العالم تسعى للبحث عن علاج لإحتواء هذا

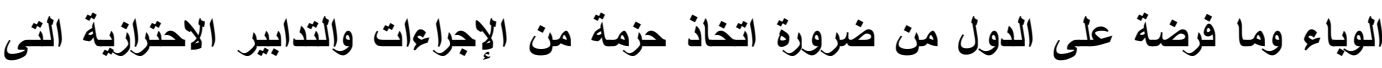

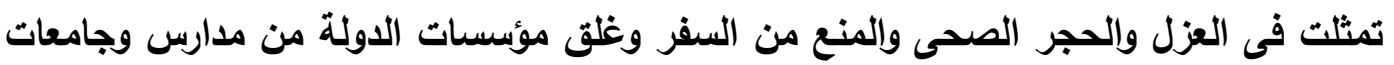
وشركات ومصانع كان لهذا انعكاساتة السلبية على المنظومة الاقتصادية.

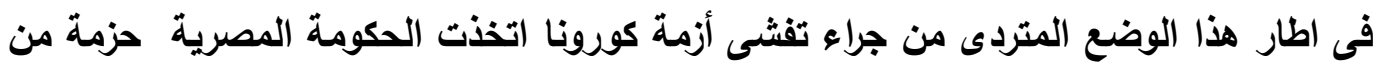
الآليات والتدابير لمواجهة الأزمة على المستوي الاقتصادى والاجتماعى والصحى من خلال التال

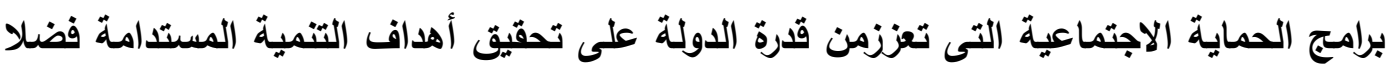

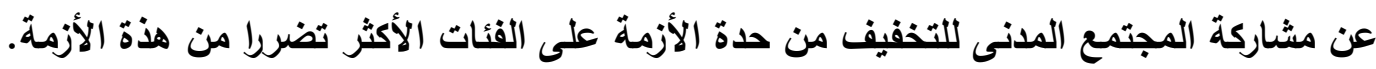

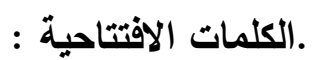
أزمة كورونا - الحماية الاجتماعية - التنمية المستدامة - المجتمع المدنى - روئية 
منذ انتشار وياء كورونا وتداعياتة السلبية على كافة الاوضاع الاقتصادية والاجتماعية ساهم فى الهى تعطيل سبل التقدم نحو تحقيق أهداف التتمية المستدامة وعلى الرغم من أن الحكومة المصرية

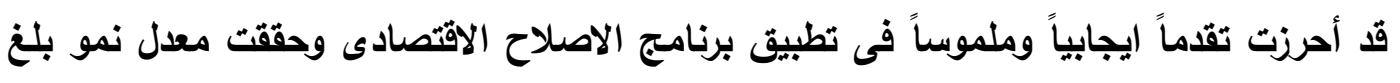

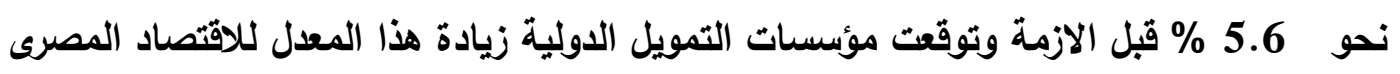

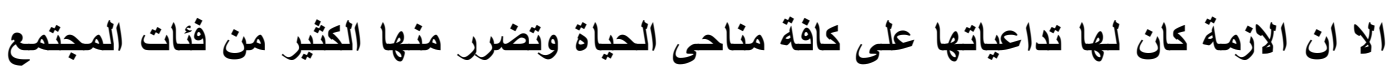
ومؤسساتة الانتاجية، لذلك كان من الضرورى على الحكومة المصرية أن تتخذ من الإجراءات والتدابير الاحترازية لمواجهة تداعيات هذا الفيروس وتحقيق أهداف التنمية المستدامة . من منطلق ذلك تكمن إثكالية البحث فى التساؤلات الآتية : - ماهى التحديات التى واجهت الحكومة المصرية للتصدى لأزمة كورونا - هل ماقامت بة الدولة والمجتمع المدنى من إجراءات وتدابير احترازية كافية لإحتواء الأزمة

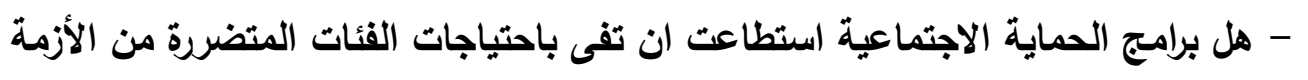
- هل برامج الحماية الاجتماعية يمكن ان تعزز النمو الاقتصادى وتحقى أهداف التنمية المستدامة

- كيف استطاعت مصر أن تحقق التوازن بين مواجهة ازمة كورونا والمحافظه على تحقيق

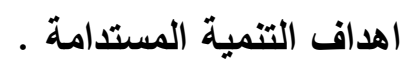
هدف البحث : - معرفة تداعيات أزمة كورونا الاقتصادية والاجتماعية - معرفة مدى فعالية برامج الحماية الاجتماعية فى احتواء أزمة تفشى فيروس كورونا المستجد - معرفة اثر تفشى فيروس كورونا فى القدرة على تحقيق أهداف التتمية المستدامة

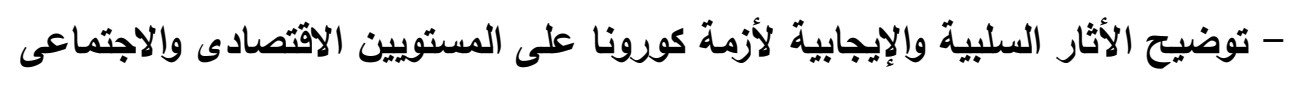
- مدى فاعلية مشاركة الحكومة المصرية و المجتمع المدنى والمنظمات الدولية للتصدى للأزمة

$$
\text { أهمية البحث : الأهمية العلمية : }
$$

- من أبرز الموضوعات التى ظهرت على الساحة الدولية فى الآونة الأخيرة لعام 2020 - يعد محل اهتمام الكثير من المفكرين والاقتصاديين وكافة حكومات دول العالم والمنظمات

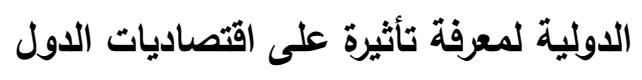
- ان تداعيات أزمة كورونا نبهت كافة دول العالم لأهمية الاستثمار فى العنصر البشرى وخاصة

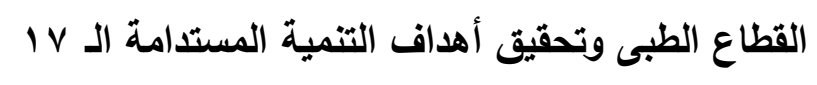
- ان فيروس كورونا المستجد من الامراض المعدية التى شجعت مراكز البحوث العلمية على الهى

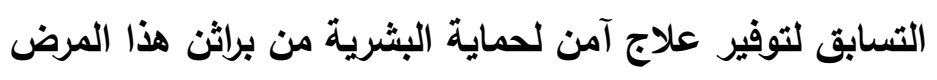
الأهمية العملية : - معرفة مدى التراجع والتقدم الذى أحدثته برامج الحماية الاجتماعية فى احتواء الازمة 
- ان التأثير السلبى لفيروس كورونا المستجد أدى الى سعى الدول الى انتهاج سياسات ويرامج

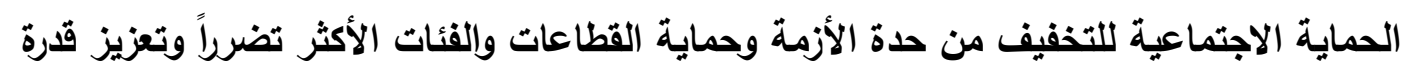
الدولة على تحقيق أهداف التتمية المستدامة الاجنة - الهية التعاون ومشاركة الدولة المجتمع المدنى فى احتواء ازمة تفثى فيروس كورونا المستجد حدود البحث : تقتصر الدراسة على معرفة اثار تفشى فيروس كورونا المستجد على الاوضاع الاقتصادية

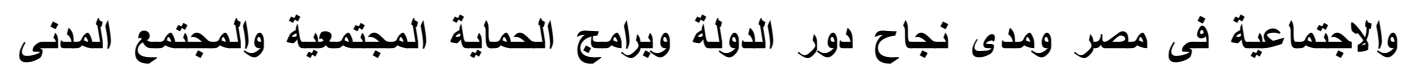

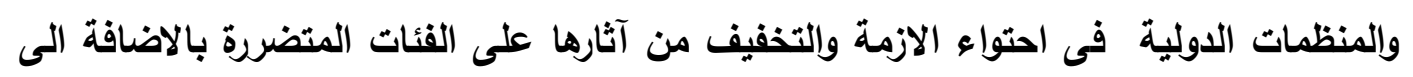

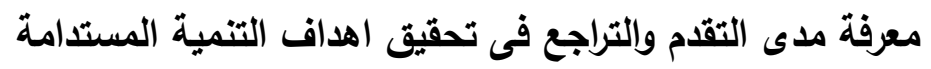

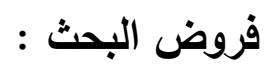

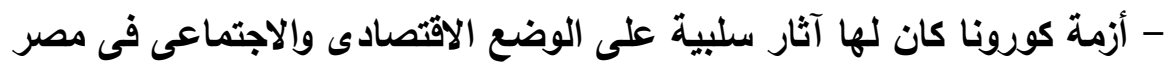

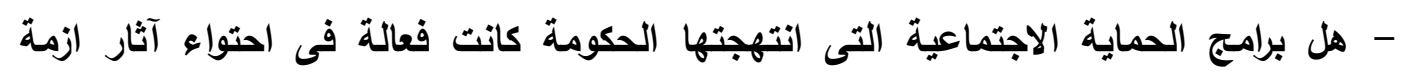

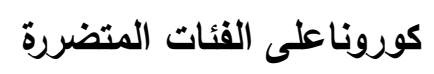
- هل برامج الحماية الاجتماعية التى انتهجتها الحكومة ساهمت فى تحقيق أهداف التنمية المستدامة منهجية البحث : البهة يتبع الباحث المنهج الوصفى التحليلى من خلال الاعتماد على المراجع والكتب والدوريات

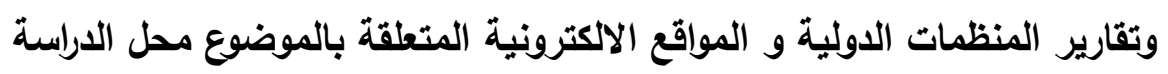

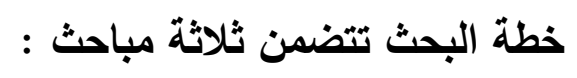

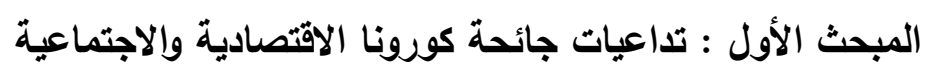

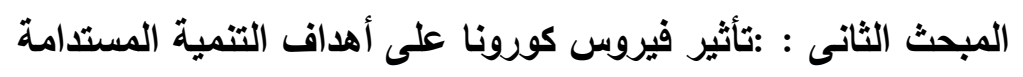

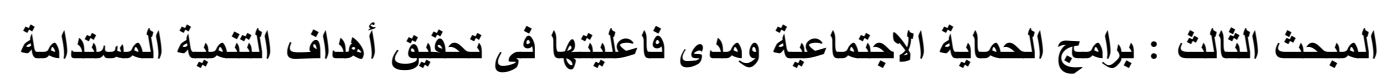

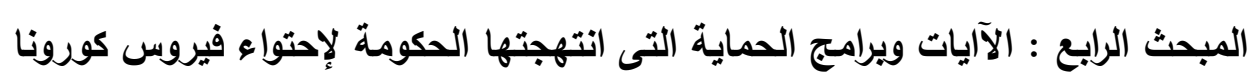
الاسراسات السابقة : الرابع : الابات (1) دراسة (حسين الطلافحة وفيصل المناور 2020) بعنوان: "تداعيات أزمة كوفيد- 19 على العيد

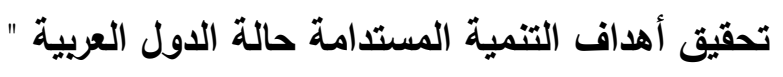

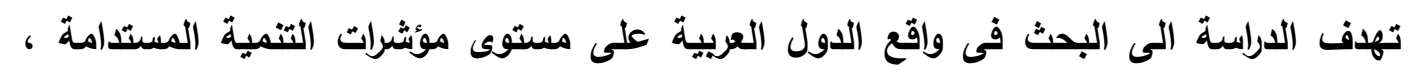

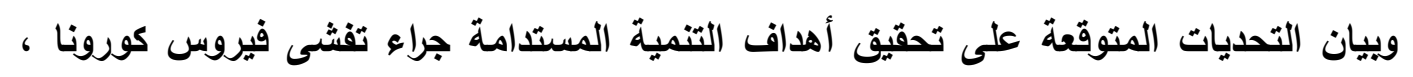

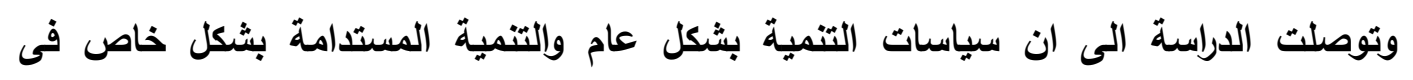

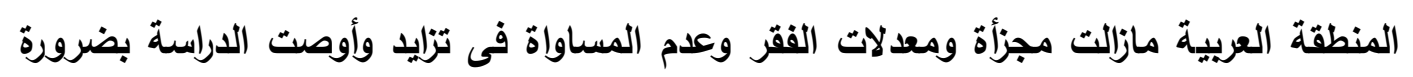

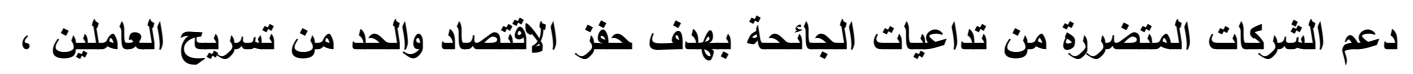

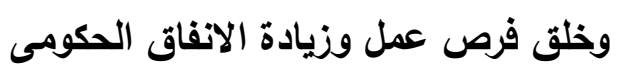


(ץ) دراسة ( محمد أمين لزعر 2020 ) بعنوان : "أزمة كوفيد -19 ودور الصناديق التنموية

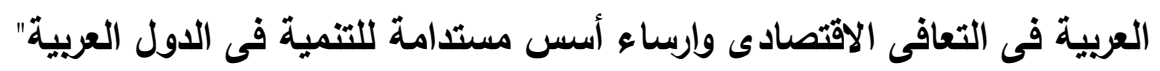
تهاف الاراسة الى معرفة دور الصناديق التنموية العربية فى تخطى الآثار العلبية لأزمة كورونا

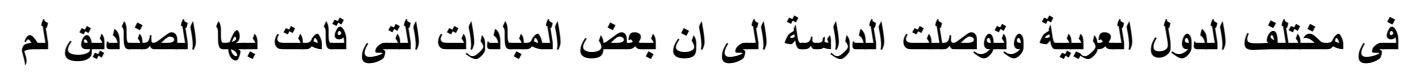

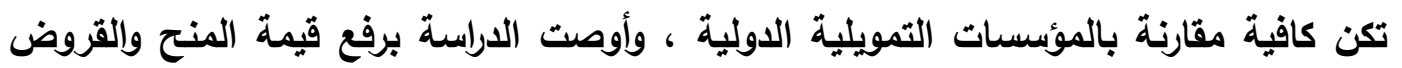
بثرط أكثر يسراً وتمديد فترات السماح وتخفيف أعباء الديون ، وخلق التهات آليات تمويل جليدة ومتنوعة . وبنز

(ץ) دراسة ( علم الدين بانقا 2020) بعنوان : "دور السياسات المالية والنقدية فى حفز النمو

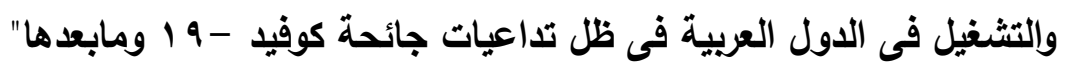

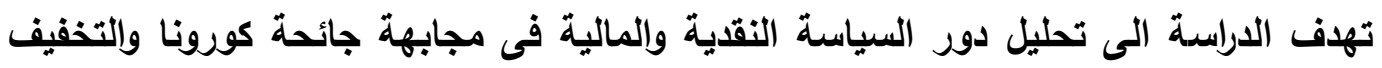

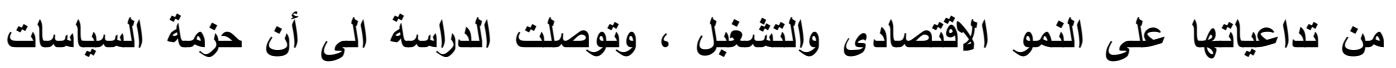

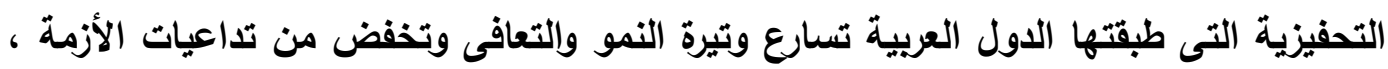

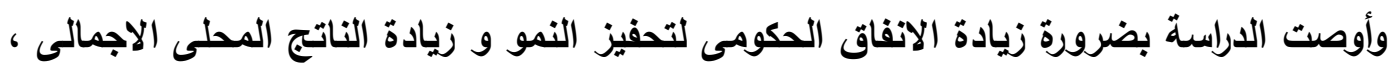

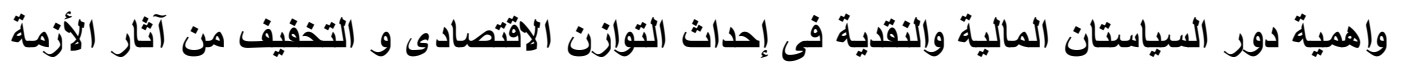

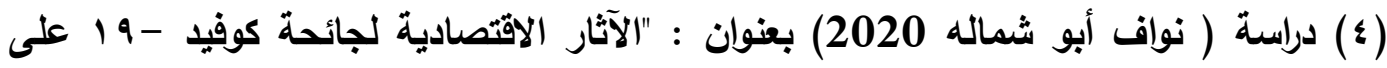

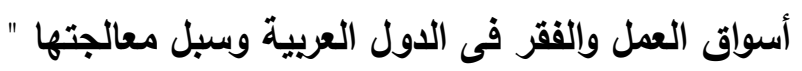
تهدف الدراسة الى تحديد الآثار الاقتصادية لأزمة كورونا على أسواق العمل والفقر فى الدول

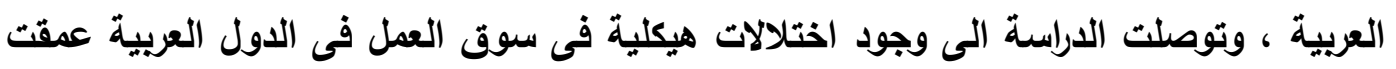

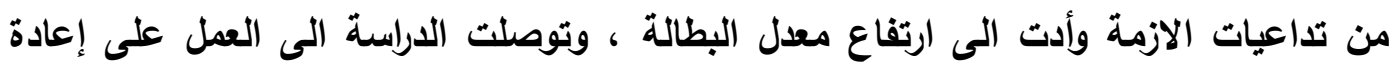

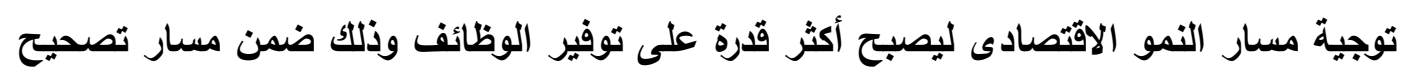

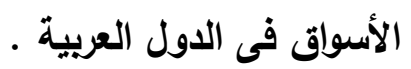

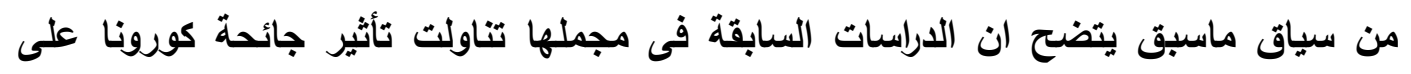

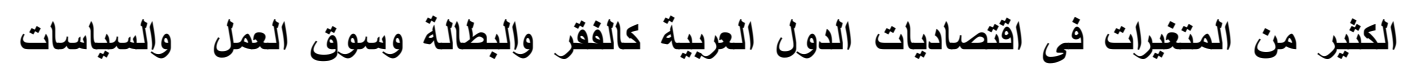

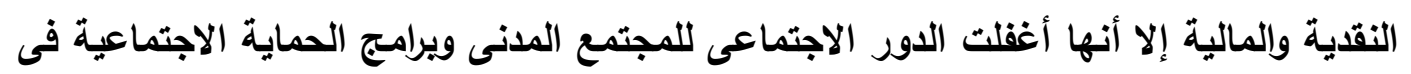

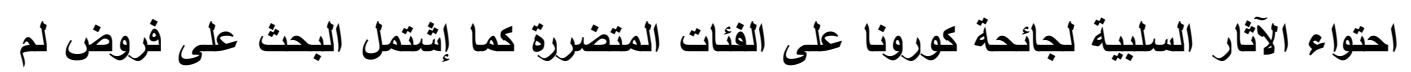

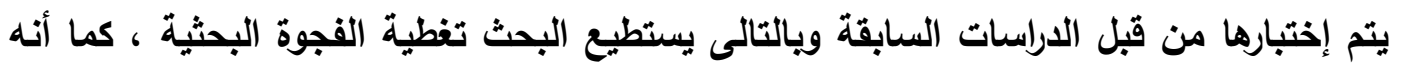

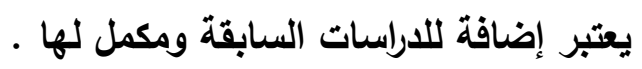




\section{المبحث الأول}

\section{تداعيات جائحة فيروس كورونا الاقتصادية والاجتماعية}

تواجه دول العالم أزمة صحية إنسانية جديدة بدأت فى مدينة ووهان بالصين بتفشى فيروس والتهات Covid-19 أى أزمة سابقة تعرض لها العالم منذ الكساد العظيم عام 1929 - 1939 والأزمة المالية

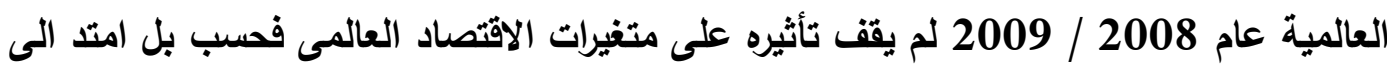

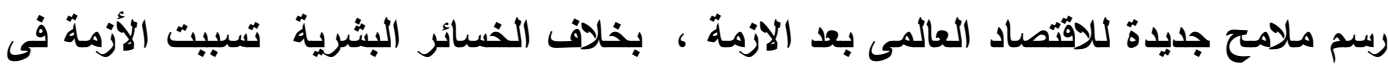

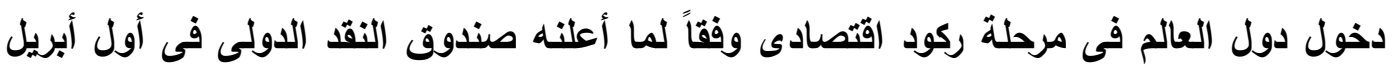

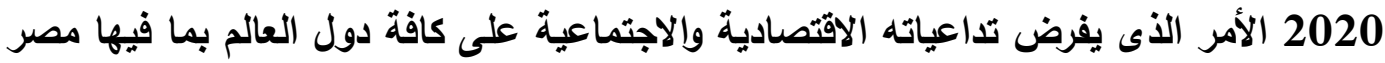

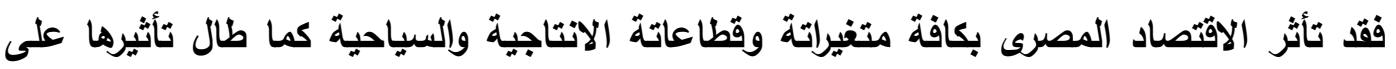

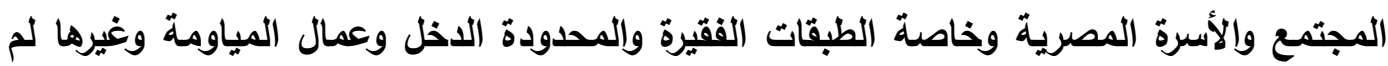
يقتصر الأمر على هذا فحسب فانتشار الفيروس وماترتب علية من توقف جزئى وشامل للأنثطة

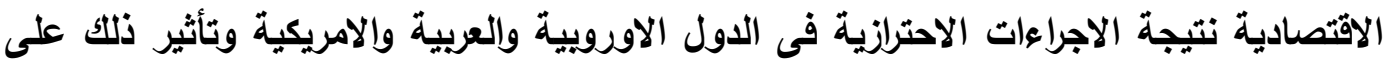

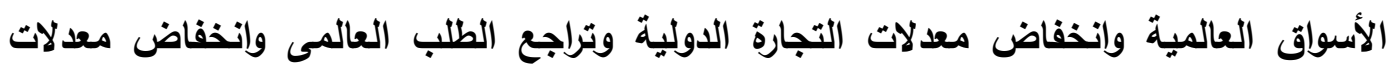

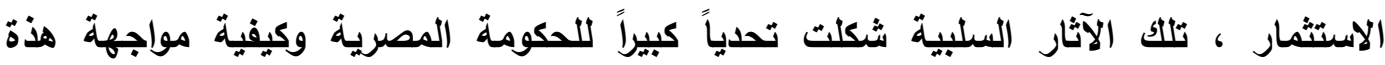

التحديات.

من منطلق ذلك نتناول بالاراسة والتحليل النقاط الآتية :

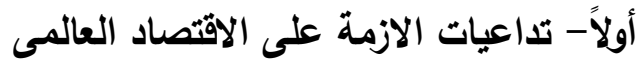

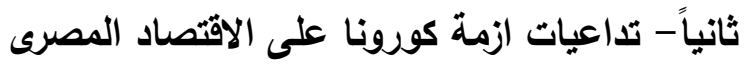
ثالثاً - تداعيات ازمة كورونا على المجتمع والأسرة المصرية

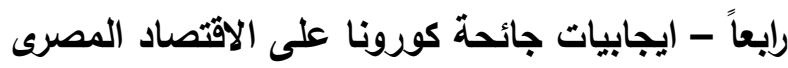

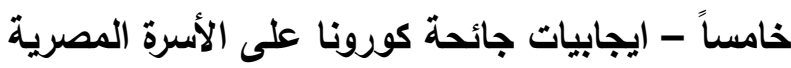
سادساً - التحليات التى تواجة الحكومة المصرية لاحتواء أزمة فيروس كورونا المستجد

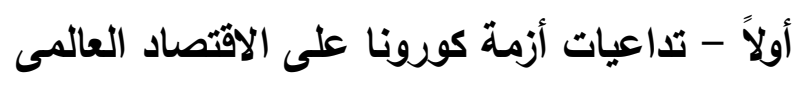

سبيت جائحة 19 COVID-1 العلديد من التداعيات السلبية على الاقتصاد العالمي، وما زال هناك

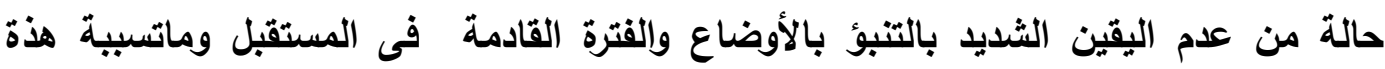

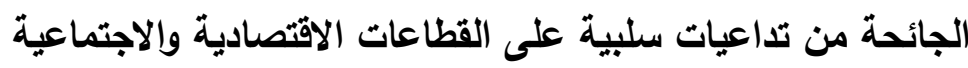
فقدا اجتاح العالم فيروس كورونا المستجد ، وشهـ تطور هذا الفيروس اللعين الذى نبع من بلدة

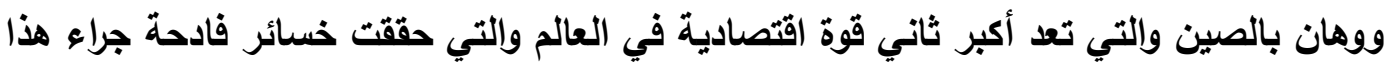

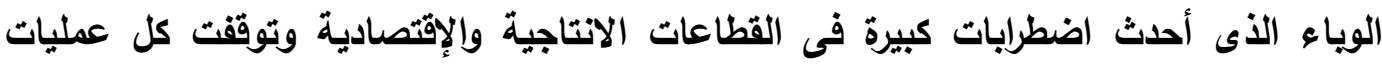


التنمية الاقتصادية والمستدامة وإنخفضت معدلات التجارة الدولية علي مستوي العالم وكان قطاع السياحة الأكثر تضرراً بين القطاعات الاقتصادية بسبب الغاء الرحلات الجوية واغلاق العديد من

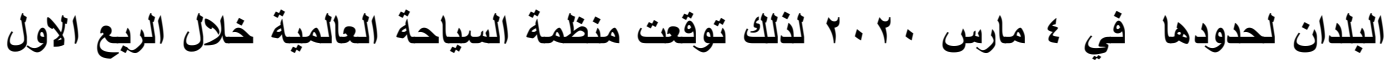
من عام 2020 انخفاض عدد السياح فى العالم بنسبة 22\%، وكذا تراجعت الإيرادات السياحية العالمية مابين 910 بليون دولار و 1.2 ترليون دولار ، كما توقعت المنظمة أن يتسبب الوياء

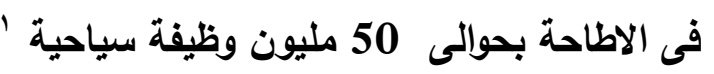
أكد صندوق النقد الدولي أن اقتصاديات الدول تتجه نحو مسارات أكثر ركودا وأكثر خطورة و أن هذا الوياء يختلف عن باقي الأويئة التي مر بها العالم في العصور القديمة لأنه سبب أضراراً جسيمة باقتصاديات الدول الكبري ومن أهمه الصين واليابان والمانيا ويريطانيا وايطاليا وفرنسا والولايات المتحدة الامريكية فقد تراجعت معدلات التجارة الدولية علي المستوي العالمي بسبب أن هذه الدول تمثل حوالي اء؛ من الصادرات الصناعية علي مستوي العالم و ه ٪\% من التصنيع

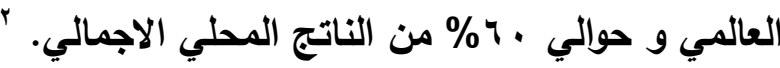
تفاوتت تقديرات المؤسسات الدولية بحجم خسائر الاقتصاد العالمى فقد قدرت مؤسسة بلومبرج أن الأزمة تسببت فى خسائر بلغت 2.7 تريليون دولار بينما قدر مؤتمر الأمم المتحدة للتجارة والتنمية UNCTAD أن فيروس كورونا المستجد قد تسبب فى انخفاض الانتاج العالمى وخسائر فى قطاع التصدير وحده وصلت الى 50 مليار دولار وتراجعت الاستثمارات الأجنبية المباشرة على مستوى العالم بنسب تراوحت بين · r - . ؛ \% من قيمتها ، وأيضاً قدرت منظمة العمل الخسائر

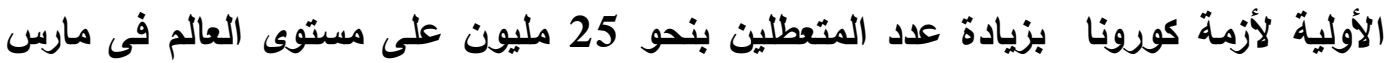

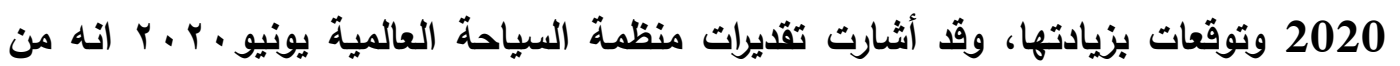
المتوقع انخفاض عدد السياح عالمياً بحوالى 97 \% عام 2020 مما يؤدى الى تحقيق خسائر تقدر بنحو 195 مليار دولار وتضرر نحو 120 مليون وظيفة مباشرة فى قطاع السياحة على مستوى العالم خلال عام 2020 " ، وأن 147 مليون شخص فقدوا وظائفهم ،وإنخفض الاستهلاك العالمى بنسبة 4.2 \% أى مايعادل 3.8 ترليون دولار ؛؛ كما قدر البنك الدولى ملى

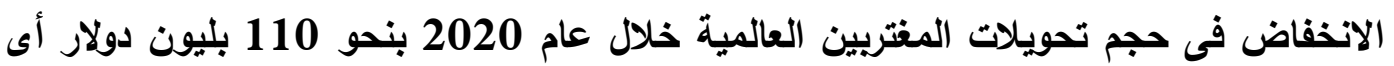
بنسبة 20 \%مع توقع بانخفاضها فى دول افريقيا جنوب الصحراء بنسبة 23\%. • هذا

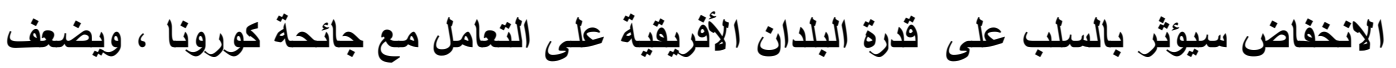

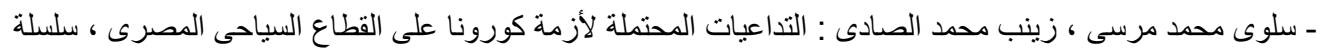

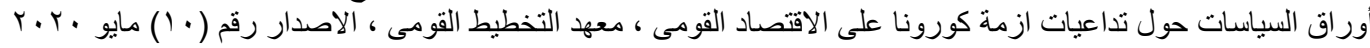

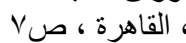

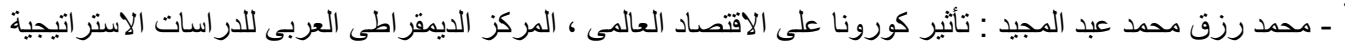

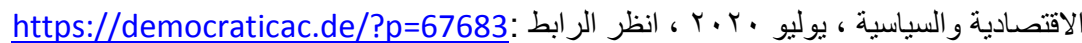

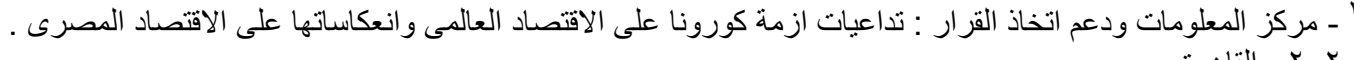

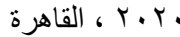
https://www.skynewsarabia.com/business/1360270 :

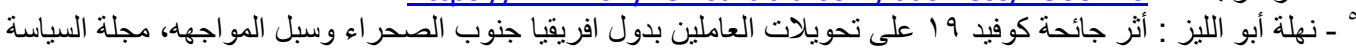

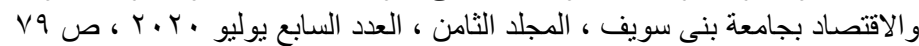
-Source: world bank, COVID-19 Crisis Through a Migration Lens, Migration and Development, Brief no. 32 , (world bank Washington D.C., April 2020), p.8
} 
من قدرتها على تحقيق أهداف التنمية المستدامة، وقد حذر المعه العالمي لأبحاث التنمية والاتتصاد التابع للأمم المتحدة من أن تداعيات كورونا المدمرة قد تتسبب في زيادة معدلات الفقر العالمي بما يعادل نصف مليار شخص (^٪ من اجمالي تعداد سكان العالم) وهي المرة الأولى التي سيزيد فيها الفقر خلال 30 عاما منذ 1990' بالاضافة الى تفاقم حدة الدين على العالمى ليصل إلى ^ه ب تريليون دولار (ما يعادل هبr\% من الناتج الاجمالي المحلي العالمي)، وتعود هذة الخسائر الى طبيعة الاقتصاد العالمى الأى أصبح أكثر تداخلاً وتثابكاً فى القرن الواحد والعشرين لتعاظم دور ثورة الاتصالات والعولمة التى جعلت العالم قرية صغيرة سريعة

الاتصال والتشابك فيما بينهما . التواند ثانياً - تداعيات أزمة كورونا على الاقتصاد المصرى تعد أزمة كورونا أزمة لم يشه التاريخ مثلها فهى لم تكن أزمة اقتصادية فحسب بل أزمة الزمة صحية واجتماعية وإنسانية أصابت البشر والمجتمعات بكارثة لم يدرك العالم مداها أدت الي حدوث ركود اقتصادي عالمى ومصر من الدول التى تأثرت بهذا الوياء . واجه الاقتصاد المصرى داعيات تفشى فيروس كورونا المستجد فى توقيت يأتى بعد الجهود المضنية التى بذلتها مصر لعلاج الاختلالات التى كان يعانى منها الاقتصاد المصرى وذلك من لأن خلال برنامج الاصلاح الاقتصادى منذ عام 2016 والذى بدأت مصر تجنى ثمارة الإيجابية على الأنى الأوضاع الاقتصادية والاجتماعية بشهادة المؤسسات المالية الدولية فقد حققت معدل نمو بأل

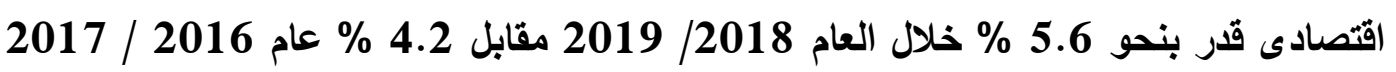
، إلا أن جائحة فيروس كورونا كادت أن تطيح بانجازات الاصلاح الاقتصادى لولا صلابة الاقتصاد المصرى وقوتة، فانخفض الى 2.3 \% رغم أنة مازال ايجابى مقارنة بدول عربية أخرى حققت معدلات نمو سلبية فقد كان لتداعيات الأزمة آثار سلبية على معظم قطاعات الاقتصاد القومى نتيجة اعلان التدابير الاحترازية لمواجهة أزمة كورونا فقد حققت مصر خسائر مالية باهظة بلغت حوالي 4 مليارات جنيه و خسائر قطاع الطيران بلغت حوالي 2.25 ملياري جنيه كما

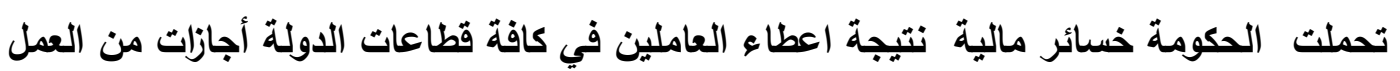
لتقليل الكثافة ، وكان قطاع السياحة من ضمن القطاعات الأكثر تضراً حيث بلغت خسائرة

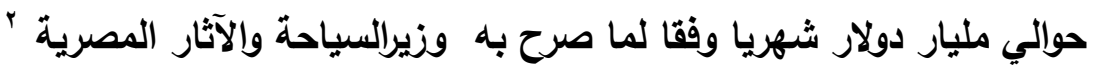

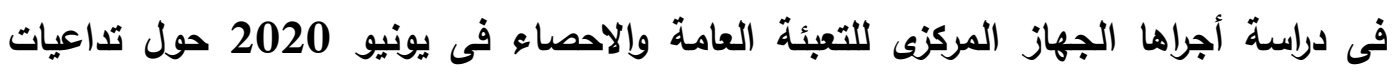
فيروس كورونا المستجد على الاقتصاد المصرى فقد بينت الدراسة التغيرات فى بعض المؤشرات الاقتصادية الكلية حيث انخفض الناتج المحلى الاجمالى الحقيقى فى الريع الثالث من عام 2019 / 2020 بمقدار 0.6 نقطة مئوية حيث سجل 5\% فى 2020/2019 مقابل 5.6 عام 2018/ 2019 ، كما شهر الجنية المصرى انخفاضاً خلال الفترة من فبراير حتى مايو

$$
\text { ' ـ دعاء عبد المنعم : أثر كورونا على الدول النامية ، جريدة الأهرام اليومية ، مؤسسة الأهرام ، القاهرة ، بتاريخ. }
$$

World Tourism Organization,UNWTO:International Tourism Arrivals Could Fall By $20-30 \%$ in 2020 ,newsrelease,27 March,2020,p.21 
2020 بلغ نحو 1.8\% تزامناً مع تراجع التدفقات الدولارية نتيجة انخفاض الصادرات السلعية بمعل 39.4\%عن نفس الفترة ، وانخفضت ايرادات قناة السويس لتأثر التجارة العالمية بشكل عام بجائحة كورونا وسجل معل التغير الثهرى للايرادات أدنى مستوى فى شهر مايو 2020 (27.5\%) كما انخفضت الحمولات من 101.8 مليون طن الى 84.2 مليون طن ، وانخفضت فئس أعداد السفن من 1731 الى 1381 سفينة خلال الفترة أبريل - يونيو 2020 ، كما لحق الضرر الجسيم بقطاع السياحة والصناعات المغذية من خلال خفض ساعات العمل أو تقليص

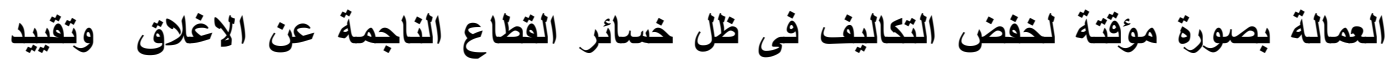
السفر فى جميع انحاء العالم حيث تم الغاء 70 - 80\% من حجوزات الفنادق فانخفضت

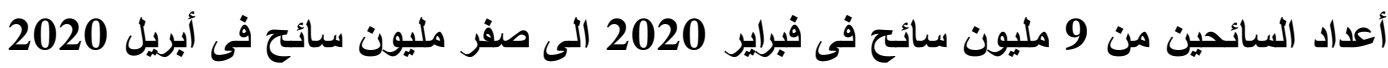

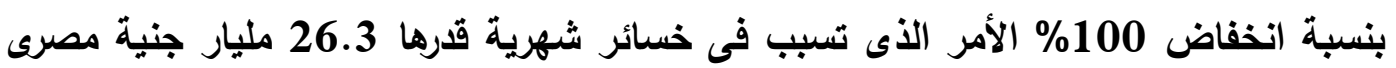

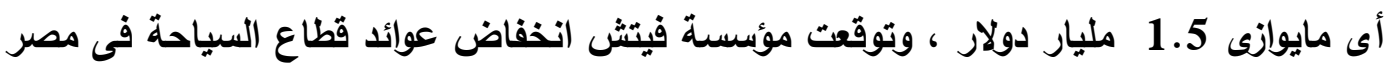

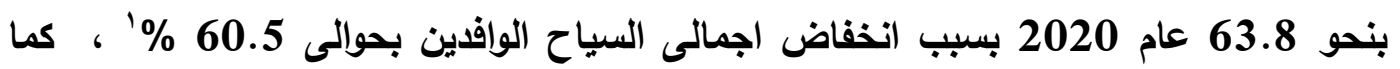
انذفضت ايرادات السكك الديدية بنسبة 55.7\% خلال الفترة من فيراير- ابريل 2020

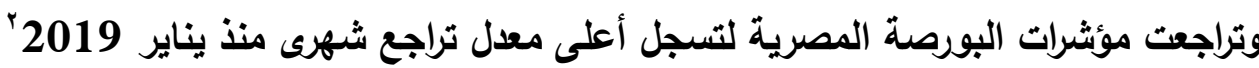

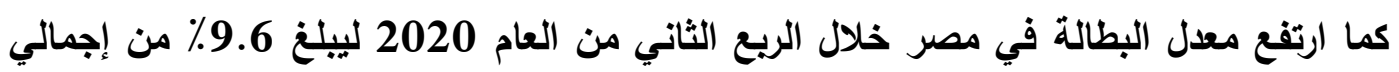

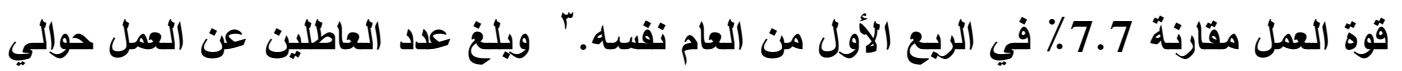
2.5 مليون، مقارنة 2.2 مليون متعطل في الريع الأول من العام 2020، كما سجل معلد الأل التضخم السنوى لإجمالى الجمهورية 6.8\% لعام 2020 ، و تراجع معدل التغير السنوى

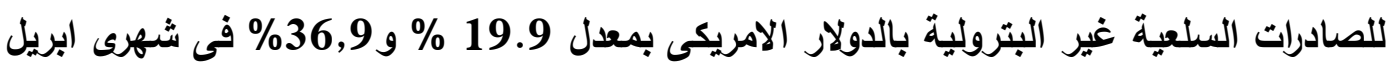
ومايو 2020 على التوالى ، كما شهذ معدل التغير السنوى للواردات السلعية غير البترولية

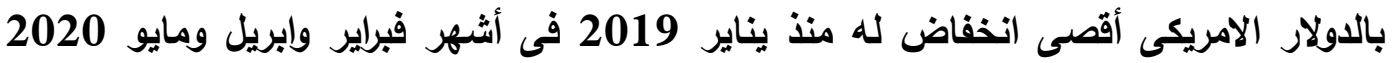

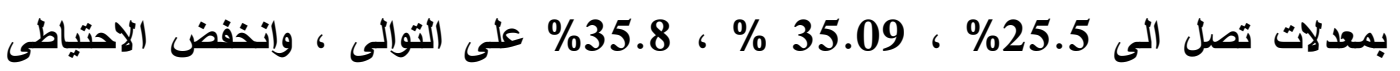
الأجنبى الذى بلغ 45.5 مليار دولار عام 2019 25.5 ، 40 مليار دولار فى الربع الاول من عام الام

ثالثاً - تداعيات أزمة كورونا على الأسرة المصرية

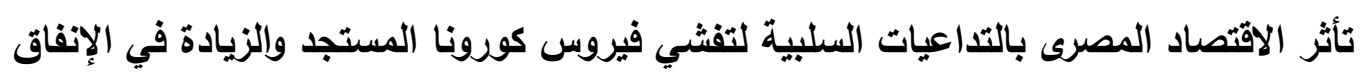

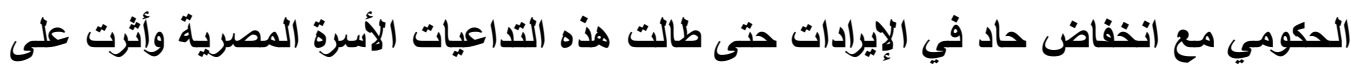

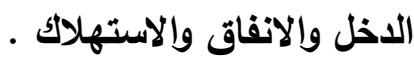


فى دراسه أجراها الجهاز المركزي للتعبئة العامة والإحصاء' للكثف عن تأثير جائحة فيروس كوروناعلى جميع العوامل التى تؤئر فى دخل ونمط استهلاك الأسرة المصرية منذ بداية تفشي الفيروس في فبراير 2020 حتى نهاية مايو2020 بينت الدراسة أن أزمة فيروس كورونا أثرت على تغير الحالة العملية للمشتغلين من( 15- 64 سنة) حيث تبين أن 61.9 \% تأثرث حالتهم العملية منهم 26\% تركوا أعمالهم نهائياً ، وأن أعلى فئة تأثرت بالتغير فى الحالة العملية الفئة

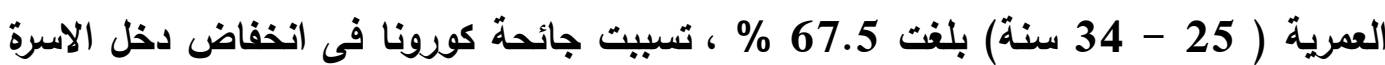
المصرية وخاصة عمال المياومة والعمال اللأين ليس لايهم دخل ثابت بسبب الإجراءات الإحترازية التى اتخذتها الحكومة لمنع تفشى الفيروس ، وأن نسبة 73.5\% أفادوا بانخفاض دخولهم وأن 31.8\% من الأسر المصرية فى المناطق الحضرية و34.3\% من الأسر فى المناطق الريفية أفادوا بأن مستويات الدخل لاتكفى لتلبية احتياجاتها؟ وأن نسبة قليلة من الأسر حوالى 5.4 \% حصلت على منحة العمالة غير المنتظمة . كما تأثر نمط الاستهلاك اليومى لاى الأسرة المصرية من السلع الغذائية والسلع غير الغذائية فقد تبين انخفاض استهلاك الأفراد من اللحوم بنسبة 25.7 \% والطيور بنسبة 22.8 \% \%الاسماك بنسبة 17.5 \% والفاكهة بنسبة 14.5 \% وذلك بسبب زيادة أسعار السلع وإنخفاض دخل الأسرة المصرية وعلى الجاتب الآخر ارتفع استهلاك الأسرة من السلع الغذائية

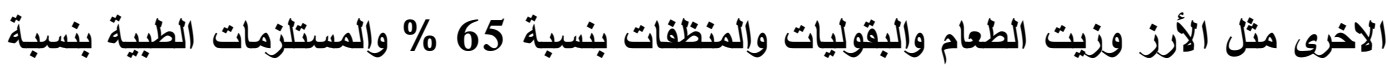
45 وفواتير الانترنت بنسبة 38.6 \% لحوالى 80\% من الأسر المصرية وذلك لملاءمة

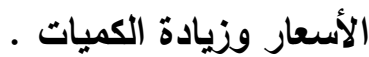

بالنسبة لاستهلاك الاسرة المصرية من السلع غير الغذائية حوالى 90 \% من الأسر المصرية

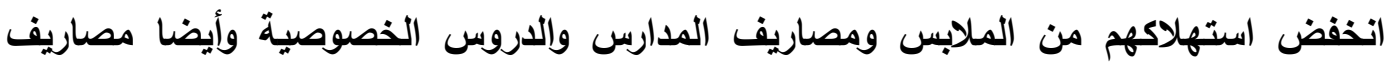
النقل والمواصلات بنسبة 27.2 \% ، 30.8\% ، 33.5 \% ، 33.2 \% على التوالى ويرجع ذلك الى الإجراءات الإحترازية التى اتخذتها الحكومة المصرية للحد من انتشار الفيروس مثل اغلاق المدارس والمطاعم والمقاهى وساعات الحظر، واستطاعت الأسرة المصرية مواجهه الفيروس وتغطية احتياجاتها من خلال التصرفات الآتية :

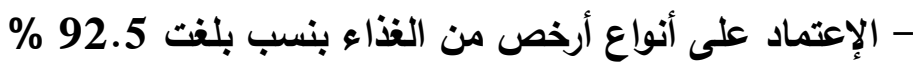
- تخفيض نسب الاستهلاك الإسبوعى من اللحوم والاسماك والطيور 89.8 \% - الاعتماد على الأصدقاء والأقارب بنسبة 50.1 \% أو استخدام المدخرات - تقليل كمية الطعام بين الوجبات بنسبة 36\% والاعتماد على بدائل أقل تكلفة مثل البقوليات والمعلبات و تقليل عدد الوجبات الغذائية اليومية 19.8\% أو شراء الطعام بالأجل . 
على الجانب الآخر أفرزت الجائحة مصطلح جديد وهو التباعد الإجتماعى *' لكن الأسر المصرية

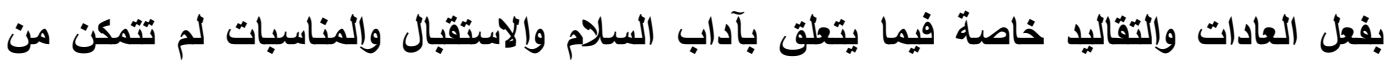
تطبيق التباعد الاجتماعى رغم أن مصر وجميع بلانان العالم تمر بخطر الجائحة فى الموجة الثانية مازالت التقاليد الخاصة بالزيارات فى المناسبات خارج السيطرة الصحية وهناك ميل كبير للأسرة لإخفاء خبر اصابة أحد أفرادها وتفضيل العزل المنزلى كذلك المخالطين يبدون تعاطفهم

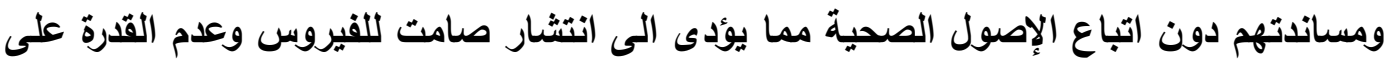
تقلير خطورة الأزمة ، كما أن بعض الأسر المصرية لديها أبناء فى المرحلة الثانوية وفى الأدئ

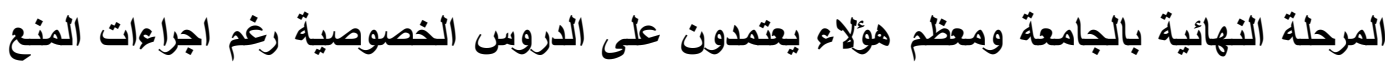

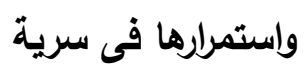

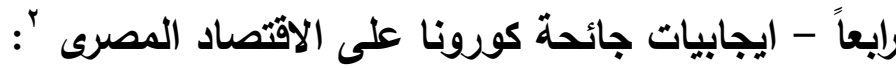
على الرغم من التداعيات السلبية لجائحة كورونا على الاقتصاد المصرى مثل غيرة من التهاتيات اقتصاديات العالم الا أن الإصلاحات الاقتصادية التى انتهجتها الدولية والتوازن والتتسيق بين التهات السياسات النقلية والمالية منحت الاقتصاد المصرى القدرة على التخفيف من تداعيات الازمة الإنة وظهر ذلك جليا فى تماسك المؤشرات الاقتصادية وتحقيقها نتائج جيدة فى عام 2020 وهو

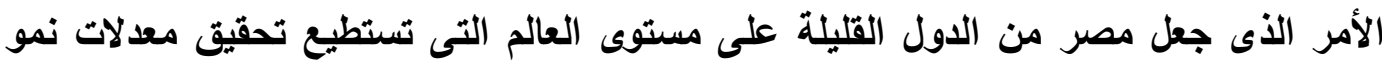
ايجابية خلال هذا العام وذلك بثهادة المؤسسات الاقتصادية الدولية فقد كان معدل النمو 2019 5.6 وفى تقرير لصندوق النقا الدولى توقع ان يتراجع معدل النمو الاقتصادى لمصر بثكل

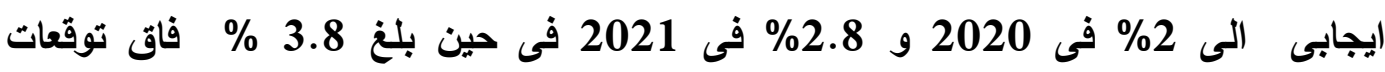

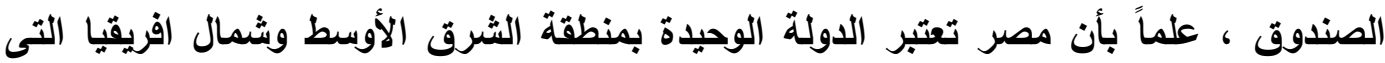
سيظل معلل النمو بها موجب بحسب تقديرات الصندوق ، كما أثشار الى تراجع النمو فى دول

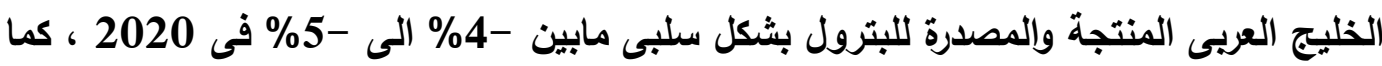

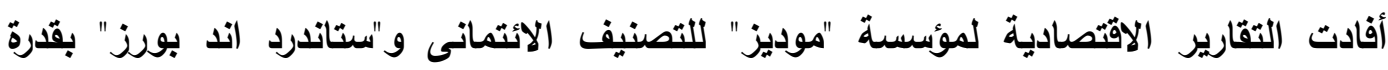

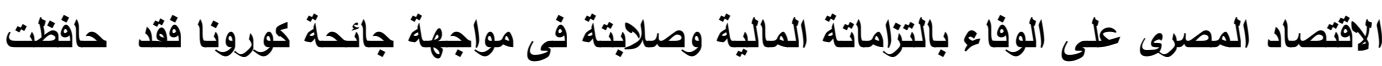
مصر على تصنيفها الإنتمانى خلال جائحة كورونا وهذا يرجع الى تنفيذ مصر برنامج الاصلاح

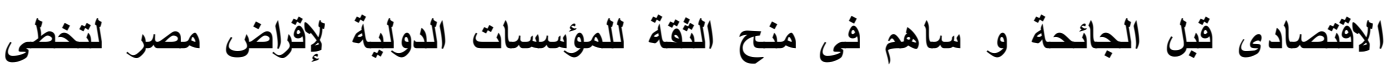
تذاعيات أزمة كورونا ، وقد نجح برنامج الاصلاح الاقتصادى فى وصول احتياطى النقد الأجنبى

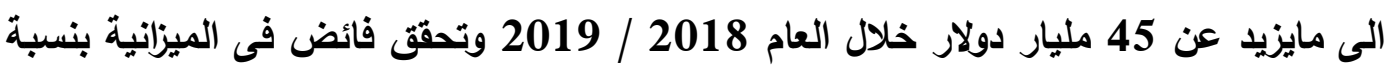

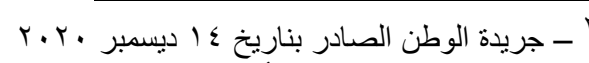

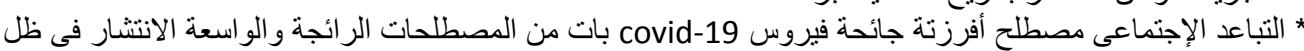

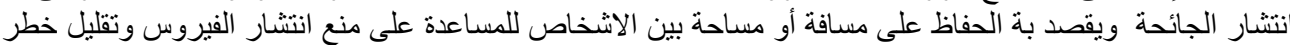

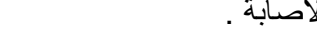

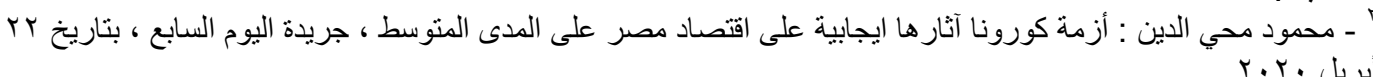

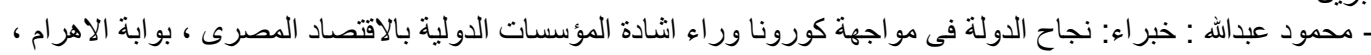

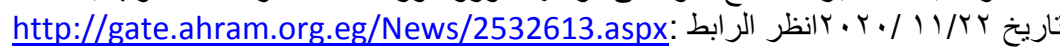




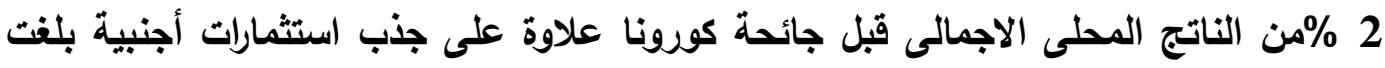

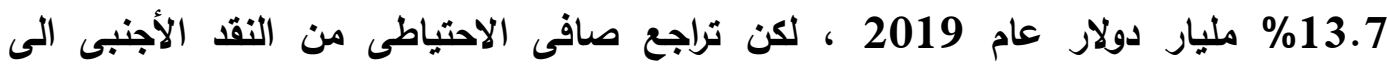

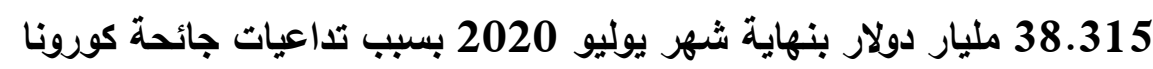
كما انخفض معدل البطالة فى الريع الثالث من عام 2020 بنسبة 2.3 \% مقارئة 2.3 مارنة بنسبة 9.6

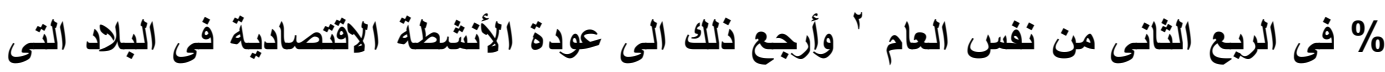

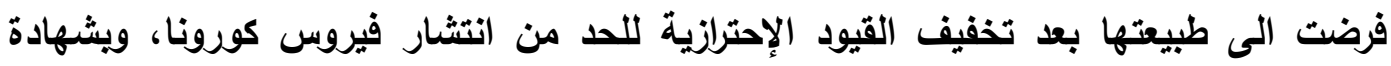
المنظمات الدولية أن السلطات المصرية تعاملت بثكل جيد مع جائحة

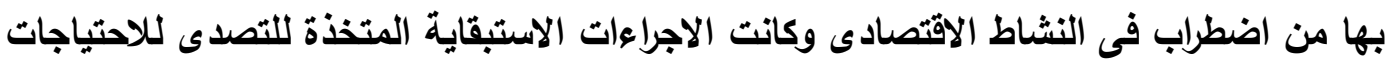

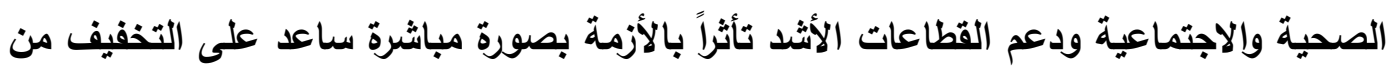

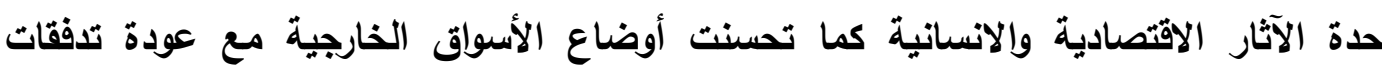
الاستثمارات الوافدة ، وأن ظهور الموجة الثانية من جائحة

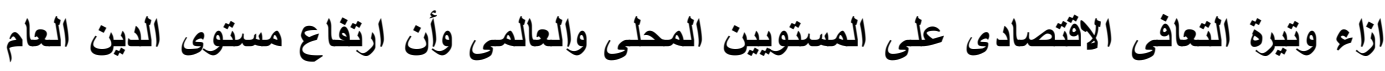

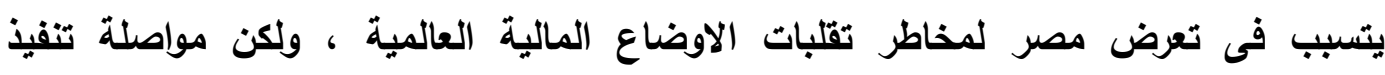

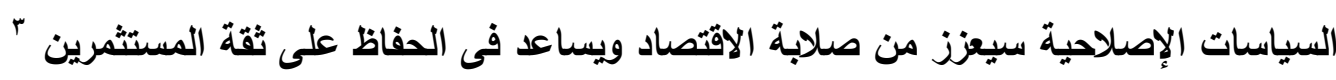

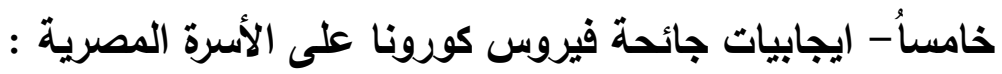

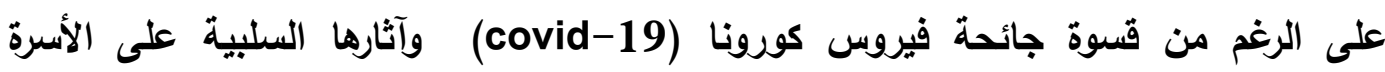

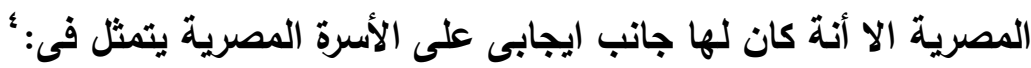

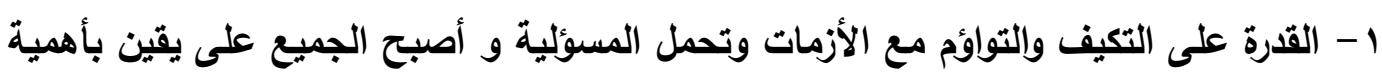
الحفاظ على صحة الأسرة وتزايد الوعى الصحى.

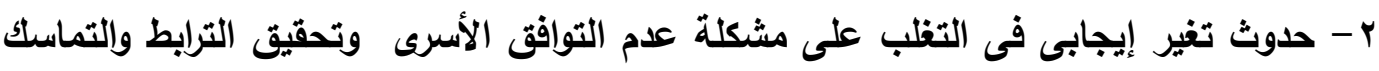

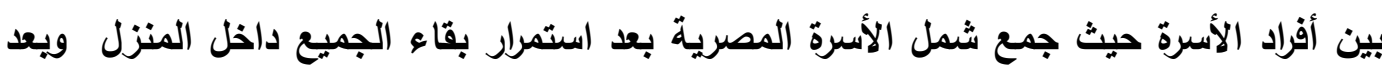

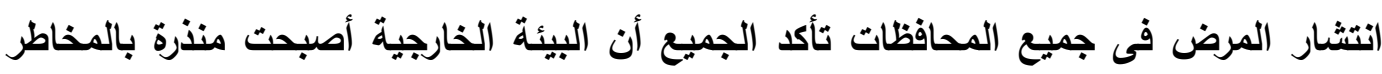
المباشرة وأن البيئة المنزلية أصبحت الأكثر أماناً.

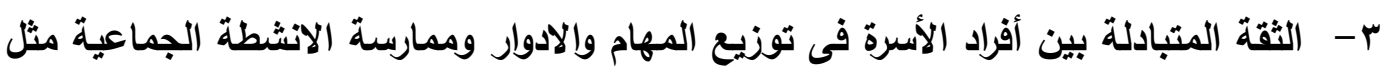

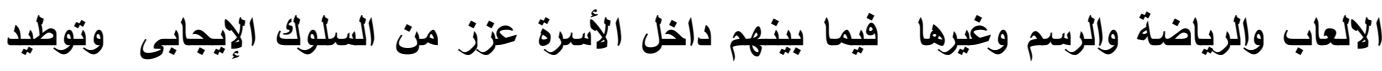

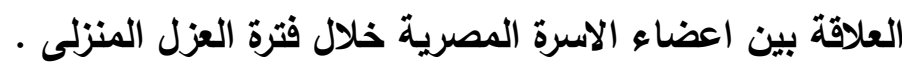

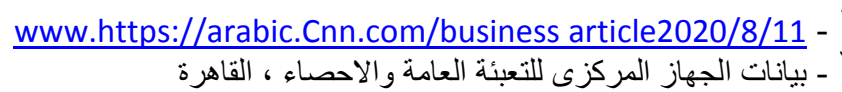
https://www.imf.org/ar/News/Articles/2020/07/09/na070920-egypt-takes-proactive-approach-- ${ }^{r}$ approach-to-limit-the-pandemics-fallout - نعمة فوزى : تأثير جائحة كورونا على الأسرة وتغير نمط الاستهلاك انظر :

/https://www.agri2day.com/2020/11/05 https://www.unescwa.org/sites/www.unescwa.org/files/ar-escwa-covid-19-economic-costarab-region.pdf 
ع - حُسن استخدام شبكات التواصل الإجتماعى والإيجابية فى استخدامها لمساعدة الآخرين ونشر سبل الوقاية والتوعية بين متابعيهم ه- أتاح العزل المنزلى بعض الهُوء لمن كانوا يعانون من التوتز والضغوط فى أعمالهم او دراساتهم فقد منحهم الفرصة للإبتعاد عن الضغوط اليومية وإعادة ترتيب أفكارهم كما أتاح الفرصة للبعض الآخر اكتشاف المواهب الدفينة لديهم كالإبتكار أو الرسم أو العزف الموسيقى لرئه צ- انخفاض معدلات الجرائم بسبب التزام الجميع بالحظر الذى فرضتة الدولة V- انخفاض معدلات التلوث بسبب اغلاق المصانع وتوقف العديد من الانشطة الاقتصادية بعد زيادة معدلات الإنبعاث الحرارى والتتلوث بسبب انبعاثات ثانى اكسيد الكريون الناتج من المصانع 9- اتاح تفشى الفيروس مجالا للعمل فى المنزل من خلال الانترنت مثل التسوق الاكترونى ويستطيع الفرد الأى يجيد استخدام التكنولوجيا ان يعمل وهو مقيم بالمنزل ويحقق دخلا يمكنة تحسين مستوى المعيشة . • 1 - نجاح تجرية التعليم عن بعد لإستكمال مسار العملية التعليمية وتعميمها فى جميع المدارس والجامعات للحد من التزاحم و منعا من تزايد الإصابات بين الطلاب لهاب لهاب

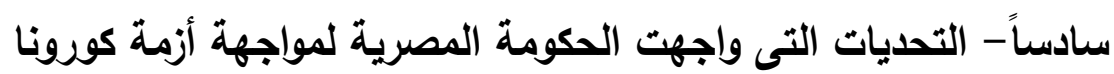
لاثكك أن أزمة كورونا التى أثرت فى العالم على المستويين الاقتصادى والاجتماعى شكلت تحدياً

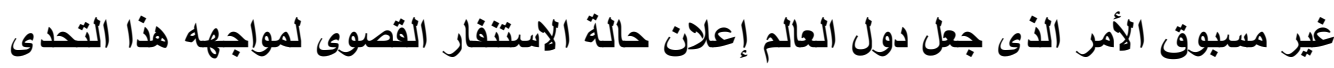

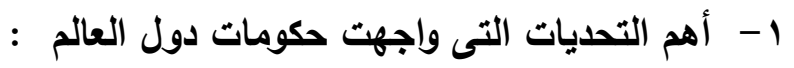

- واجه العالم من قبل أزمات عسكرية و مالية و بيئية تلك الأزمات كان العالم يعلم جيدأ كيفية مواجهتها بينما فى ظل أزمة وياء كورونا الأى أثر على كافة مناحى الحياة وأجبر سكان الكرة ولئه الأرضية على التزام المنازل وياء مجهول يتغير ويتحور مسببا الوفاه والإضرار بصحة الانسان - مفاجأة العالم بأزمة صحية لم تكن متوقعة ولم تكن الدول بجاهزية لمواجهتها شكلت تحدياً لجميع دول العالم و أحدثت حالة من الطوارى ع لم تكن فى الحسبان فضلاً عن هثاشة الأنظمة الصحية فى معظم بلاد العالم خاصة الرأسمالية وعدم قدرتها على مواجهه الأزمة

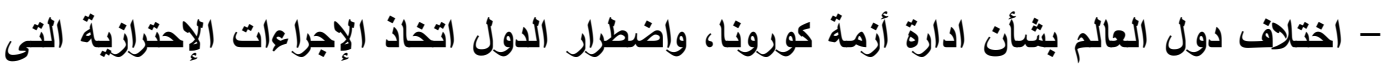
لم يتوافر لايهم أى معلومات ولا سيناريوهات مسبقة للتعامل بشأن الأزمات الصحية - ضعف الآليات الدولية للعمل الجماعى على الرغم من وجود منظمة الصحة العالمية ولكن ليس

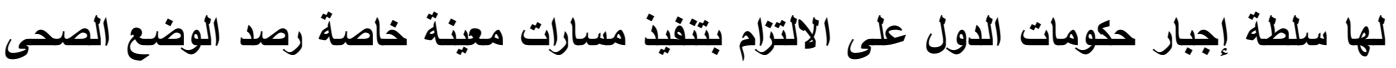

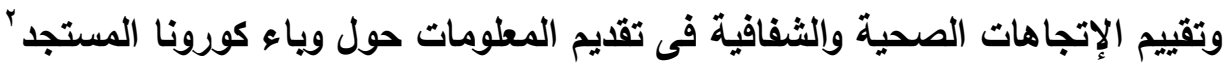


- هشاشة الأنظمة الصحية فى الدول الرأسمالية التى تقوم اقتصادياتها على الحرية الاتتصادية وعدم تلخل الاولة فى النشاط الاتصادى رغم ما يتوافر لايها من قوة اقتصادية وعسكرية لكن أزمة كورونا وضحت عدم قدرة هذة القوة على مواجهه الأزمات الطارئة r - أهم التحديات التى واجهت الحكومة المصرية بصفة خاصة : - إمكانية توسيع نطاق التأمين الصحى ليثمل عمال المياومة والباعة الجائلين وغالبا دخولهم غير مستقرة الأمر الذى يقتضى وضع آليات ومعايير مختلفة لتسوية أوضاعهم - التسيق بين كافة القطاعات المعنية بالصحة لتعزيز منهجية الاستجابة لفيروس كورونا والاستغلال الأمثل للموارد وتوفير المسنلزمات الطبية و الحماية للأطقم الطبية والمرضى فضلاً عن ماواجهته الحكومة من عجز فى الأطقم الطبية مما يشكل عبئاً على المنظومة الصحية والطية

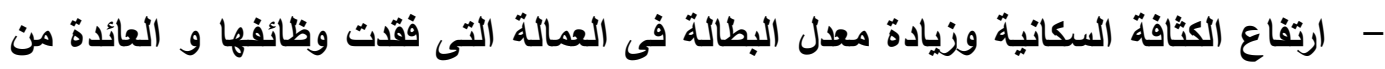
الدول الاوروبية ودول الخليج كان من أكبر التحديات التى واجهت الحكومة المصرية - توسيع قاعدة الحماية الاجتماعية وشبكات الأمان الاجتماعى لجميع أفراد المجتمع خاصة الفئات الفقيرة وقاطنى المناطق العشوائية وضمان مرونتها و تكيفها مع الأزمات . . لتحقيق العدالة الاجتماعية والتنمية المستدامة وتعزيز الإستقرار الاجتماعى من خلال الإجراعات

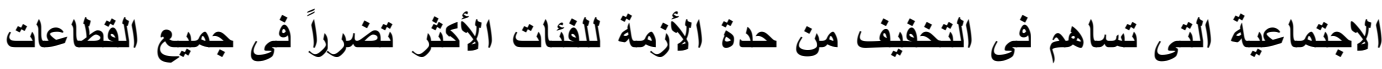
مثل قطاع السياحة والعاملين بالمياومة والمشروعات المتناهية الصغر هذة الفئات غير مشتركين فى صناديق التأمين الاجتماعى ويمثلون تسبة كبيرة من قوة العمل - تأثر جميعَ مصادر النقا الأجنبي في مصر بدعاً من السياحة إلى التحويلات الخارجيّة والاستثمار الأجنبى المباشر وصادرات الغاز الطبيعى وتدفقات رؤوس الأموال الدولية عائدات

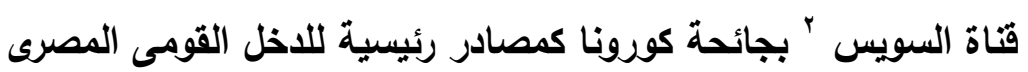
- توقف الأسواق بسبب جائحة كورونا والعزل المنزلى والحاجة الى المشتروات وتوفير المستلزمات المعيشية وزيادة الطلب الأى يفوق العرض ادى الى ارتفاع أسعار السلع والخدمات "ومعاناة الكثير من أفراد المجتمع ودينات

و ـ ـ الأمم المتحدة : اصلاح نظم الحماية الاجتماعية فى البلدان العربية ، اللجنة الاقتصادية والاجتماعية لغربى آسيا (الأسكوا)، -Ishac Diwan , Nadim Houry and Other : Egypt after the Coronavirus: Back to Square One , https://www.arab-reform.net/publication/egypt-after-the-: إنظر الر 26 August, 2020

/coronavirus-back-to-square-one Vinay Sharma: COVID-19 Challenges and Response: How procurement underpins the World -

Bank's response to the pandemic,world bank, 15 APRIL, 2020, https://blogs.worldbank.org/voices/covid-19-challenges-and-response-how-procurementunderpins-world-banks-response-pan 


\section{المبحث الثانى}

تأثير أزمة فيروس كورونا (COVID-19) على أهداف التنمية المستدامة

ان خطة التنمية المستدامة 2030 وأهدافها الـ 17 التى أقرها الدول الأعضاء فى ديسمبر 2015 فى الأمم المتحدة ترسم خارطة طريق بعيدة الروئة لسائر الدول كى تعمل جاهدة على إرساء عالم ينعم بالإزدهار والمساواة والإندماح الاجتماعى والحفاظ على الموارد الطبيعية وحقوق

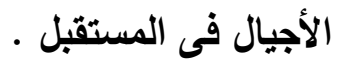

ان نجاح عملية التخطيط لأهداف التنمية المستدامة 2030 يتوقف على مدى مرونه الخطة وقدرتها على التكيف مع التغيرات فى المناخ أو الأويئة أو كوارث انسانية فكل هذة الصدمات من طبيعة الحياة المتوقع حدوثها شهدت الالفية الثالثة أزمات عالمية اقتصادية ومالية وأويئة مثل سارس وفئه وفيروس الأنفلونز HINI وغيرها ، لكن لم يكن يتوقع العالم أن تكون جائحة فيروس COVID -19 بهذة الخطورة والتفشى السريع وما خلفة من أضرار جمه زعزعت استقرار النمو الاقتصادى العالمى وقادت العالم الى أزمة ركود عالمى هددت آمال وطموحات تحقيق برامج وأهداف التنمية المستدامة لمختلف شعوب العالم ولا سيما الدول الفقيرة ودول منطقة الشرق الأوسط وشيمال أفريقيا التى التى كانت قات بدأت منذ سنوات ليست بالبعيدة فى اتخاذ خطوات جدية وحثيثة نحو تحقيق هذة الأهداف بما يتشق وروئة أهداف منظمة الأمم المتحدة

من سياق ماسبق نعرض لمفهوم التمية المستدامة و تأثير أزمة كورونا على أهداف التنمية المستدامة الـ 17، ووضع مصر على خريطة مؤثرات التنمية المستدامة

$$
\text { أولاًا - مفهوم التنمية المستدامة وأبعادها }
$$

استخدام مصطلح التنمية المستدامة كثيراً فى الأدب التنموى المعاصر ، وتعد الإستدامة نمطاً تنموياً يمتاز بالعقلانية والرشد حيث تتعامل مع الأنشطة الاقتصادية التى تهدف الى تحقيق النمو والمحافظة على البيئة والموارد الطبيعية وتحقيق الرفاهية للمجتمعات ، عرف تقرير برونتلاند

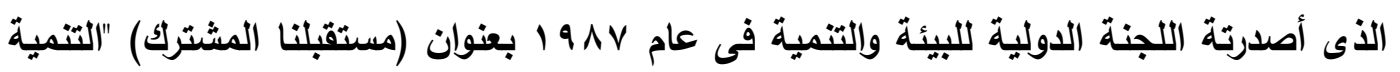
المستدامة بأنها التتمية التى تلبي احتياجات الحاضر دون أن يعرض للخطر قدرة الأجيال التالية

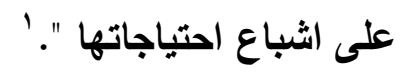

تعريف منظمة الأغذية والزراعة (الفاو) "التتمية المستدامة هى ادارة وحماية قاعدة الموارد الطبيعية وتوجية التغير التقنى والمؤسسي بطريقة تضمن تحقيق واستمرار ارضاء الحاجات البشرية للأجيال الحالية والمستقبلية ،ان تلك 
التنمية المستدامة تحمى الأرض والمياة والمصادر الوراثية النباتية والحيوانية ولا تضر بالبيئة وتتسم بأنها ملائمة من النواحى القنية و الاقتصادية ومقبولة من الناحية الاجتماعية " تعددت مفاهيم التتمية المستدامة لكنها جميعها تدور حول التنمية الثاملة التى ترتبط باستمرارية الجواتب الاقتصادية والإجتماعية والمؤسسية والبيئية للمجتمع بحيث تُمكن التنمية المستدامة المجتمع ومؤسساتة من تلبية احتياجاتهم فى الوقت الحالى مع حفظ التنوع الحيوى والحفاظ على النظم الإيكولوجية و على حقوق الأجيال فى المستقبل

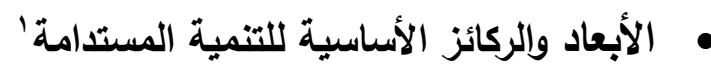
1- البعد البيئي : تهدف التنمية المستدامة الى تحقيق الأهداف الآتية : - الاستخدام الرشيد للموارد الطبيعية غير المتجددة حفاظا على حقوق الأجيال القادمة مستقبلاً - مراعاة القدرة المحدودة للبيئة على استيعاب النفايات - تحقيق التوازن بين التنمية الاقتصادية والمحافظة على البيئة مع مراعاة حقوق الاجيال

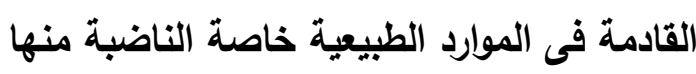

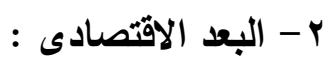
ترشيد استهلاك الطاقة والموارد الطبيعية والتى تصل الى اضعاف اضعافها فى الدول الغنية مقارنة بالدول الفقيرة على سبيل المثال يصل استهلاك الولايات المتحدة الامريكية من النفط

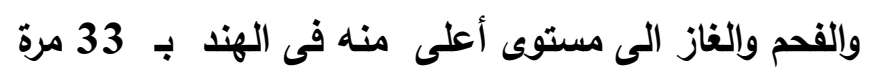

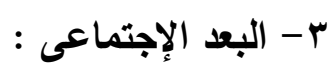

تتضمن التتمية المستدامة تتمية العنصر البشرى وتحسين مستوى المعيشة والرعاية الصحية والتعليمية والتصدى للفقر وعدم المساوة والاقصاء وتحقيق العدالة والمساواة بين افراد المجتمع. ع - البعد التكنولوجى اضافة للأبعاد الثلاثة الرئيسية البعد التكنولوجى يهدف الى تحول المجتمعات الصناعية الى تكنولوجيا نظيفة تحافظ على البيئة من التلوث ، ويعد التحسن التكنولوجى وسيلة هامة لتحقيق التوازن بين أهداف التنمية والقيود التى تفرضها البيئة بحيث لاتتحقق التنمية على حساب البيئة ثانياً- تأثير أزمة فيروس كورونا على تحقيق أهداف التتمية المستدامة

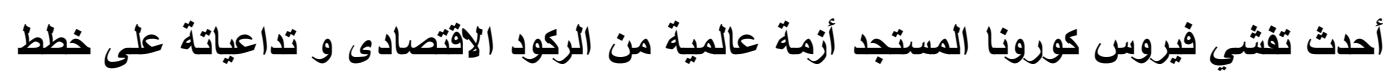
التنمية الاقتصادية والاجتماعية قصيرة المدى، وتطور إلى أثر أكثر سلبية على الاستراتيجيات

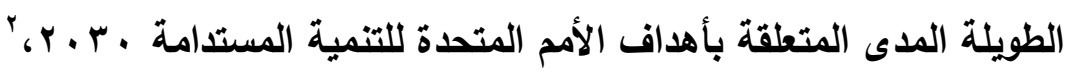
https://www.eg.undp.org/content/egypt/ar/home/ourwork/sustainable development/overview.html https://www.lebarmy.gov.lb/ar/content/ - الأمم المتحدة : التقرير العربى للتنمية المستدامة 2020 ، لجنة الأمم المتحدة الاقتصادية والاجتماعية لغربى آسيا ( الإسكوا)

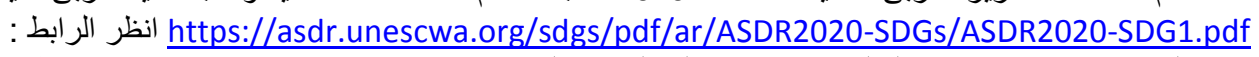

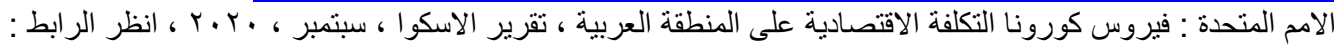
https://www.unescwa.org/sites/www.unescwa.org/files/ar-escwa-covid-19-economic-cost-arab- 
الهذف الأول : القضاء على الفقر ( التأثير سلبى للغاية ) '

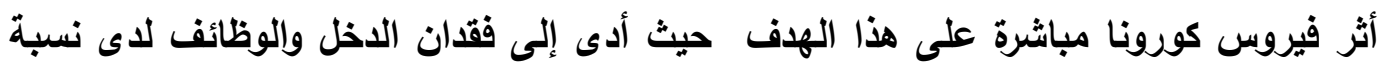

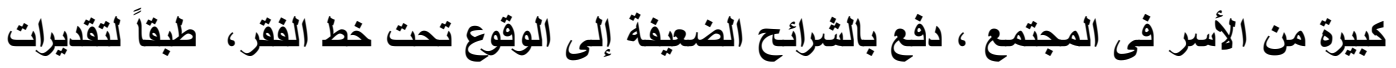

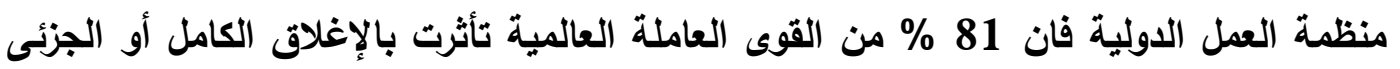

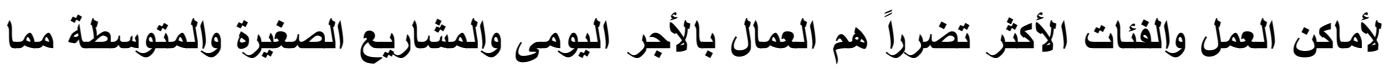

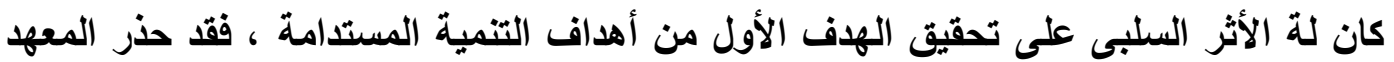

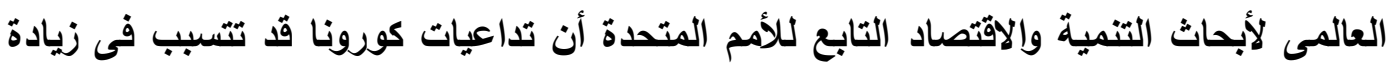

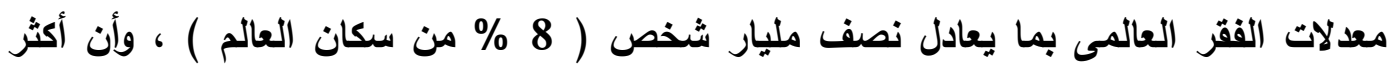
من 700 مليون شخص (10\% من سكان العالم ) مازالوا يعيشون فى فقر مدقع يعانون من الأل

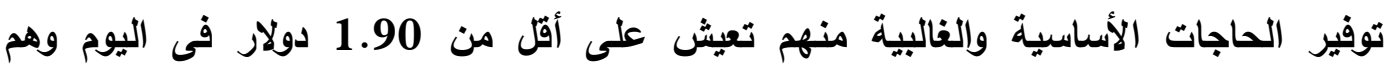

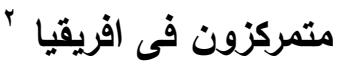

الهذف الثانى : القضاء التام على الجوع ( التأثير سلبى للغاية )

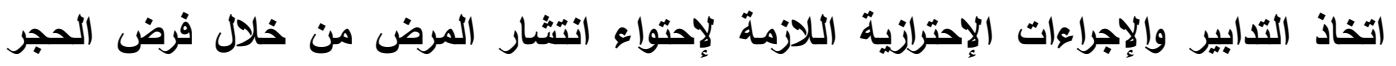

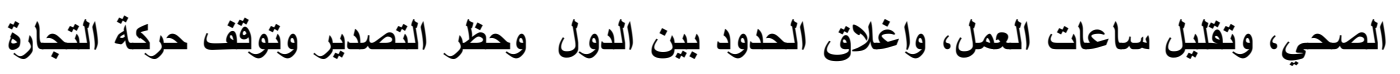

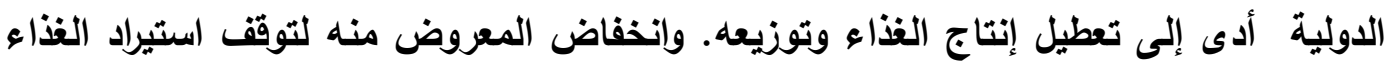

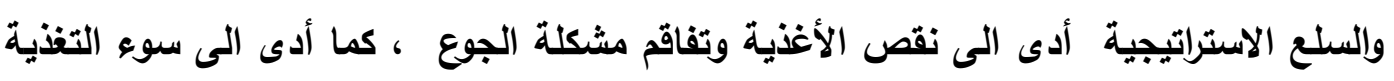

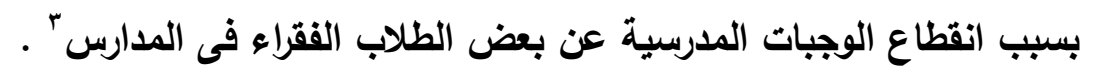

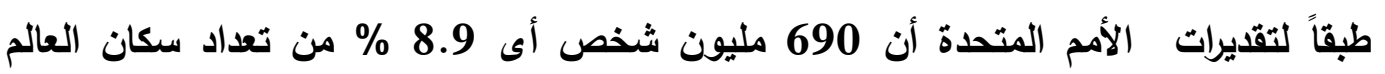

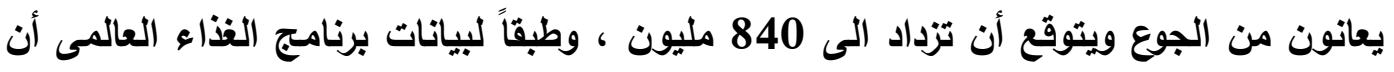

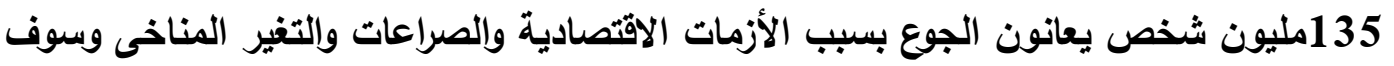

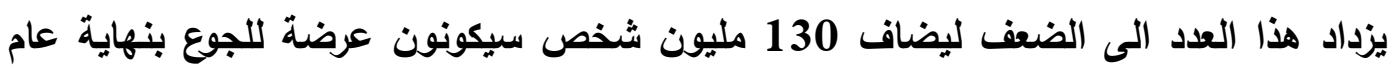

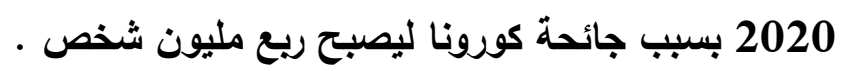

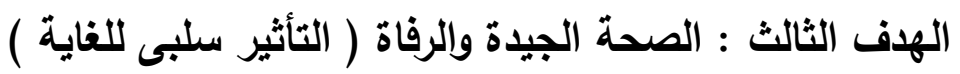

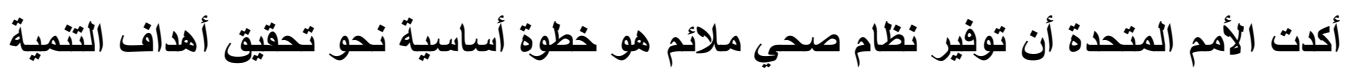

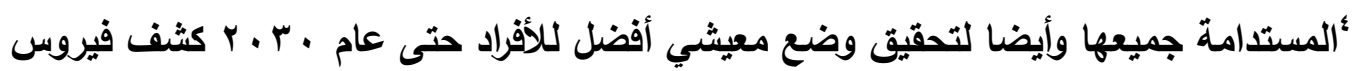

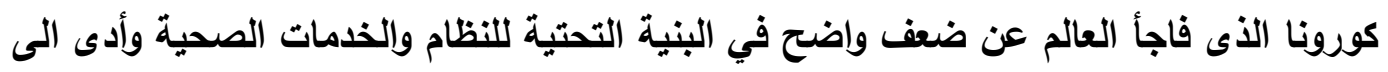

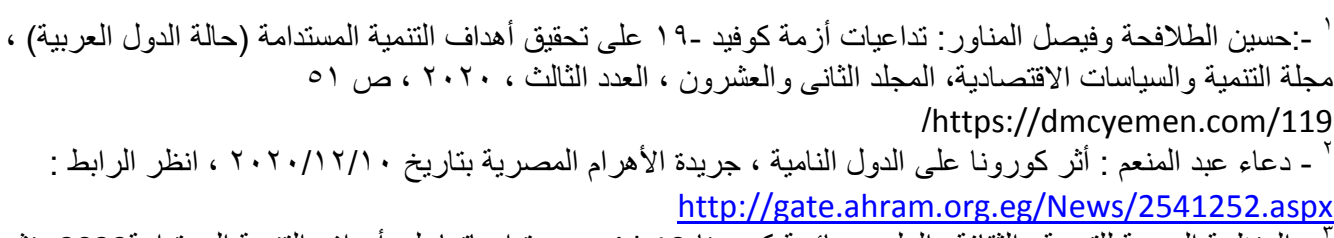

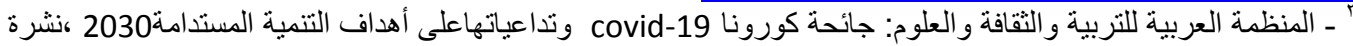

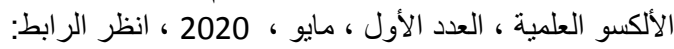
http://www.alecso.org/nsite/images/pdf/corona-final1.pdf World Health Organization: Consideration for implementing and adjusting public health and social measures in the context of Covid-19, 4November,2020 .p.3. 


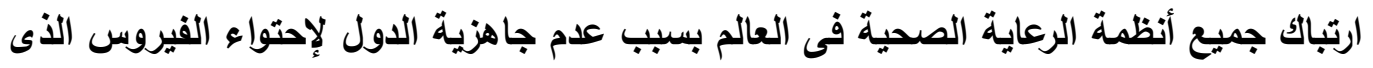
أظهر العديد من السلبيات في المجال الصحي خاصة فى الدول النامية والأسواق الناشئة أهمها:

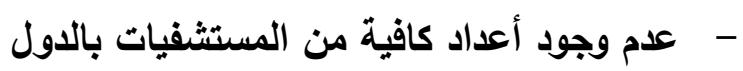

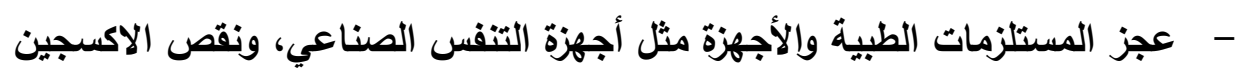

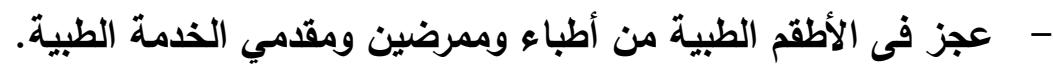

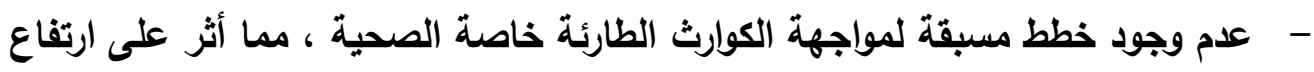

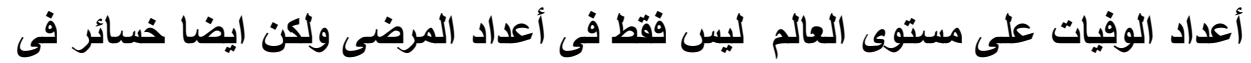

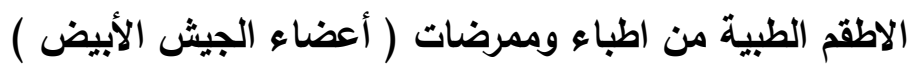

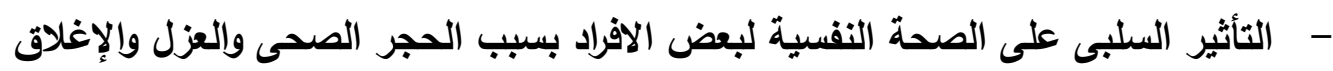

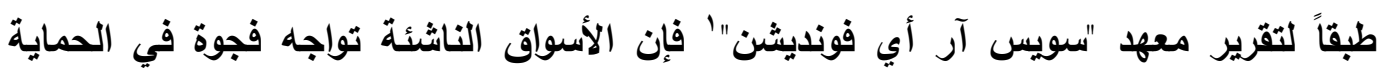

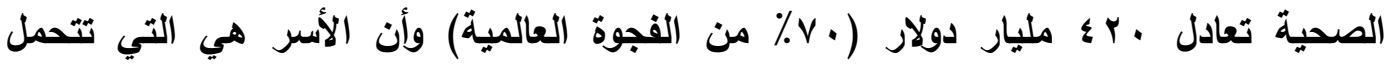

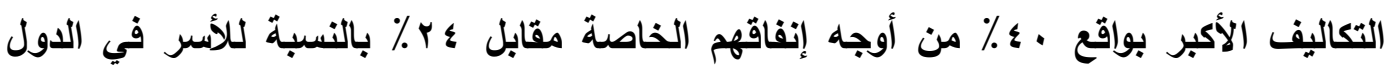

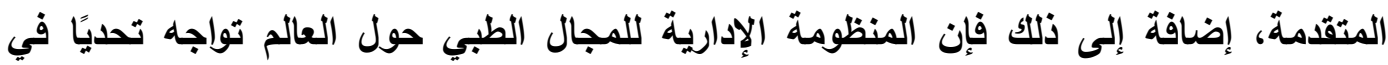
وضع أسس واضحة لسياسات التعامل مع المخلفات الطبية المتعلقة بالأزمة بما يضمن فصل

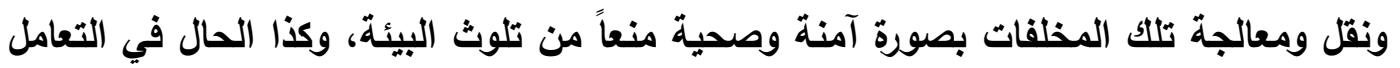
مع جثث الضحايا من هذا المرض وكيفية دفنها، وهو ما شكل مؤخراً بعض المشاكل داخل المجتمع المصري، بسبب مخاوف بعض السكان من دفن الضحايا في مقابر أسرهم.

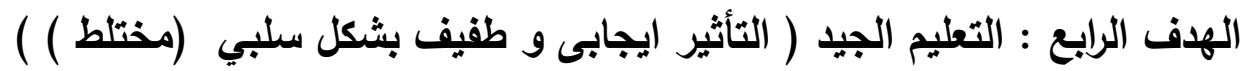

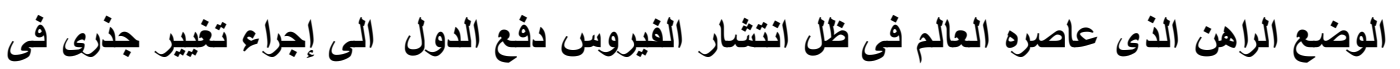

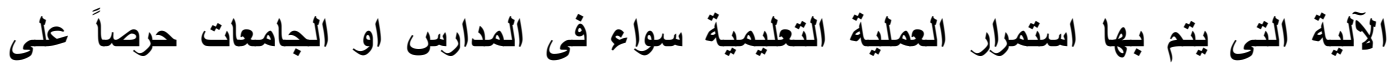

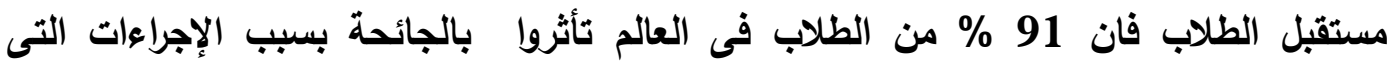

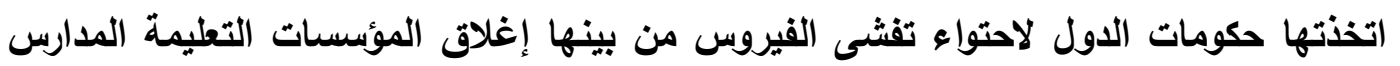

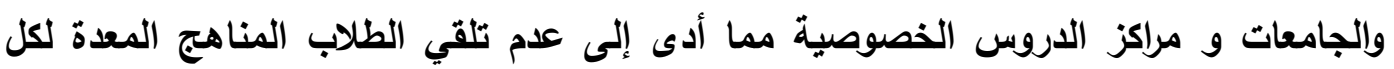

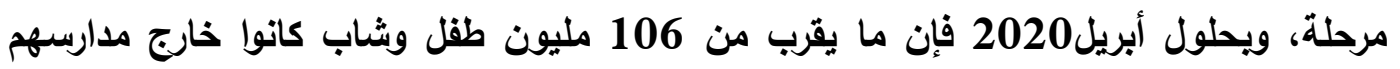

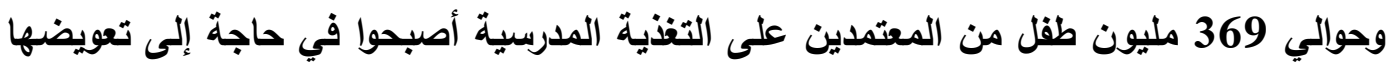

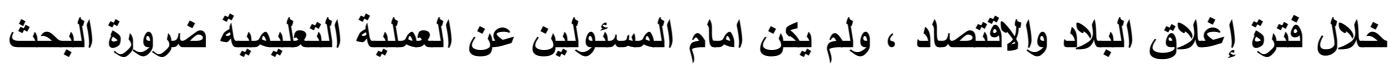

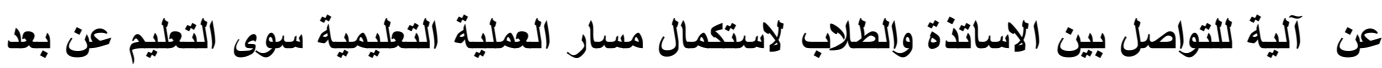
وكان من التحديات التى واجهت بعض الدول والتى أظهرتها الأزمة عدم جاهزية غالبية الدول

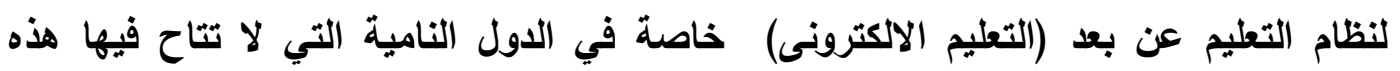

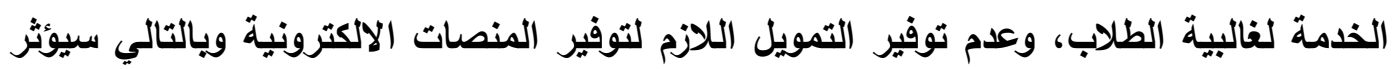

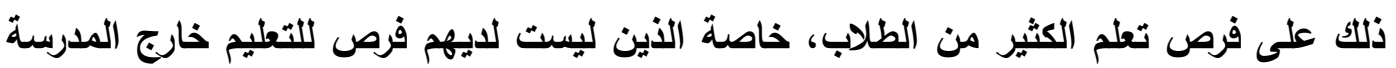


مثل الأسر منخفضة الاخل التي تكون فرصتها أقل في الوصول إلى التكنولوجيا والإنترنت وخدمات رعاية الأطفال ، كما يُعرض التوقف المؤقت لتعليم الأطفال الأكثر حرماناً لخطر الانقطاع

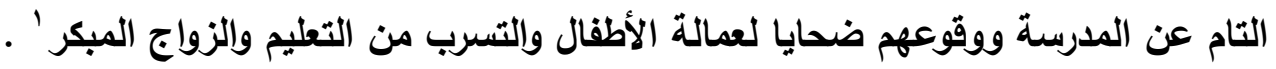
أما على الجانب الإيجابي لهذا الهذف فإن العملية التعليمية بجميع مراحلها لم تتوقف في مصر وفي معظم الدول، وذلك بعد وضع خطة بديلة للتحول الرقمي في التعليم، وإن كانت العملية بها بعض العيوب، إلا أنها في مصر خصوصاً أثبتت فعاليتها في زمن قياسي ويرجع جزء من ذلك النجاح إلى الاستعدادات المتبعة منذ سنوات بواسطة وزارة التربية والتعليم، وكذلك الحال في مراحل التعليم العالي المختلفة بسبب جاهزية الجامعات الخاصة وإلحكومية بأنظمتها الإلكترونية، الا انة مازال هناك تحديات تتعلق بهذا المجال وستؤثر حتماً على خطط التنمية المستدامة أثناء تعديلها للقترة المقبلة، من هذه التحديات ضعف البنية التحتية ويطء سرعة الإنترنت في مصر والعالم بعد زيادة معدلات الاستخدام سواء للعمل والدراسة أو الترفيه أو التواصل الاجتماعي.، فقد وجد الاتحاد الدولى للاتصالات أن 53.6\% فقط من سكان العالم تثوافر لهم سبل الوصول الى

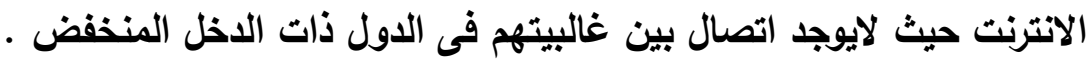
الهدف الخامس : المساواة بين الجنسين (مختلط أو سلبى بشكل طقيف ) إن هدف تحقيق العدالة بين الجنسين، وتمكين المرأة يُعد واحداً من الأهداف المتكاملة في كافة أهداف التنمية المستدامة، وأن حصول المرأة على كافة حقوقها في جميع الأهداف يضمن العدالة والاندماج الاجتماعي وجني المجتمع والأجيال القادمة ثمار التنمية المستدامة. إن أهمية المساواة بين الجنسين في كافة المجالات خاصة الصحة والتعليم يقلل من أوجه التفاوت في المجتمع، فضلاً عن المساهمة في زيادة فرص تثنغيل المرأة وتمكينها، يساهم بشكل إيجابي في تحقيق النمو الاقتصادى ورفاهية الأطفال. الا ان هذا الهذف لم يسلم من تأثير فيروس كورونا فكانت النساء الفئة الأكثر تضرراً حيث أن 70 من مجموع العاملين فى الرعاية الصحية من النساء سواء طبيبات أو ممرضات مما يزيد من احتمالات تعرضهن لخطر العدوى وفقدان حياتهن ويثقل كاهلهن بأعباء إعالة أفراد أسرتهن ومنهن من تعرض لفقد وظيفتة أو تقليص دخولهن وهو ما أثر سلبياً على الأمن الوظيفى و

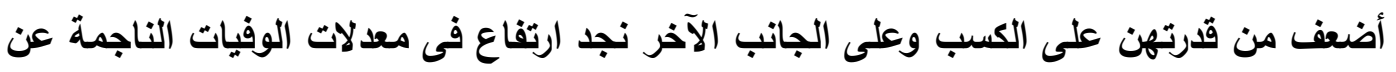
الفيروس بين الرجال لأنهم الأكثر عرضة للأمراض التنفسية المزمنة بسبب ارتفاع معدل المدخنين رغم ذلك لانغقل الجانب الايجابى لتماسك بعض الأسر والتعاون بين افراد الاسرة

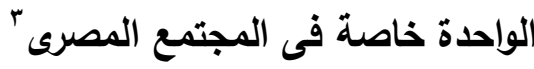

-,UNICEF MEAN: The Impact of Covid-19 on Cheeldren on the Middle East and North Africa, November2020. ' - منار رمضان : كورونا تلقى بظلالها على اهداف التنمية المستدامة فهل ستعيد ترتيبها ، مركز الإعلام التنموى (استدامة)

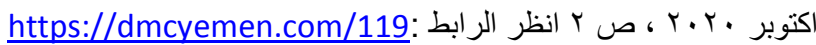

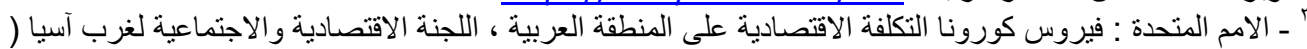


الهلف الساد: المياة النظيفة وإلنظافة الصحية:(مستوى التأثير:مختلط ) من أهم الوسائل الوقائية من فيروس كورونا هو غسيل اليدين بالمياه النظيفة. هذه الوسيلة قد

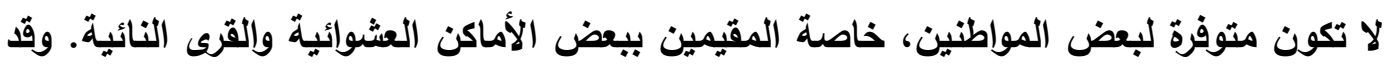

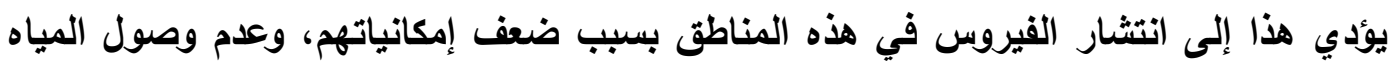

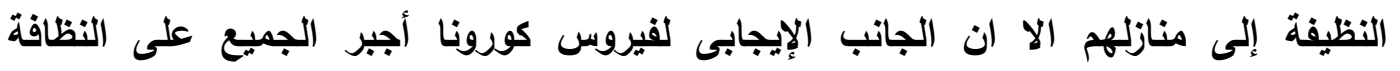

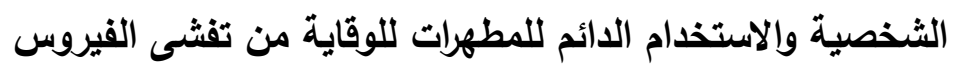

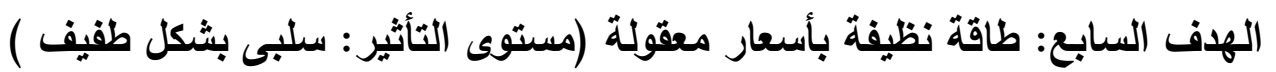

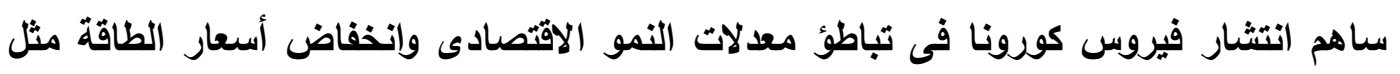

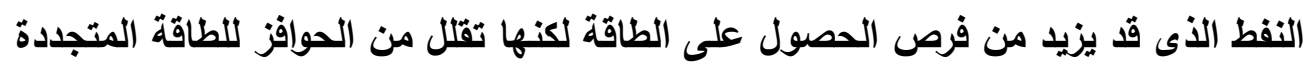

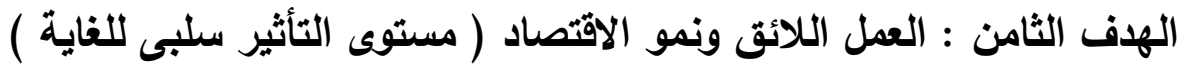

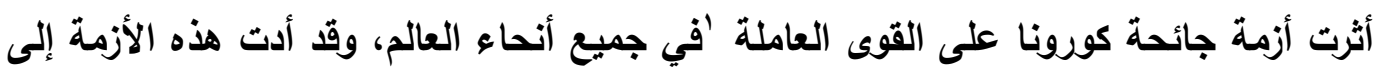

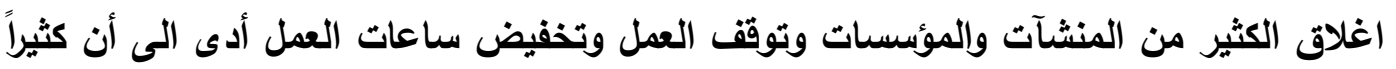

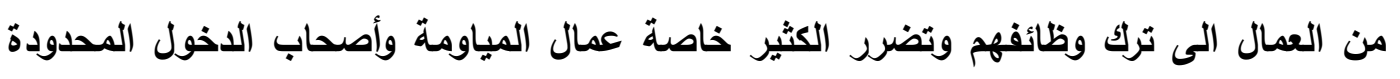

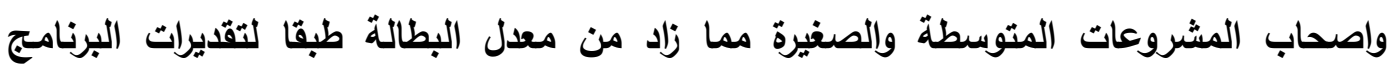

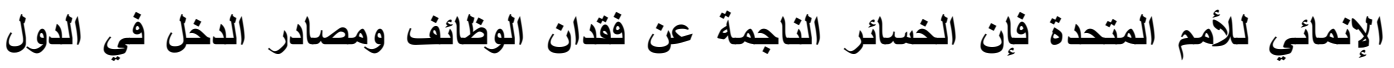

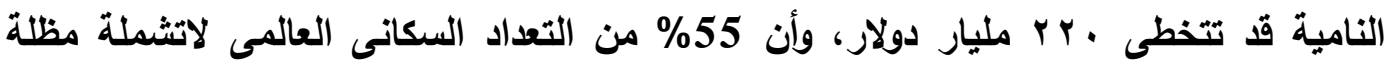

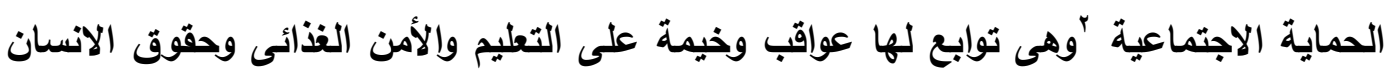

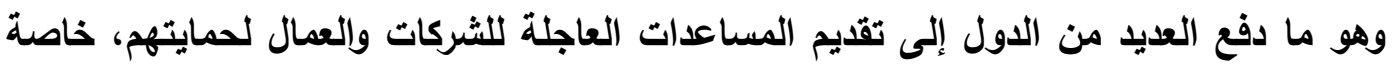

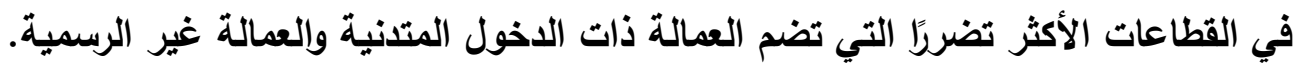

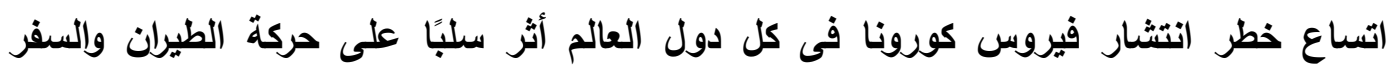

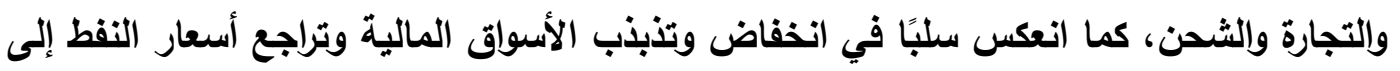

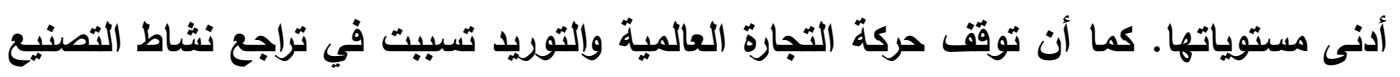

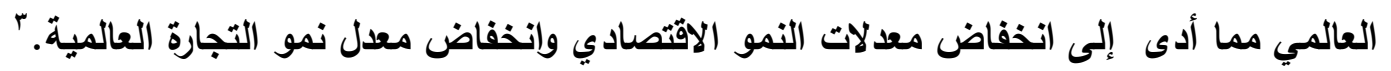

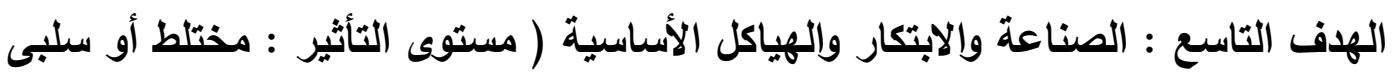
بشكل طفيف )

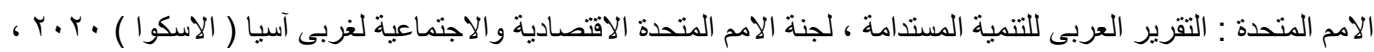

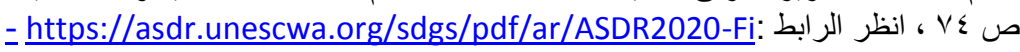
- The Sustainable Development Goals Report- 2019 Arabic

-World Health Organization:Covid-19: Occupational health and safety for health workers,2February 2021

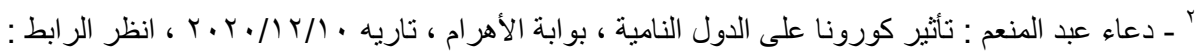
http://gate.ahram.org.eg/News/2541252.aspx " - سحر عبود ، أسماء مليجى : التداعيات المحتملة لازمة كورونا على الاقتصاد المصرى ، سلسلة أوراق السياسات ، اصدار

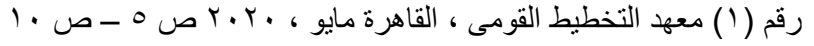


تسبب انتشار وياء الكورونا فى اغلاق العديد من المصانع والثركات وتوقف العمل والانتاج كما

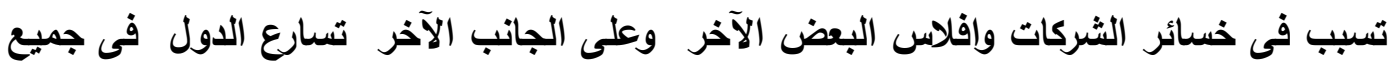
انحاء العالم الى ابتكار علاج أولقاحات لاحتواء الفيروس والحد من انتثارة ، وتطوير التكنولوجيا

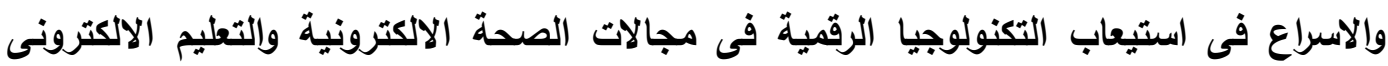
والحوكمة الاككترونية

الهدف العاشر : الحد من أوجه عدم المساواة ( مستوى التأثير سلبى للغاية ) أثر فيروس كورونا على هذا الهدف بطريقة غير مباشرة، حيث إن الأزمة ستؤدي إلى توسعة الفجوة بين الطبقات، خاصة بالنسبة للأسر الفقيرة والأثثد فقرًا التي ليست لديها إمكانيات متاحة لمواكبة التعايش مع أزمة كورونا، خاصة الأسر بالمناطق النائية والأماكن العثوائية ذات الكثافة السكانية العالية والتي ليس بها خدمات إنترنت، وليس لايها الإمكانات المادية للحصول على التكنولوجيا، ويالتالي سيؤدي ذلك إلى تدهور المستوى التعليمي للطلاب لعدم حصولهم على التعليم الموجه مقارنة بالطلاب المقيمين بالمناطق المتاح بها هذه الخدمة. بالإضافة إلى أن غالبية مسئولي هذه الأسر من العمالة غير المنتظمة التى تأثرت بالجائحة و فقدوا وظائفهم . الههف الحادى عثر : جعل المدن والمجتمعات المحلية شاملة للجميع وآمنة و مستدامة ( مستوى التأثير مختلط او سلبى بشكل طفيف ) يواجه السكان الذين يعيشون في العشوائيات والأحياء الفقيرة خطرً أكبر للتعرض لفيروس كورونا بسبب الكثافة السكانية العالية، وسوء ظروف الصرف الصحي وصعوية توافر مياه نظيفة وحرمانهم من الاماكن العامة الخضراء فضلاً عن اغلاق وسائل النقل العام على الرغم من الجهود التى تبذلها الحكومة المصرية فى هذا المجال ببناء المساكن والمدن والمجتمعات

العمراتية الجديدة من أجل حياة أفضل وكريمة لسكان العشوائيات ( طبقاً لبرنامج حياة كريمة ) الهدف الثانى عثر: كفالة وجود أنماط استهلاك وإنتاج مستدامة ( مستوى التأثير سلبى بشكل طفيف ) الهُف الحادى عشر والثانى عشر يكمل كل منهما الآخر فلن تتحقق الاستدامة الا باقامة مدن ومجتمعات ويتوافر الانتاج والاستهلاك وتوافر عامل النقل الرئيسى بهذا يتوافر طابع الاستدامة للمجتمعات على الجانب الآخر فان انتثار فيروس كورونا كان لله تاثير على عدم اكتمال هذة المنظومة بالاضافة الى تخفيض الاستهلاك من بعض السلع الغذائية وزياده الاستهلاك من الادوات الطبيه الواقية من الفيروس وايضا انخفاض الانتاج لتوقف عجلة الاقتصاد واتخفاض استخدام الموارد الطبيعية بسبب انخفاض النشاط الاقتصادى والاستهلاك ' الإنه الهدف الثالث عشر: اتخاذ إجراءات عاجلة للتصدى لتغير المناخ (مستوى التأثير مختط 
منذ تفشى وياء الكورونا وتزايد استخدام المستلزمات الطبية فازدادت المخلفات وزاد من تلوث البيئة الناتج عن الاستخدام الغير مقتن لأدوات التظيف والتعقيم والسوائل الكيماوية (الكحول

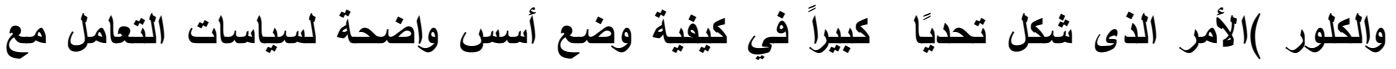
المخلفات الطبية المتعلقة بالأزمة، بما يضمن نقلها ومعالجتها بصورة أمنة وصحية حرصا على عدم تزايد نسبة التلوث وانتثار العدوى ، وكذا الحال في التعامل مع الجثث المتوفاه وكيفية دفنها، وهو ما شكل مؤخراً بعض المشاكل داخل المجتمع المصري، بسبب مخاوف بعض السكان من دفن الضحايا في مقابر أسرهم' ، وعلى الجاتب الآخرتسببت الأزمة فى بعض الآثار الإيجابية للبيئة، حيث أدى توقف النشاط الاقتصادى واغلاق بعض المصانع وتقليل عدد ساعات العمل بها إلى تقليل الغازات المنبعثة منها و وحظر التجوال ساعد فى انخفاض العوادم المنبعثة من السيارات، وهذا أدى إلى تقليل غاز ثاني أكسيا الكريون في الغلاف الجوي. الهُف الرابع عشر: الحياة تحت الماء ( مستوى التأثير سلبى ) بسبب تفشى فيروس كورونا والإجراءات الإحترازية توقفت أنشطة التنمية البحرية والساحلية ومصايد الأسماك وحركة الصيد والسياحة البحرية كما فى مصر فى الغردقة وشرم الشيخ والبحر الأحمر وتوقف النشاط السياحى فضلا عن تأثير الإحتباس الحرارى والنفايات الملوثة للبحار

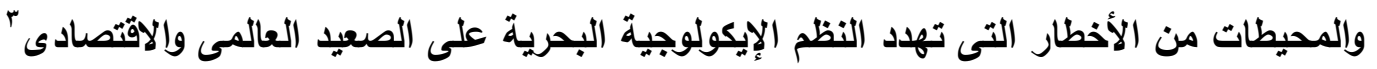
الههف الخامس عشر : الحياة فى البر ( مستوى التأثير مختلط ) تدهور الأراضى والتصحر يشكلان تهدياين رئيسيين للتنوع البيولوجى والأمن الغذائى وسبل العيش كما أن تراجع التنوع البيولوجى وتوقف التوسع العمرانى واستصلاح الأراضى وتوقف الأعمال بسبب العزل المنزلى والإجراءات الإحترازية شكلت تحديات رئيسية للتنمية المستدامة على الرغم من أن مصر من الدول الرائدة فى حماية التنوع البيولوجى بمشاركتها فى اتفاقية

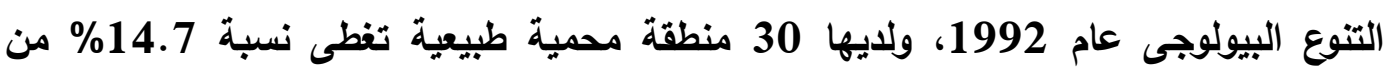

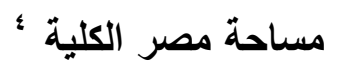

الهدف السادس عشر : السلام والعدل والمؤسسات القوية ( مستوى التأثير مختلط ) تسعى حكومات الدول للتخفيف من عواقب الفيروس كما تحاول دول العالم جاهده توفير اللقاح للحماية من الفيروس وتوزيعه بالعدالة بين جميع أطياف المجتمع ،و محارية الفساد ومقاومة العنف ضد المرأة والأطفال وقيام مؤسسات فعالة لها قوة القانون تخضع للمساعلة تحقق مجتمع أكثر عدالة . • ، على الجانب الآخر هناك مناطق فى العالم أكثر تأثرًا بجائحة كورونا هي مناطق

ـ ـ الامم المتحدة : النقرير العربى للتنمية المستدامة ، لجنة الامم المتحدة الاقتصادية والاجتماعية لغربى آسيا ( الاسكو ا )

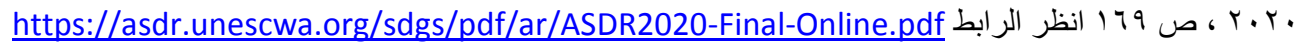

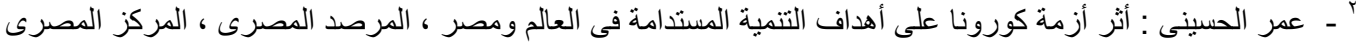

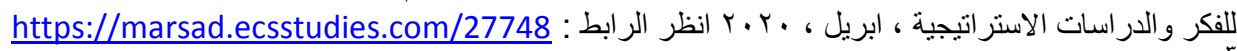

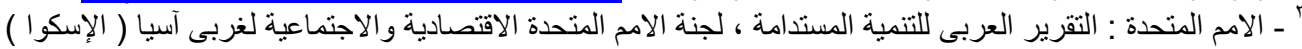

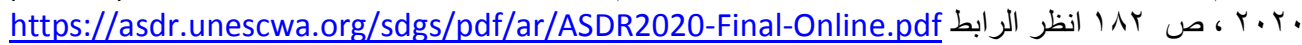

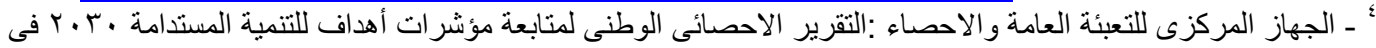


النزاع التى لايتحقق فيها السلام العادل لما يعانيه شعوب هذه المناطق من ضعف الإمكانيات في جميع المجالات الطبية والاجتماعية والاقتصادية من قبل ظهور الفيروس ويعد ظهور هذه الجائحة تعاني هذه المناطق من عدم وجود وسائل الحماية من الفيروس والعلاجات المتاحة له هن أو المستثفيات التي يتلقى فيها المرضى العلاج من هذا الفيروس بالإضافة إلى صعوية وصول المساعدات الطبية لهذه المناطق بسبب الحروب والنزاعات الموجودة بها على سبيل المثال النزاعات الموجودة في سوريا وليبيا واليمن وفلسطين.

الهدف السابع عشر : عقد الشراكات لتحقيق الأهداف ( مختلط أو سلبى بشكل طفيف ) على الرغم من أن أزمة كورونا أحدثت رد فعل قوى ضد العولمة، وإغلاق الحدود والمجالات الجوية لكل دولة، وعدم استقبال رعايا الدول الأخرى ، وإيقاف الرحلات السياحية خوفًا من انتقال العدوى من خلال انتقال رعايا الدول التي بها حالات إصابة كثيرة ، وتوقف حركة التجارة الدولية إلا أنها أكدت على ضرورة التكاتف والتعاون الدولي لتبادل الخبرات في مجال مكافحة الأمراض والفيروسات والسعى لايجاد علاج لهذا الفيروس الأى أثر على تحقيق أهداف التنمية المستدامة

يتضح مما سبق أن فيروس كورونا المتقدمة والنامية والعربية ، وتراجعت الدول عن الاهتمام بتحقيق أهداف التتمية المستدامة بسبب سيطرة هذا الفيروس على فكر وسياسات والموازنات المالية لكافة دول العالم وتوجية الانفاق الحكومى لإحتواء الفيروس والبحث عن العلاج الآمن لإفاظ على صحة مواطنيها ، لإنى

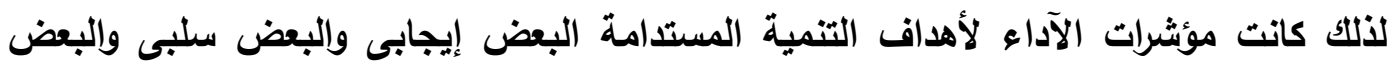
الآخر مختلط (يجمع بين السلب والايجاب) ومن ثم يجب على الدول إعادة رسم خريطة جديدة

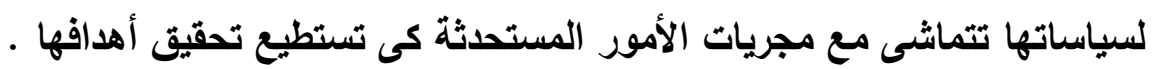

ثالثا- وضع مصر على خارطة مؤثرات التنمية المستدامة لعام 2020 - وضعت مصر محور التنمية المستدامة فى مقدمة أولوياتها الوطنية وتجسد ذلك فى استراتيجية التنمية المستدامة (روية مصر 2030) والتى تعمل على تحقيقها فى جميع

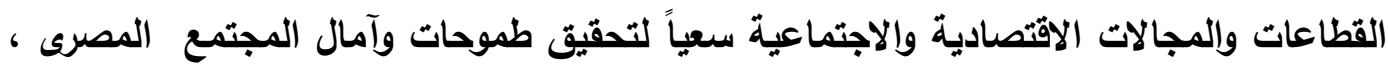
فقد تقدمت مصر 9 مراكز فى مؤثرات التنمية المستدامة عام 2020 حيث حصلت على المركز 83 من بين 166 دولة مقارنة بعام 2019 كانت تحتل المرتبة 92 من بين 162 دولة مصنفة

كما احتلت المرتبة 10 مقارنة 16 دولة من الأسواق الناشئة المصنفة فى عامى 2019 / 2020 كما تقدمت مصر على المستوى العربى لتحصل على المركز السابع من بين 20 دولية عربية مصنفة فى عام 2020 مقارنة بعام 2019 حيث كاتت تحتل المركز التاسع من بين 19 دولة عربية مصنفة ، وعلى مستوى القارة الافريقية حصلت مصر على المركز الرابع من بين 47 دولة افريقية مصنفة عام 2020 كما احتلث المرتبة ذاتها فى عام 2019 من بين 45 
دولة أفريقية مصنفة ، كما احتلت المرتبة الأولى من بين 9 بلانان عربية فى اتباع المعايير

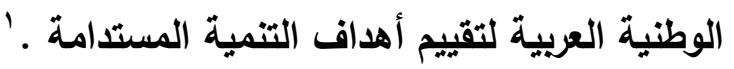

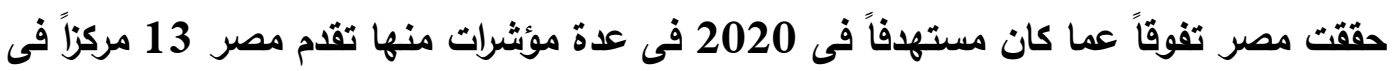

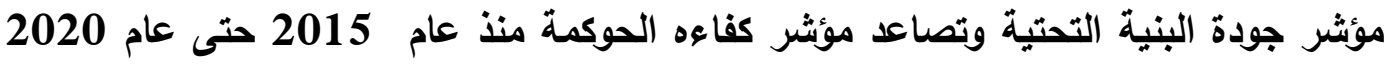

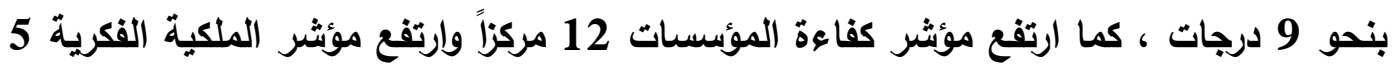

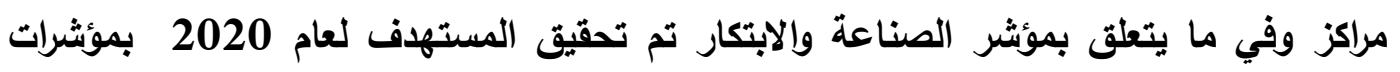

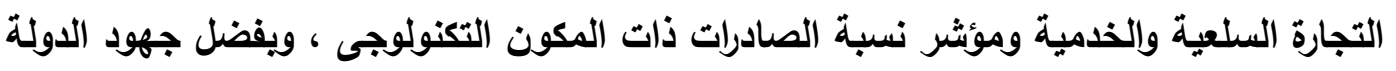

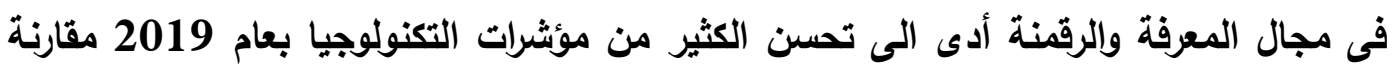

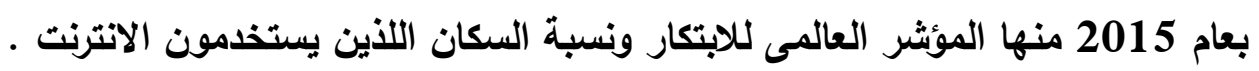

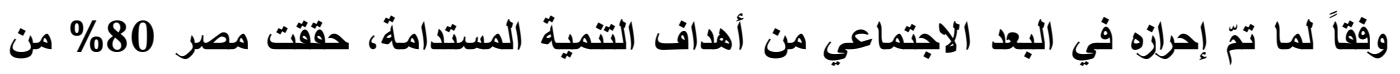

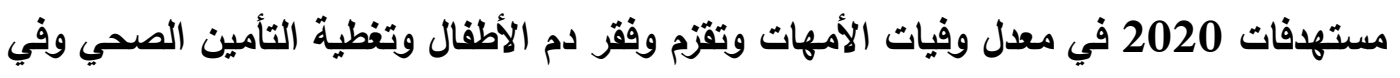

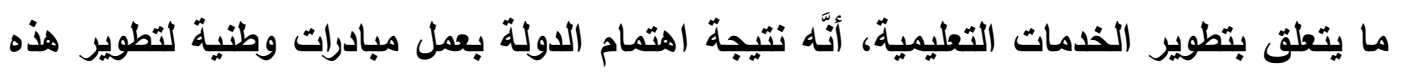

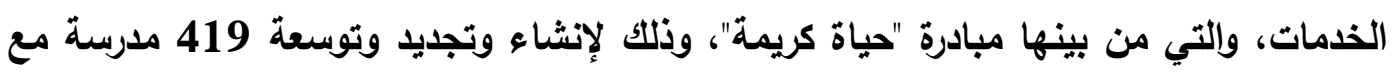

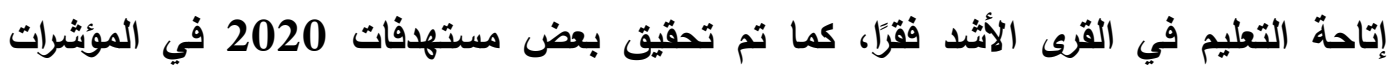

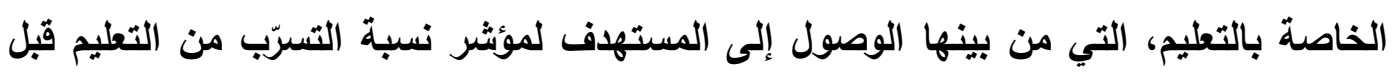

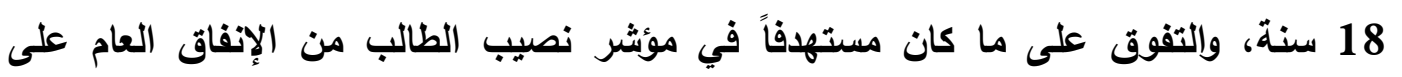

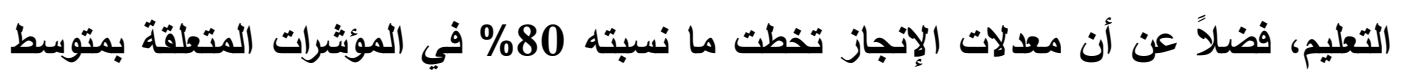
عدد الطلاب في الفصل وحجم التدفقات النقية الموجهة للمنح الدارسية، وكذا مؤشر الإنفاق

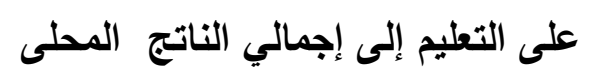
نتيجة حرص الاولة على تحقيق العدالة الاجتماعية من خلال الاهتمام بفئات المجتمع المختلفة

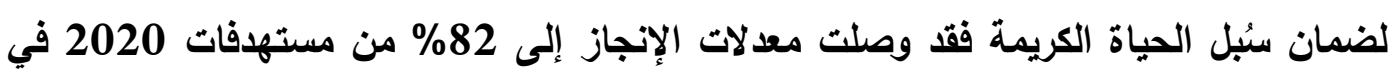

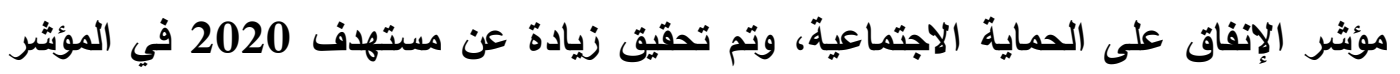

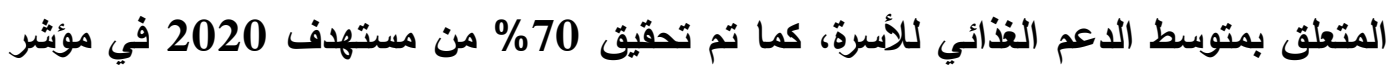

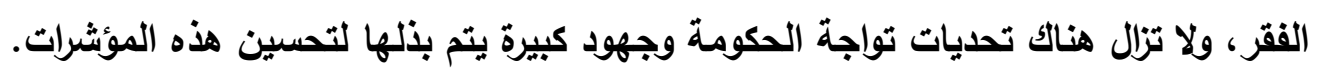

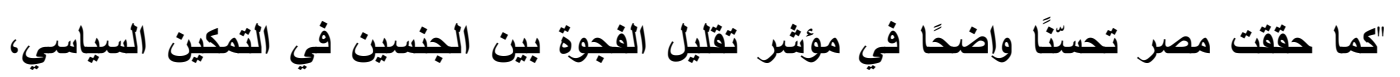

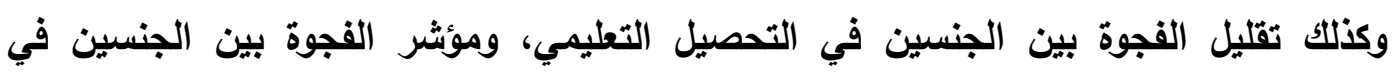

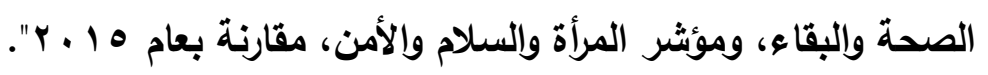
كما استقر موقف مصر بالنسبة لهاف العمل المناخى فقد تحسن مؤشر نصيب الفرد من من مأن

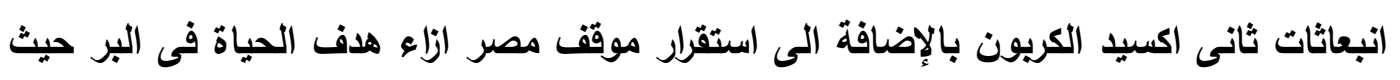

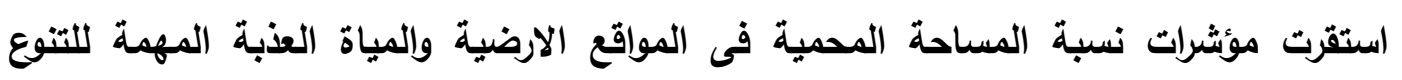
البيولوجى - البون 


\section{برامج الحماية الاجتماعية ومدى فاعليتها فى تحقيق أهداف التنمية المستدامة}

تظهر أنظمة الحماية الاجتماعية *بجلاء فى أهداف التتمية المستدامة للأمم المتحدة حيث يدعو الهدف الفرعى (1-r) من هذة الأهداف الى" استحداث نظم وتدابير حماية اجتماعية ملائمة على الصعيد الوطنى للجميع ووضع حدود دنيا لها وتحقيق تغطية صحية واسعة للفقراء والضعفاء بحلول عام 2030 ". ' كما نص إعلان منظمة العمل الدولية الصادر عام 2008 " وضع وتعزيز تدابير الحماية الاجتماعية و الضمان الاجتماعى وحماية الأيدى العاملة تكون مستدامة ومتكيفة مع الظروف الوطنية تمكن الجميع من الحصول على قسط عادل من ثمار التقدم وتوفير أجر يضمن حد أدنى

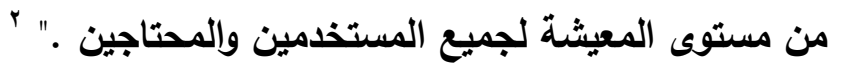
من منطلق ذلك يتناول المبحث العناصر الآتية :

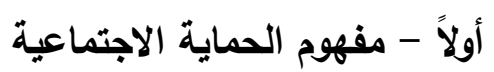
ثانياً - أهداف الحماية الإجتماعية ثالثاً - العلاقة بين برامج الحماية الاجتماعية والوثيقة الصلة بأهداف التنمية المستدامة أولاًً - مفهوم الحماية الاجتماعية :

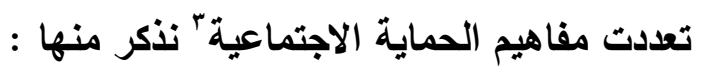
تعريف منظمة التنمية والتعاون الاقتصادى الحماية الاجتماعية : أنها السياسات والإجراءات التى تعزز قدرة الفقراء على التظلب على الفقر وتمكنهم من ادارة المخاطر والصدمات بشكل أفضل ، وتثمل اجراءات الحماية الاجتماعية : التأمين الاجتماعى والتحويلات الاجتماعية وتأمين المعايير الأساسية لضمان بيئة عمل داعمة .

united Nation Research Institute for Social Development (UNRISD)Combating Poverty and Inequality: Structural change, Social Policy and Politics ,2010 , p:135 https://ar.wikipedia.org/w/index.php?title -

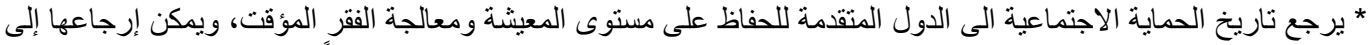

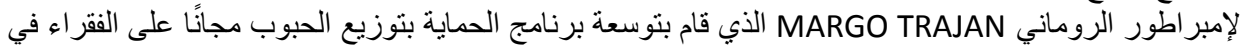

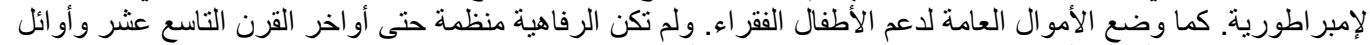

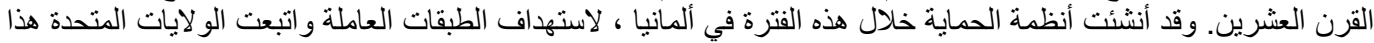

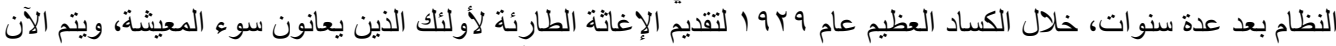

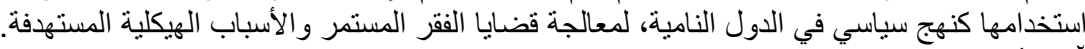

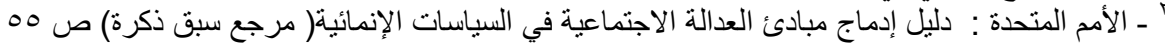

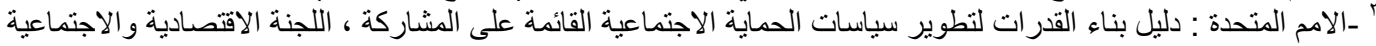

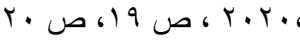

الأمم المتحدة : دليل إدماج مبادئ العدالة الاجتماعية في السياسات الإنمائية ، اللجنة الاقتصادية والاجتماعية لغربى أسيا (

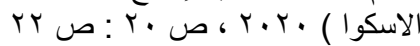


تعرف منظمة العمل الدولية (ILO) الحماية الاجتماعية على أنها تتضمن تسع مجالات تغطى مجمل جوانب حياة الأفراد ومختلف الفئات السكانية ويعتبر نظام الحماية متكاملا بقدر مايشمل

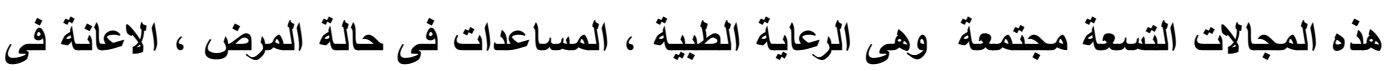
حالة البطالة ، اعانات كبار السن ، تعويضات اصابات العمل ، تعويضات الأسر ، اعانة الأمومة تعويضات العجز ، ومساعدة الناجين ، وتقترح ثلاث طرق للوصول الى حماية اجتماعية متكاملة وهى : نظم الحماية الاجتماعية الشاملة ، نظم التأمين الاجتماعى ، وخطط المساعدة الاجتماعية مفهوم البناك الاولى :الحماية الاجتماعية أنها مجموعة من التدخلات لمتابعة الأفراد والأسر والمجتمعات لمساعدتهم على ادارة المخاطر المحيطة بهم ولمحاربة الفقز ضمن هذا المنظار

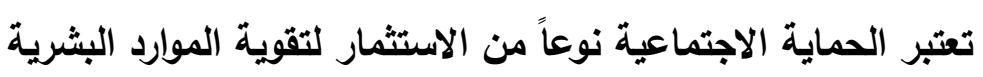
تعريف منظمة الإسكوا : الحماية الإجتماعية بأنها مجموعة من الإجراءات والسياسات والبرامج

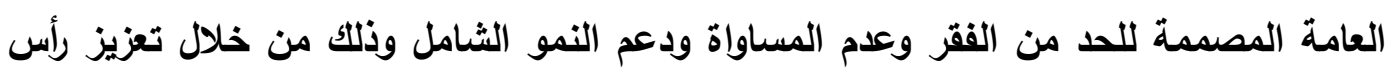
المال البشرى وفرص العمل ودعم قرة الافراد على ادارة المخاطر الاقتصادية والحياتية. ثانياً- أهداف سياسات ويرامج الحماية الاجتماعية ' يعتبر التمتع بالحماية الإجتماعية حقاً من حقوق الإنسان ضمن حقوقة الإنة الاقتصادية والاجتماعية وقد تضمنت منظمة العمل الدولية هدف توفير الحماية الاجتماعية للعاملين ضمن مكونات العمل اللائق، وتهذف سياسات الحماية الاجتماعية الى تفعيل هذة الحقوق للعاملين وجميع المواطنين فى المجتمع فتساهم بذلك فى تحقيق التماسك الاجتماعى وإرساء الأمن المجتمعى وإعادة توزيع ثمار النمو والتنمية على نحو أكثر عدالة ، وتعزز رأس المال البشرى والانتاجية وتولا شعوراً بالإستقرار الاجتماعى لدى المشار المشمولين برعايتها جاء فى تقرير الأمين العام للأمم المتحدة من مجلس حقوق الانساعن الأنسان فى عام 2014 أن النظم

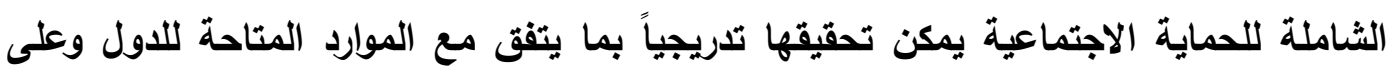
الدول ان تضع استراتيجيات للحماية الاجتماعية تحترم مبادىع عدم التمبيز والمساواة بين الجنسين والإندماج الإجتماعى و تثنمل على توليفة من التدابير حسب آليات الحماية

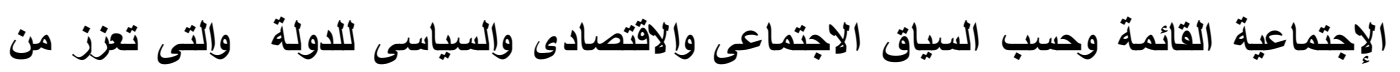

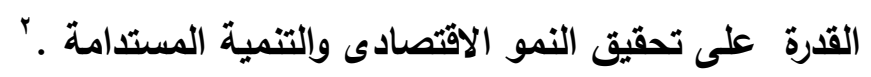
طبقاً لمعايير منظمة العمل الدولية يشمل نظام الحماية الاجتماعية المتكامل تسعة مجالات تغطى مجمل جوانب حياة الأفراد ومختلف الفئات السكانية ويعتبر نظام الحماية الإجتماعية متكاملاً بمقدار مايشمله من المجالات التسعة مجتمعة ، تلك المبادرات التسعة فى منظومة الامم

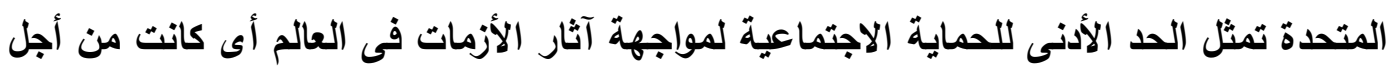

ـ الأمم المتحدة : دليل ادماج مبادىء العدالة الإجتماعية فى السياسات الإنمائية ، اللجنة الاقتصادية والاجتماعية لغربى آسيا (

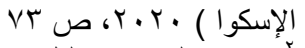

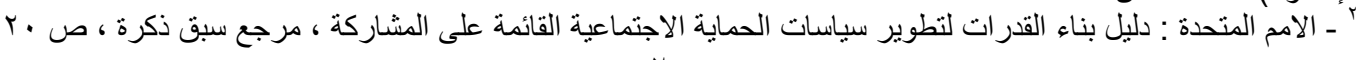


تعزيز الاستقرار الاجتماعى ، وعلى الدول اتخاذ مايلزم من السبل الكفيلة لتوسيع نطاق الحدود الانيا للحماية الاجتماعية وتكيفها مع الظروف الاقتصادية والاجتماعية والسياسية لكل دولة. يوضح الثكل الآتى المجالات التسعة لنظام الحماية الاجتماعية شكل (1) المجالات التسعة لنظام الحماية الاجتماعية

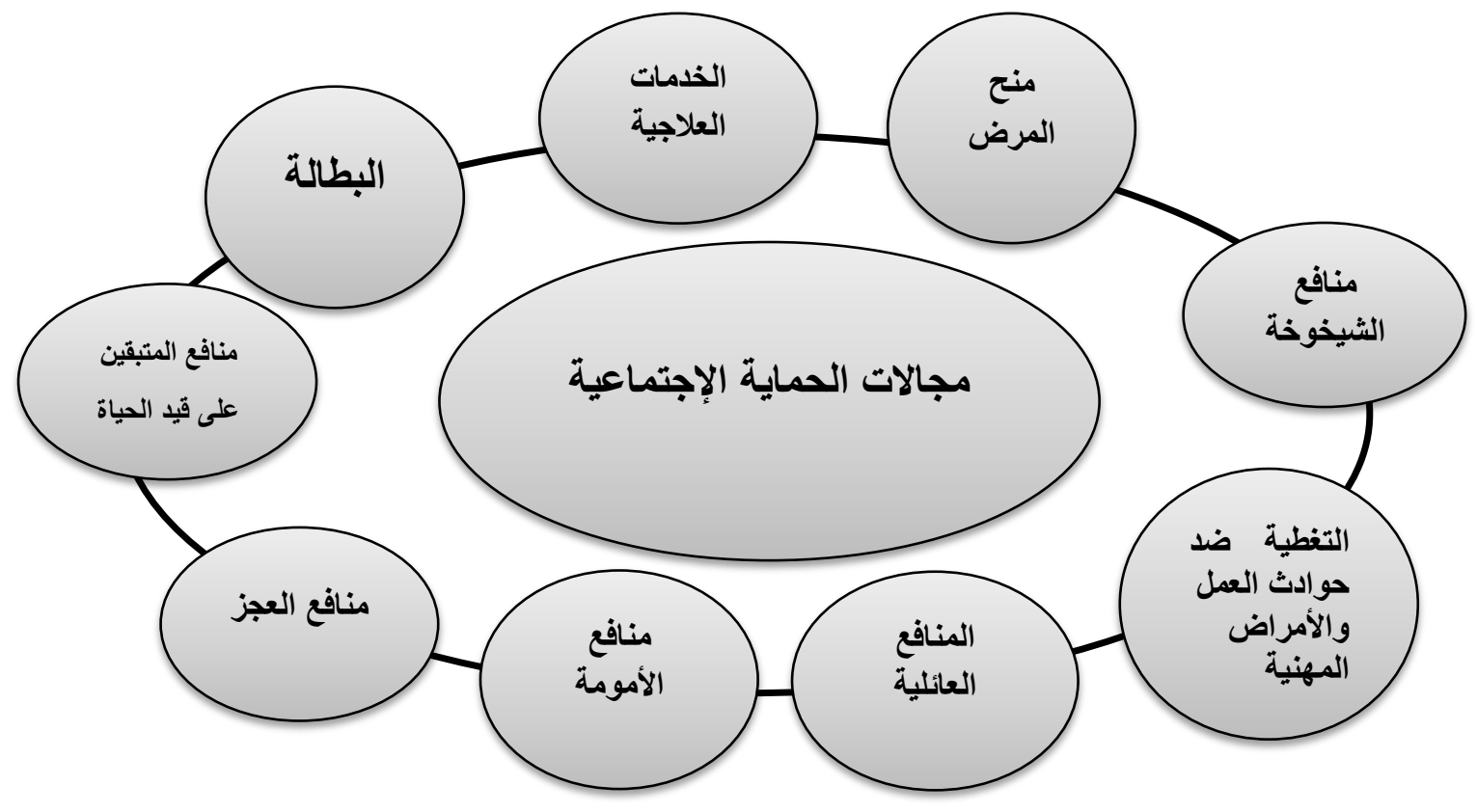

المصدر : الامم المتحدة : دليل بناء الققرات لتطوير سياسات الحماية الاجتماعية القائمة على المشاركة اللجنة الاقتصادية

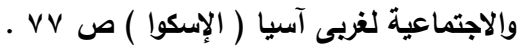

ثالثاً - العلاقة بين برامج الحماية الاجتماعية وأهداف التنمية المستدامة هناك علاقة وثيقة تربط بين بعض أهداف ومقاصد التمية المستدامة والحماية الاجتماعية' حيث تمثل الحماية الاجتماعية موقعاً مركزياً فى التوجهات التنموية الجديدة التى عبرت عنها خطة

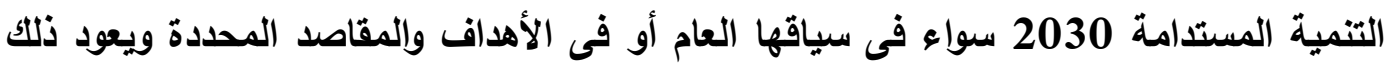
الى قصور التغطية بالحماية الاجتماعية وعدم شمولها مختلف أبعاد الحياة الانسانية الفردية والجماعية ، طبقاً لتقديرات البرنامج الإنمائى للأمم المتحدة فان 55 \% من التعداد السكانى العالمى لاتثمله مظلة الحماية الاجتماعية وهى توابع سيكون لها عواقب وخيمة على أهم أهداف التنمية المستدامة كالتعليم وحقوق الانسان والأمن الغذائى والتغذية ، فالعالم الأى تصبو الية حسب خطة التنمية 2030 هو عالم تتاح فية للجميع سبل متكافئة للحصول على التعليم الجيا على جميع المستويات وعلى الرعاية الصحية والحماية الاجتماعية ( الفقرة 7 من ديباجة الخطة) والالتزام بالقضاء على الفقر أى أنه لابد أن يتمتع الجميع بمستويات المعيشة الأساسية 
عن طريق وسائل منها نظم الحماية الاجتماعية ( فقرة 24 ) ويثمل ذلك قطاع الأعمال التجارية

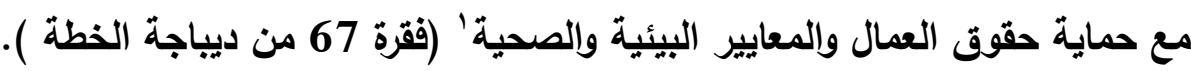
فى سبتمبر 2015 أقرت الجمعية العامة للأمم المتحدة خطة على المعاير المستوى الداولى للتنمية

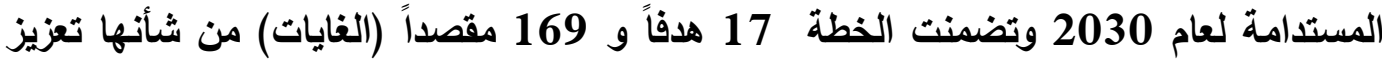
الجهود والسياسات التنموية للسنوات الـ 15 القادمة تتناول مجموعة من القضايا مثل القضاء الفياء على الفقر ومكافحة الجوع والتعليم للجميع والمساواة بين الجنسين والجوانب البيئية والطاقة النظيفة والتنوع البيولوجى والمناخ والجوانب الاقتصادية .

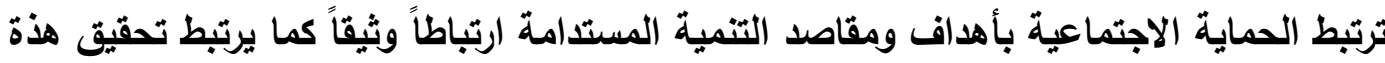
الاهداف بالعدالة الاجتماعية فقد أقر اعلان كوينهاجن الصادر عن مؤتمر القمة العالمى للتمية الاجتماعية فى عام 1995 بأن العدالة الاجتماعية والتنمية الاجتماعية العادلة عنصران

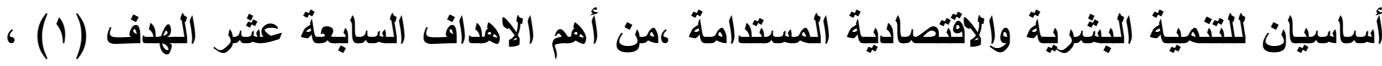

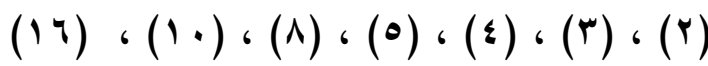

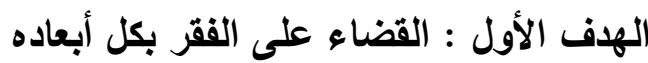

يرتبط هذا الهاف بالحماية الاجتماعية والعدالة الاجتماعية حيث القضاء على الفقر بكل أبعادة

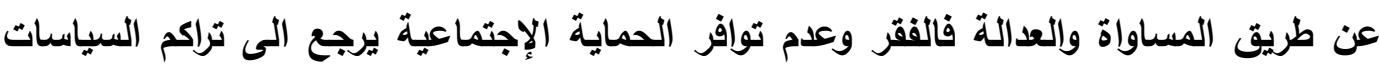
وإهمال الفئات الضعيفة والفقيرة ويشترك هذا الهلف مع مجموعه من الأهداف ترتبط بالفقر منها

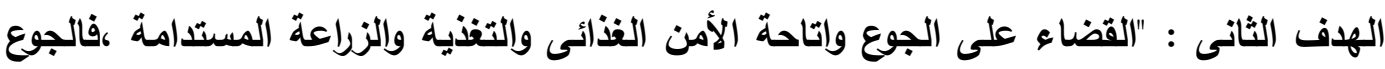
والفقر حالات متداخلة ، والفقر من مسبيات الجوع و أن معالجة الجوع وتوفير الغذاء لايعالجان الفقر ومن الممكن أن يقع الأفراد تحت خط الفقر بدون التعرض للجوع ، كذلك الهدف الثالث :

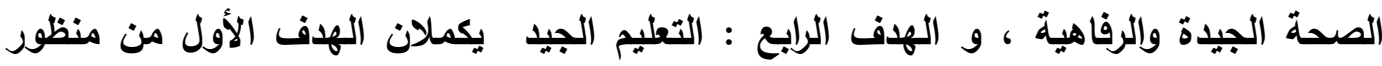

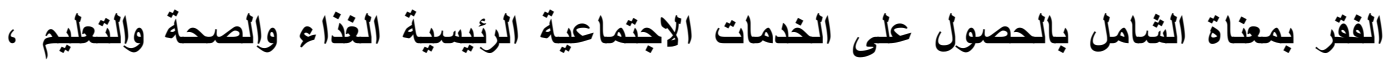

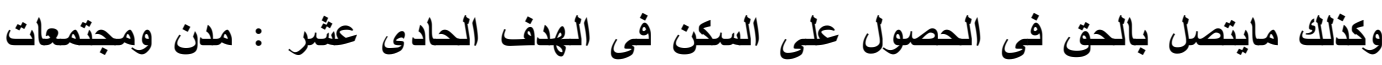

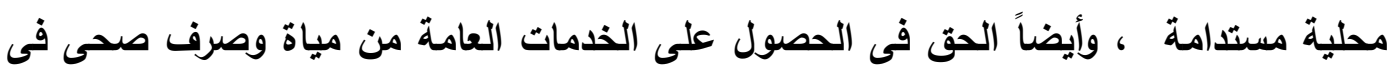
الهلف السادس: المياة النظيفة والنظافة الصحية ، والحق فى توفير الكهرياء فى الهدف السابع طاقة نظيفة ويأسعار معقولة تلك الاهداف جميعها من مكونات الفقر متعدد الأبعاد والتى تم

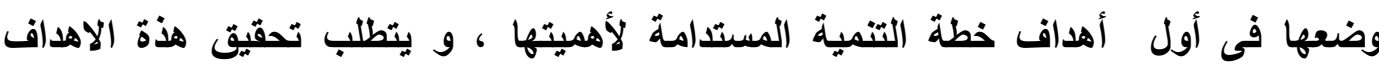

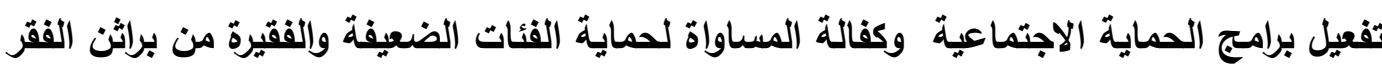

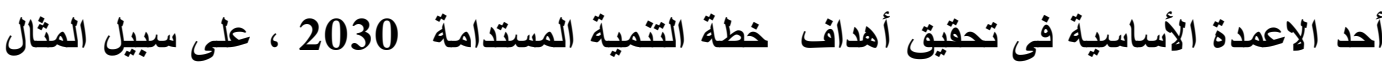
:من مقاصد الهاف الاول (1-1) استحداث نظم وتدابير حماية إجتماعية ملائمة على الصعيد الوطنى للجميع ووضع حدود دنيا لها وتحقيق تغطية صحية واسعة للفقراء الضعفاء بحلول

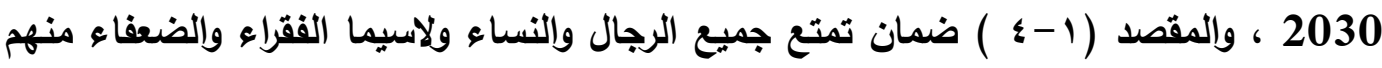

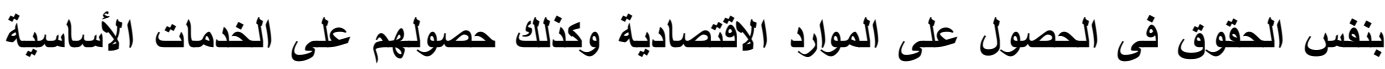


وعلى حق ملكية الأراضى والتصرف فيها' ، والمقصد (1 -ه) بناء قدرة الفقراء وإلفئات الضعيفة على الصمود والحد من تعرضها وتأثرها بالظواهر المتصلة بالمناخ وغيرها من الهزات والكوارث الاقتصادية والاجتماعية والبيئية بحلول عام 2030 يوضح الشكل التالى مكونات القضاء على الهدف الأول من أهداف التنمية المستدامة (الفقر)

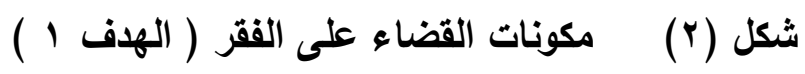

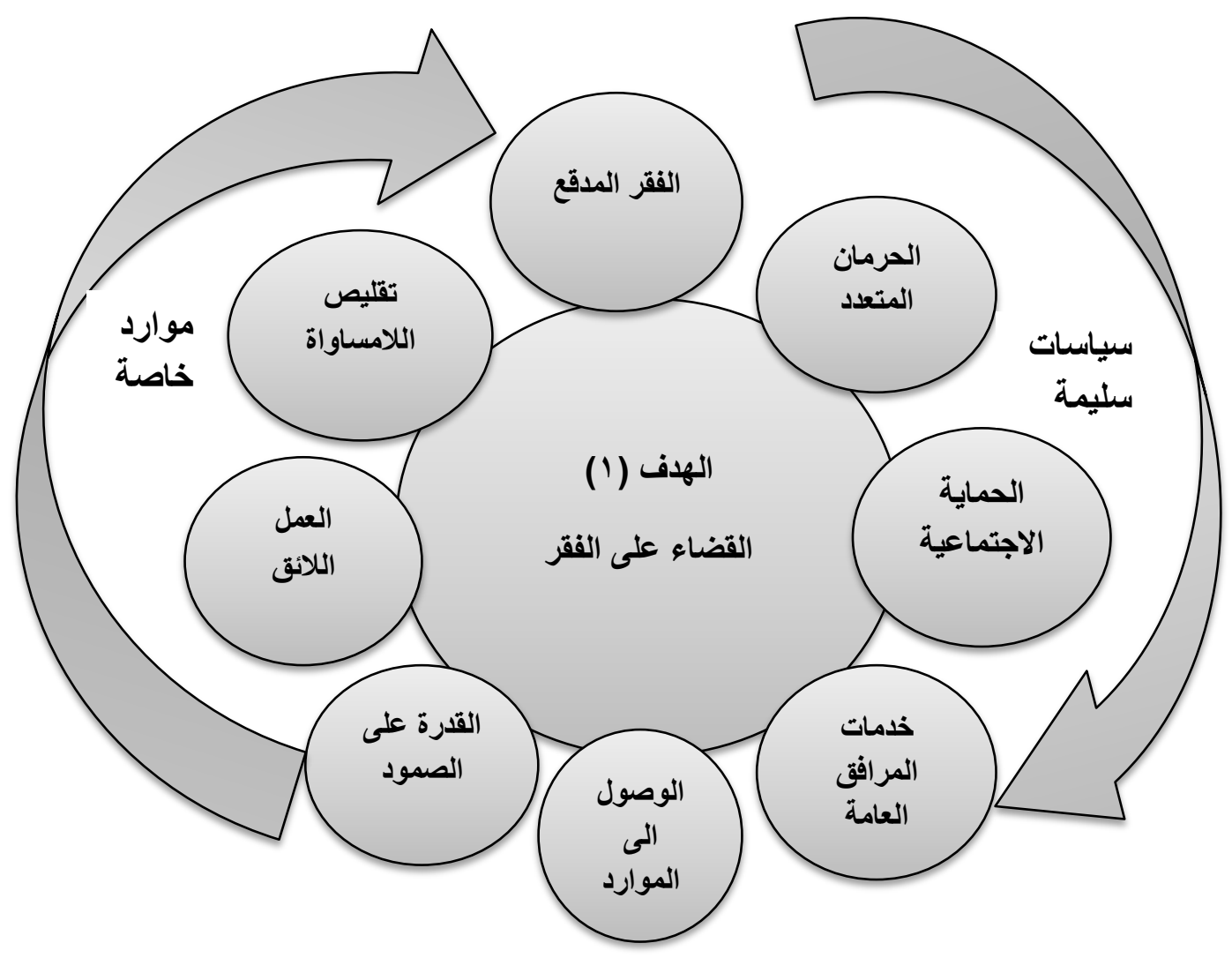

المصدر : الأمم المتحدة : ليل إدماج مبادئ العدالة الاجتماعية في السياسات الإنمائية ، اللجنة الاقتصادية

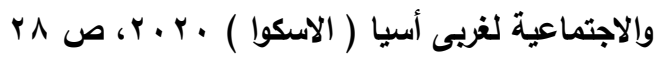

طبقاً لتفسير المجلس الدولى للعلوم لخطة 2030 يتطلب القضاء على الفقر المدقع ضمان إمكانية حصول الجميع على الموارد الأساسية وتوفير الحماية الإجتماعية والتصدى للتفاوت بين الفئات الإجتماعية ، ويعنى تحقيق المقاصد تصميم وتتفيذ سياسات إجتماعية ملموسة تتناسب

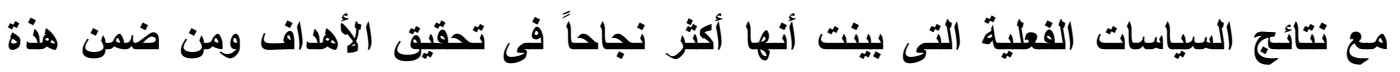
السياسات الناجحة سياسة الحد الأدنى للحماية الإجتماعية والتأكيا على أن الحماية الإجتماعية لابد أن تكون شاملة ولا تففل أى فئة إجتماعية ويقع هذا التوجة فى صلب مفهوم العدالة الاجتماعية و خطة التنمية المستدامة ، ومن ثم لابد أن يكون الهذف (1) القضاء الثهاء على الفقر 


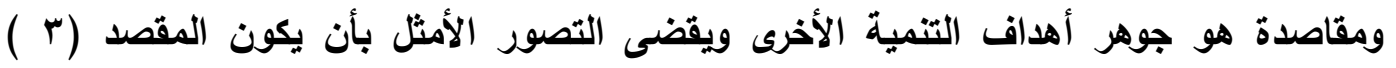

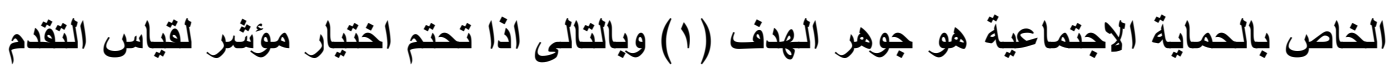

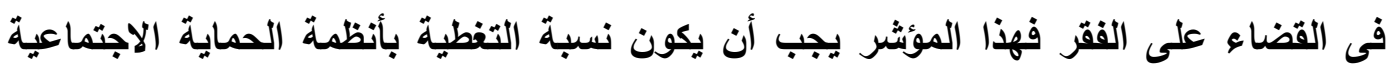

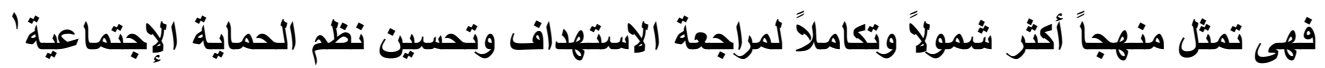

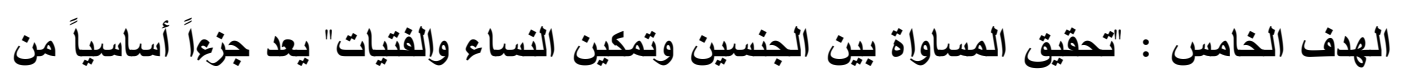

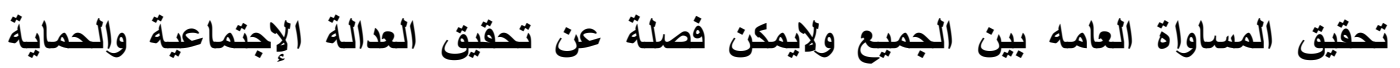

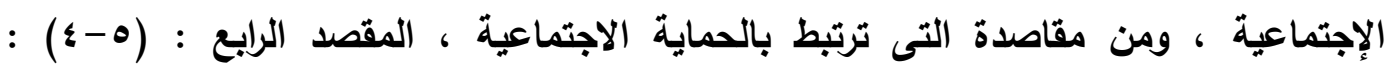

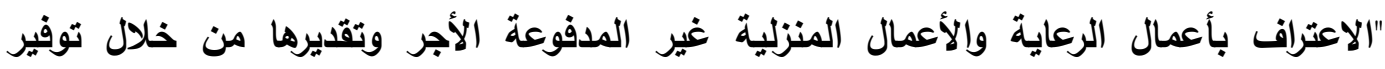

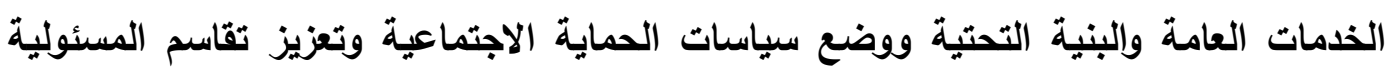

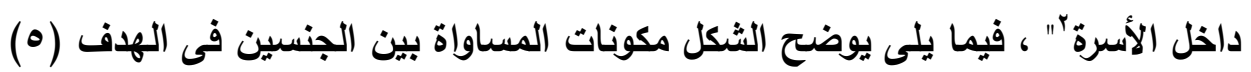

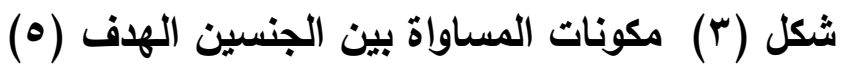

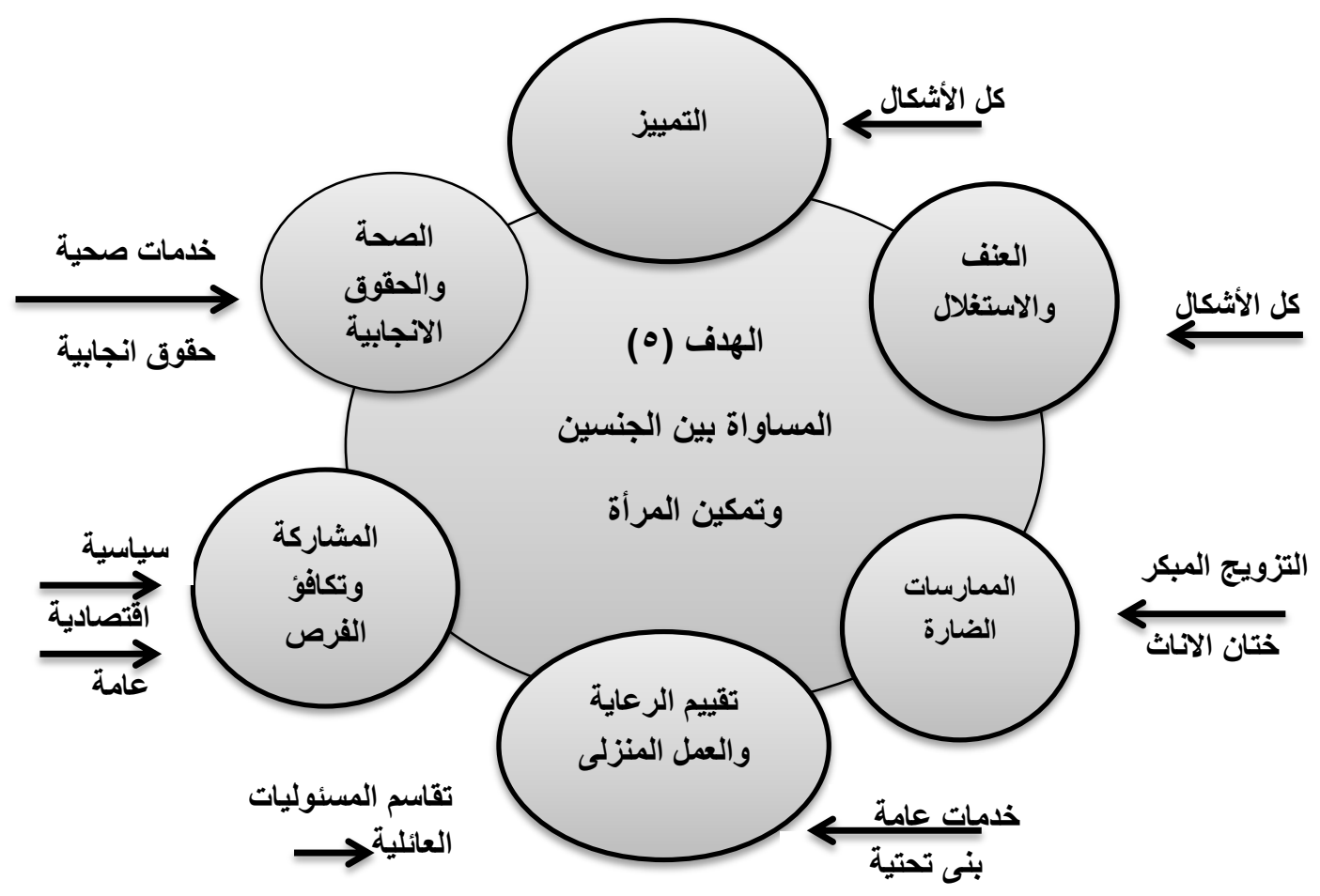

المصدر : الأمم المتحدة : دليل إدماج مبادئ العدالة الاجتماعية في السياسات الإنمائية ، اللجنة الاقتصادية والاجتماعية

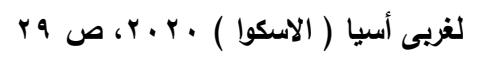

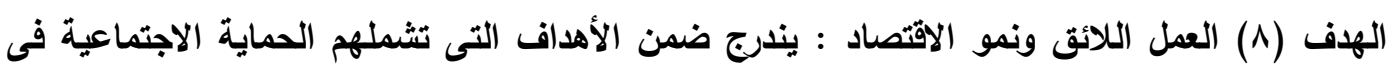

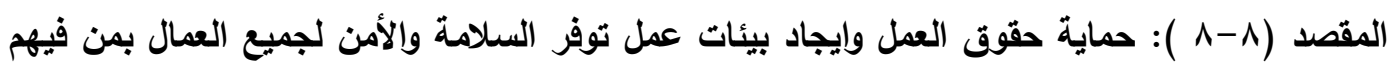

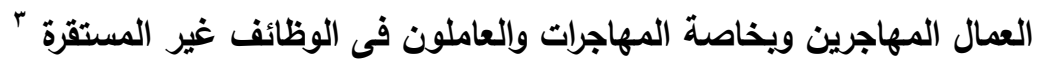

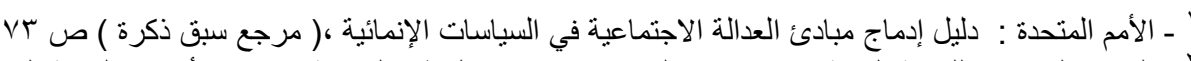

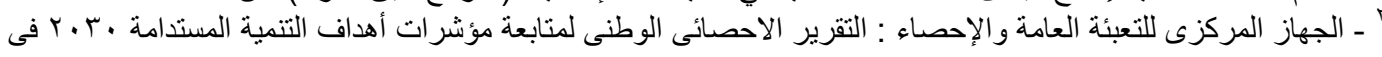

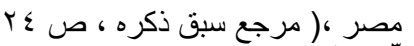
' - الأمم المتحدة : الحماية الاجماعية أداة للعدالة ، اللجنة الاقتصادية والاجتماعية لغربى آسيا ( الاسكوا ) ، نثرة التمبية

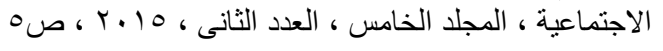


الهدف ( • 1) : "الحد من عدم المساواة داخل البلدان وفيما بينها" ، يهاف الى تحقيق العدالة الإجتماعية

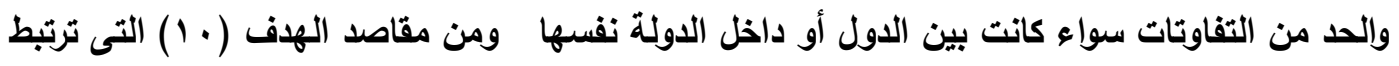
بالحماية الاجتماعية بصفتها إحدى السياسات المحورية فى تحقيق قدر أكبر من المساواة المقصد

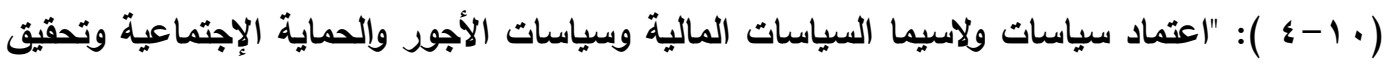
قرر أكبر من المساواة تدريجياً" يوضح المقصد طبيعة السياسات المطلوية لتحقيق العدالة الاجتماعية

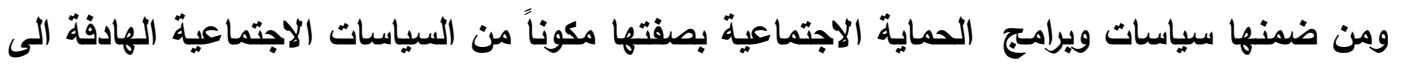
تحقيق العدالة الاجتماعية حيث مفهوم العدالة الاجتماعية (المساواة) أوسع نطاقاً من مفهوم القضاء على الفقر ويشملأبعاداً وفئات اجتماعية أوسع. طبقاً لمعهدالأمم المتحدة لبحوث التنمية الاجتماعية يمكن توزيع حزمة المئماعية السياسات الاجتماعية التحويلية وفق أريعة محاور هى الانتاج و أعادة التوزيع و إعادة الانتاج الاجتماعى و الحماية الإجتماعية الإئه

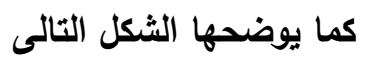

\section{شكل (؛ ) السباسة الاجتماعية التحويلية}

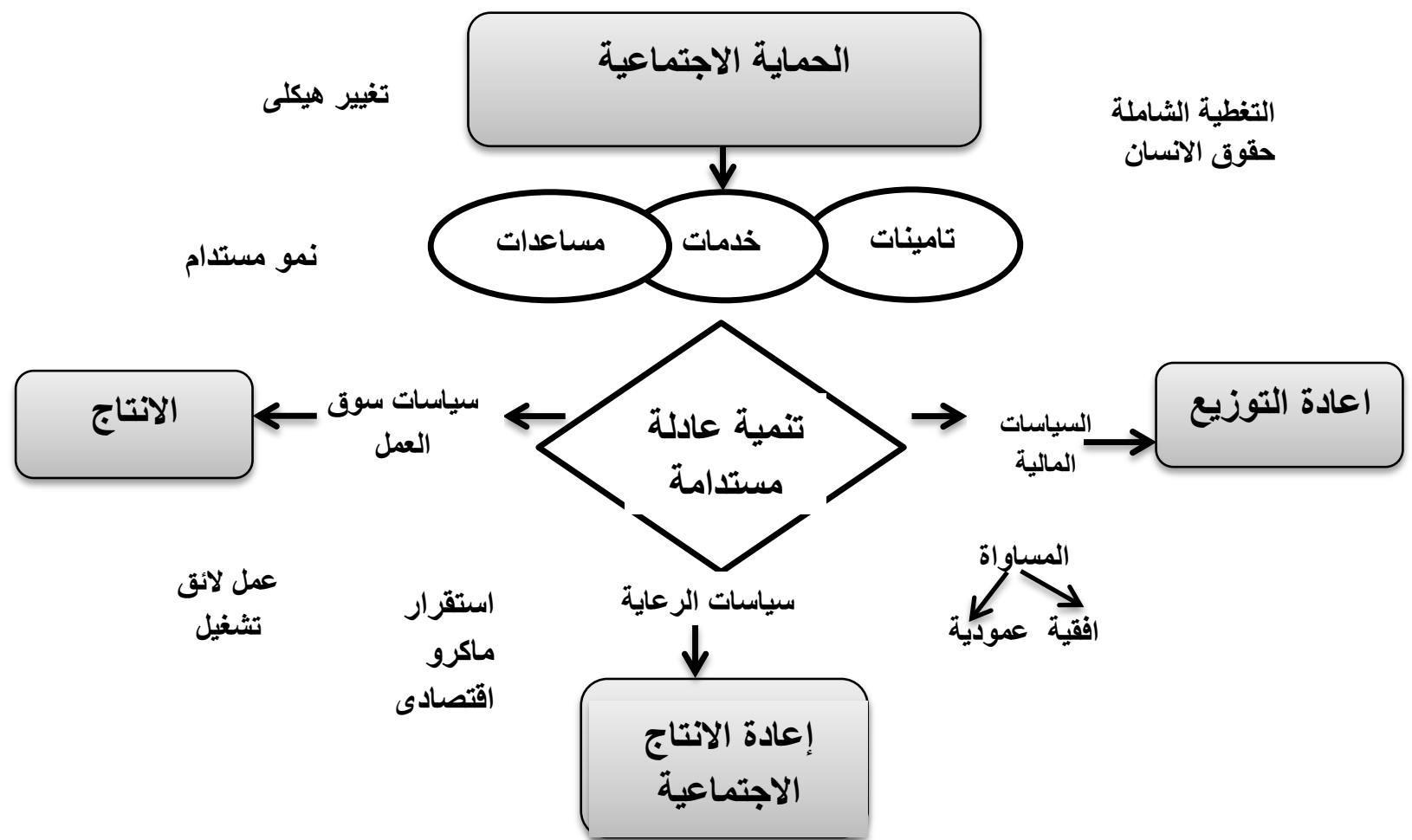

المصدر : الأمم المتحدة : دليل إدماج مبادئ العدالة الاجتماعية في السياسات الإنمائية ، اللجنة الاقتصادية

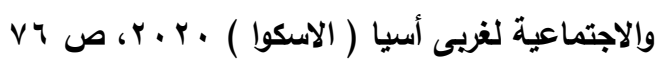

الهدف (16) : "السلام والعدل والمؤسسات القوية" يحدد خصائص المجتمع المنشود بتوفير السلم والأمن

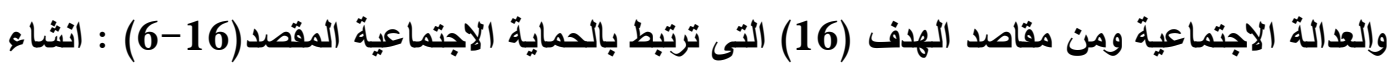

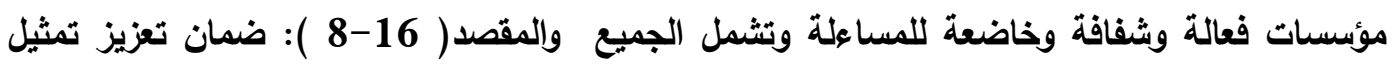

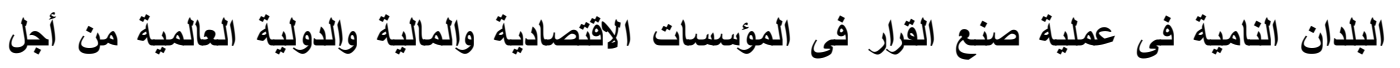

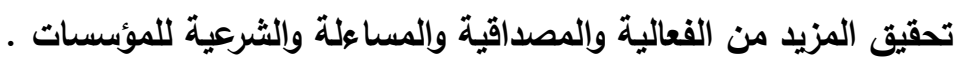




$$
\text { المبحث : الرابع }
$$

الآليات وبرامج الحماية الاجتماعية التى انتهجتها الحكومة لاحتواء فيروس كورونا

لاثكك أن انتثار فيروس كورونا فى جميع دول العالم لم يكن له آثارة السلبية على الوضع

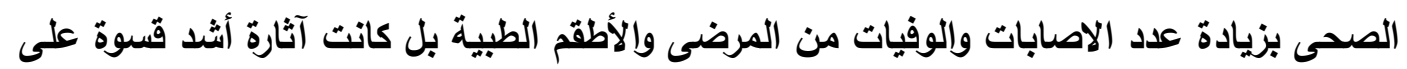
الوضع الاقتصادى والاجتماعى والفئات الفقيرة ، وأصبح مواجهة الفيروس يشكل تحدياً صعباً أمام دول العالم يتطلب حشد كافة الجهود لمواجهتة، وكان لابد من الإسراع بتغيير الخطط واتخاذ

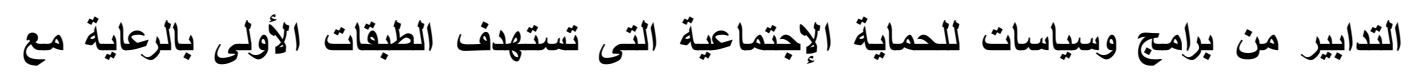

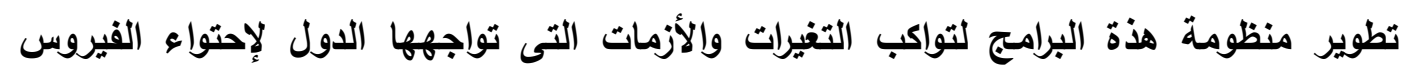
وتقديم المزيد من المساعدات للفئات الأكثر تضرراً. يقول غاي رايدر المدير العام لمنظمة العمل الدولية "أن و ج \% م ' فقط من سكان العالم يحصلون على تغطية حماية إجتماعية مناسبة ويجب على الحكومات أن تعمل على ضمان إستدامة سبل

العيش والشركات والوظائف وحماية صحة العمال وحقوقهم ودخولهم أثناء ويعد كوفيد -9 I". كما دفعت التداعيات الاجتماعية والاقتصادية لجائحة كوفيد-9 1 وكالات الأمم المتحدة إلى دعوة الدول إلى زيادة برامج الحماية الاجتماعية بهدف حماية الأشخاص الأكثر عرضة لخطر الفيروس. تعد مصر من الدول التى سعت جاهدة الى تفعيل برامج الحماية الإجتماعية وإتحداث برامج ومبادرات لمواجهة تداعيات أزمة فيروس كورونا المستجد التى تضرت من تفشى الفيروس فى جميع القطاعات ليس هذا فحسب بل شاركت جموع قوى الشعب المصرى من الشباب ومؤسسات المجتمع المدنى ورجال الأعمال والقطاع الخاص من أجل مساعدة الحكومة فى حماية الفئات الفقيرة والأكثر تضرراً. من سياق ذلك يتم مناقشة النقاط الآتية :

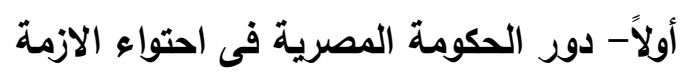

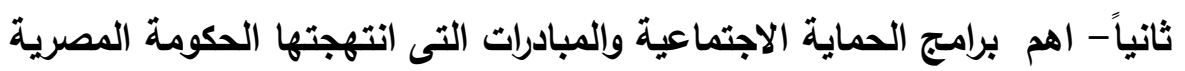
ثالثاً دور المجتمع المدنى ومساهماتة فى التخفيف من حدة الازمة لابعاً- دور المنظمات الدولية فى مساعدة الدول لاحتواعأزمة فيروس كورونا خامساً- روئية مستقبلية لمواجهة تحدى الأزمات وتحقيق التنمية المستدامة فئة

ـ ميكال روتكوفسكي : كيف ينسنى للحماية الاجتماعية مساعدة البلدان على مو اجهة فيروس كورونا ، مدونة البنك الدولى

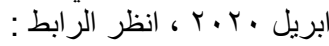
https://blogs.worldbank.org/ar/voices/how-social-protection-can-help-countries-cope-covid-19

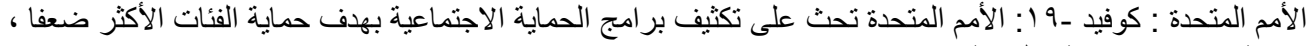

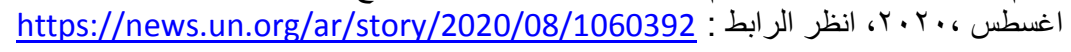


أولاً - دور الحكومة المصرية فى إحتواء أزمة فيروس كورونا

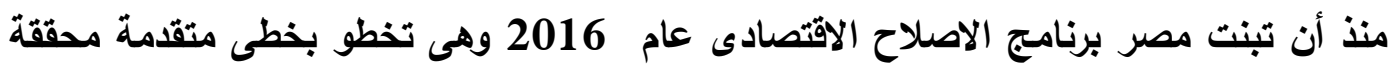

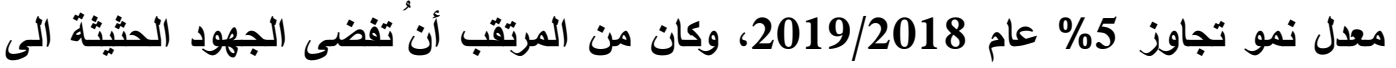

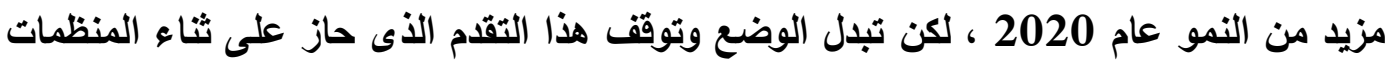
الدولية جراء تفشى فيروس كورونا ، وكان على الحكومة المصرية ان تغير فى أولويات

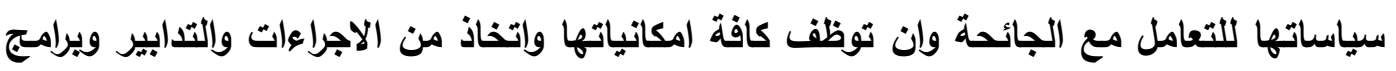
الحماية الاجتماعية التى تحمى الفئات الفقيرة والقطاعات الأكثر تضرراً.

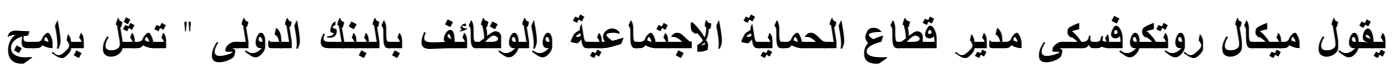

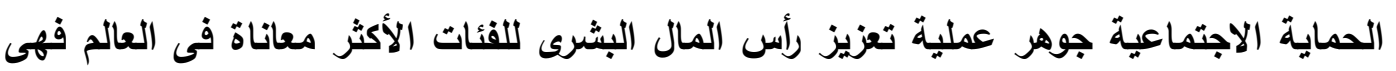

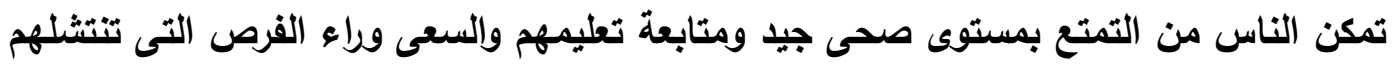

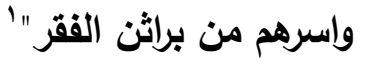

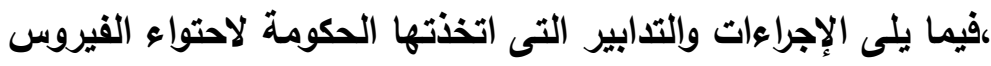

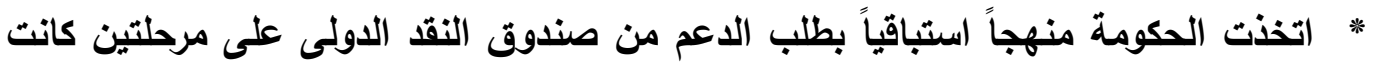

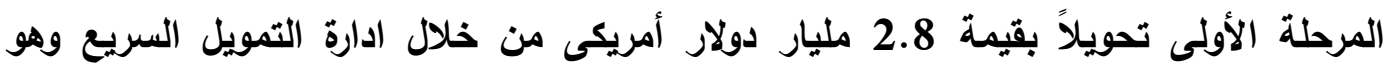

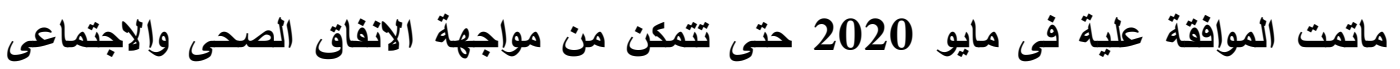

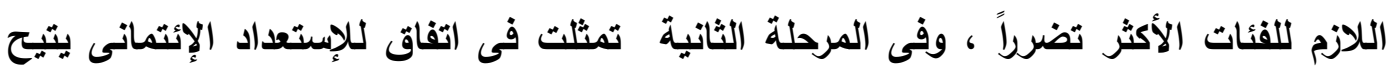

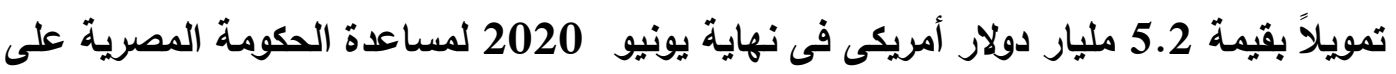

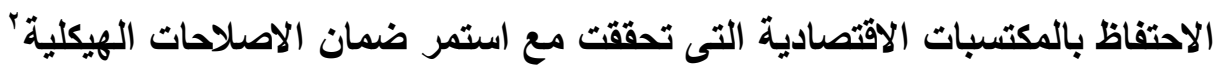

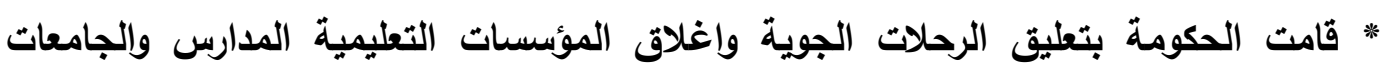

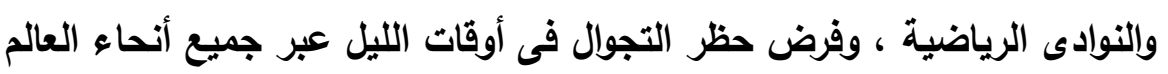

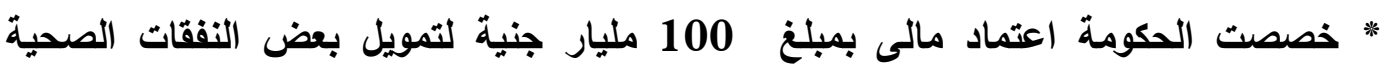

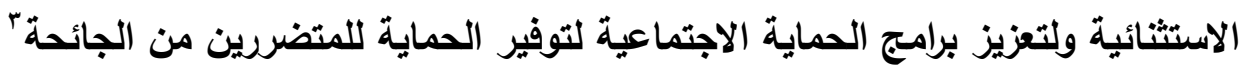

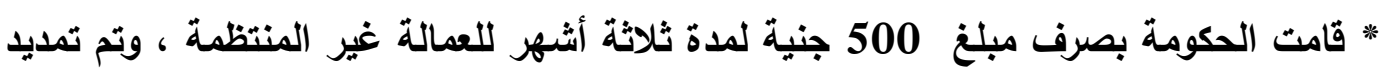

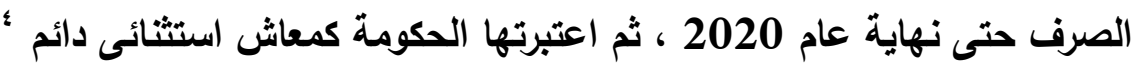
* " اتخذ البنك المركزى إجراءات تيسيرية فى السياسة النقاية لتمكين الأفراد والثركات من

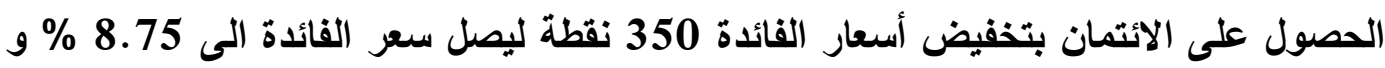

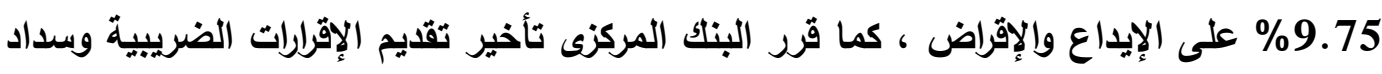

ـ سارة فرحات : بناء ونوظيف وحماية: الاستعانة بالحماية الاجتماعية في الاستثمار في البشر وسط عالم متغير، البناك الدولى الئ

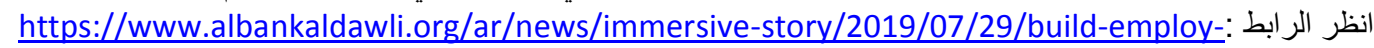
and-protect-using-social-protection-to-invest-in-people-in-a-changing-world

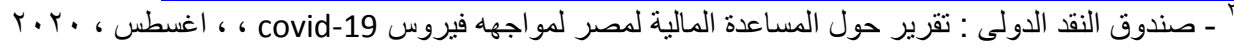
/https://enterprise.press/issues/2020/08/11/poll-sees-cbe-leaving-rates-hold-inflation-july

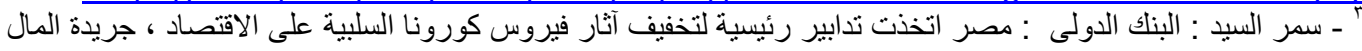

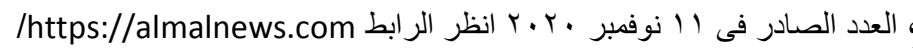

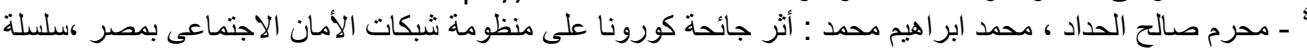

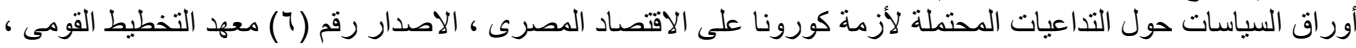


القروض لتخفيف الضغوط المالية على الأفراد والثركات ، كما أدخل تدابير لتسهيل المدفوعات الإكترونية واستخدام أجهزة الصراف الآلى ومنح قروض ميسرة بمعدل خصم بلغ 8 8 للمشروعات الصناعية والزراعية الخاصة ويمعدل 5\% لقطاع السياحة . * قامت الحكومة بتخفيض وتوحيا سعر الغاز الطبيعى ودعم أسعار الكهرياء لجميع الصناعات لمدة خمس سنوات من أجل تحسين هيكل التكلفة وتثبيث الأسعار ، كما اتخذت إجراءات لاعم البورصة المصرية بتخفيض الضريبة على أرباح الأسهم وضريبة الامغة على معاملات البورصة

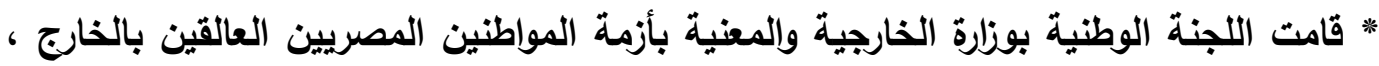
بعد قرار تعليق حركة الطيران الدولي' القيام بوضع معايير دقيقة لتحديد المواطنين العالقين بدول العالم والراغبين في العودة إلى البلاد، والتسيق مع المطارات لتحديد إمكانية استقبال الطائرات لنقل العالقين جوياً، وكذلك تحديد أعداد الأجاتب العالقين داخل مصر الراغبين في العودة إلى إلى بلادهم، فقد وصلت أعداد المصريين العائدين من الخارج إلى حوالي ، ب ألف مواطن.

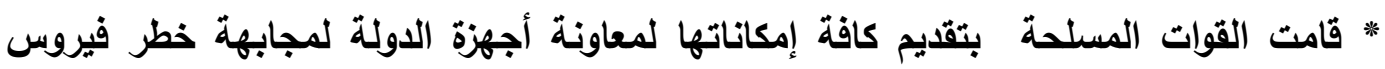
كورونا بما يكفل سلامة ووقاية المجتمع المصرى ، بدفع عريات التعقيم المتحركة و المحمولة لإجراء التعقيم والتظهير اللازم ` ، كما قامت القوات المسلحة بتوفير المطهرات والسلع الغذائية الأساسية للمواطنين من خلال منافة جهاز الخدمات العامة الثابتة والمتحركة بالمحافظات.

ثانياً- برامج الحماية الإجتماعية والمبادرات التى انتهجتها الحكومة المصرية " ضمنت الحكومة خطة التنمية للعام المالى 2021/20 آليات لتطوير منظومة الحماية الاجتماعية والنهوض بها وآليات العمل بها، اشتملت على خمسة برامج أساسية كالآتي:"

$$
\text { (1) برنامج الحماية الاجتماعية: }
$$

يهاف الى حماية الأسر من الأزمات الاقتصادية والصحية والبيئية ويضم ثلاثة برامج فرعية هي: أ- برنامج الدعم النقدي المشروط وغير المشروط لحماية الأسر تحت خط الفقر ب- برنامج الإغاثة من النكبات والكوارث الفردية والجماعية (مثل أزمة فيروس كورونا)

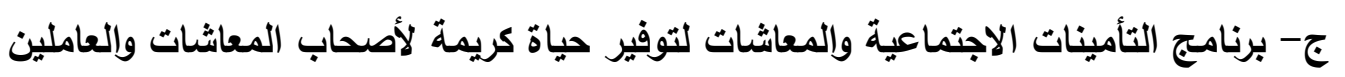
(Y) برنامج الرعاية الإجتماعية لفاقدي الرعاية

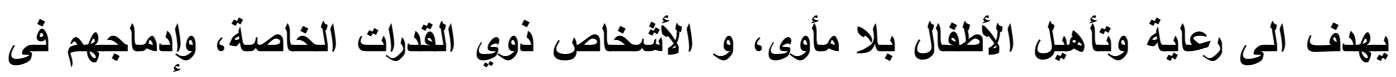
المجتمع والإرتقاء بجودة مؤسسات الرعاية الاجتماعية لتطوير خدماتها.

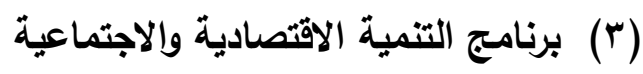
يهاف إلى تفعيل المشاركة المجتمعية والتنمية للمرأة والثباب وتوظيف مهاراتهم لخدمة المجتمع، ويضم البرنامج أنشطة دعم الأسر المنتجة والتكوين المهني والحرفي ، وعلاج الادمان

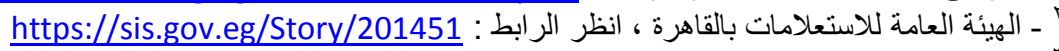


يهاف إلى مشاركة القطاع الخاص والمؤسسات الأهلية في تحقيق التتمية المستدامة، (0) برنامج التطوير المؤسسي اللجهاز الإداري يهاف إلى تحسين مستويات الأداء والذذمات و تطوير نظم الرقابة والمتابعة و الموارد البشرية.

* برامج ومبادرات الحماية الإجتماعية تحت مظلة وزارة التضامن الإجتماعى 1- 1 - برنامج تكافل وكرامة

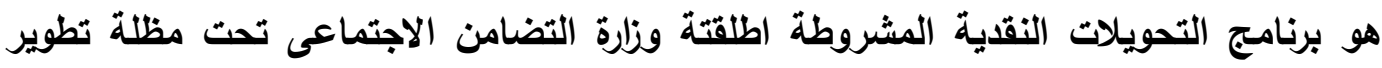

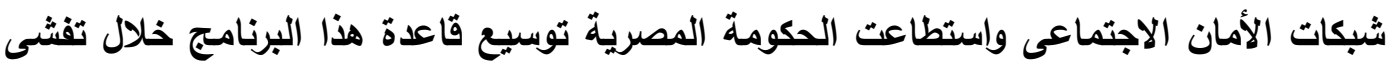

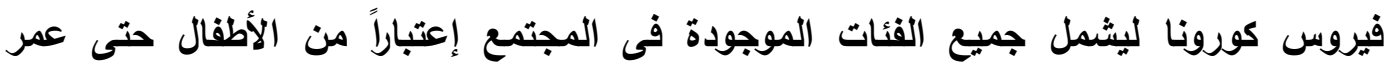

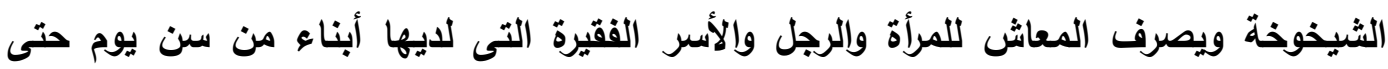

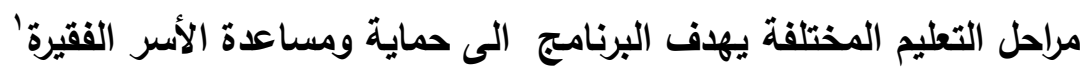

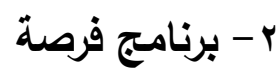
يمثل منظومة متكاملة للتأهيل لدخول سوق العمل وتوفير فرص عمل كمله كريمة وهو امتداد

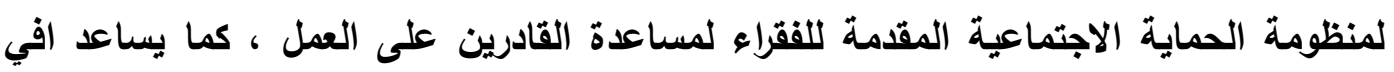

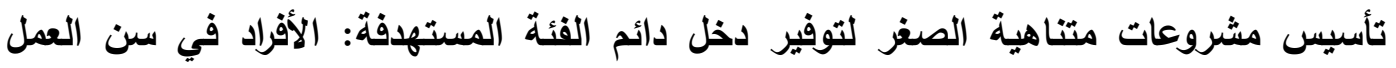

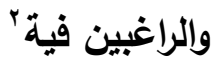

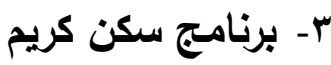

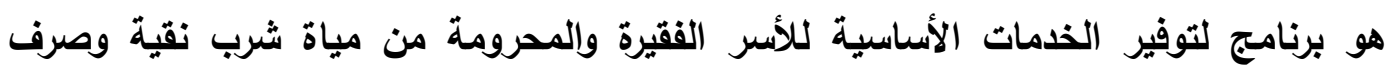

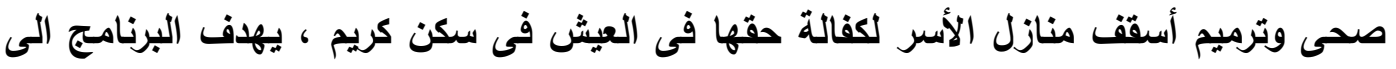

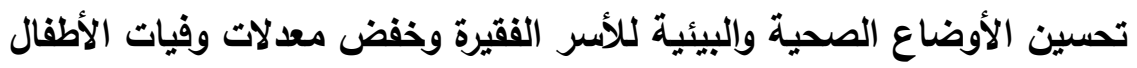
ع - برنامج اثنين كفاية

يهلف الى الحد من الزيادة السكانية بين الأسر المستفيدة من برنامج تكافل ويأتى البرنامج

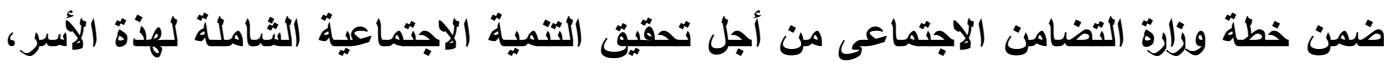

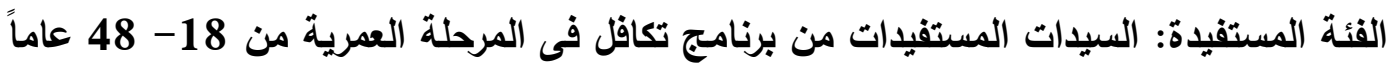
بالمحافظات الاكثر فقراً والأعلى خصوية ( البحيرة ، الفيوم ، الجيزة)

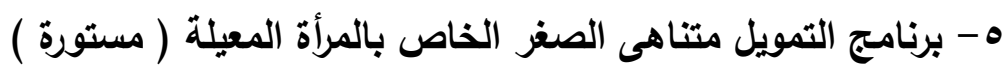

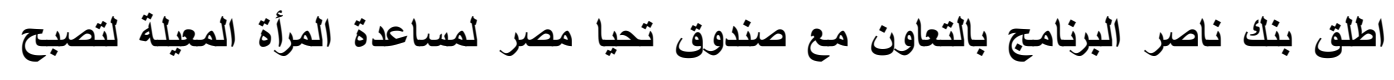

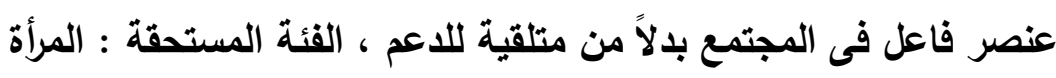


צ- برنامج تمويل لسداد المصروفات المدرسية يقوم بنك ناصر الاجتماعى بمنح التمويل لمساعدة الأسرة المصرية محدودة الاخل على سداد المصروفات المدرسية للأبناء على أقساط شهرية متساوية ، الفئة المستحقة : الأسرة

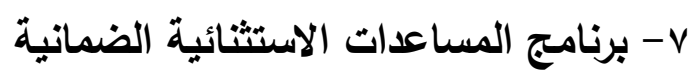
يخضع البرنامج لمظلة الثئئن الإجتماعية يقوم بصرف مساعدة مالية دفعة واحدة للأفراد والأسر

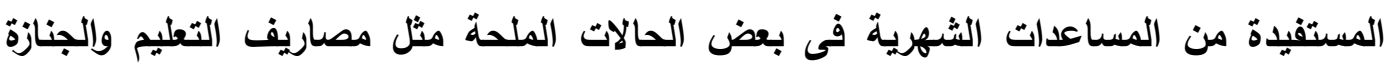

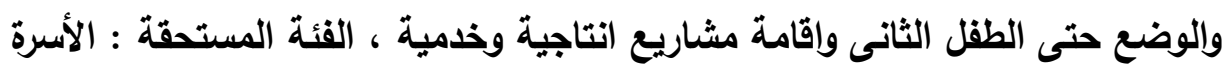

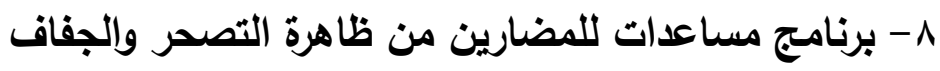

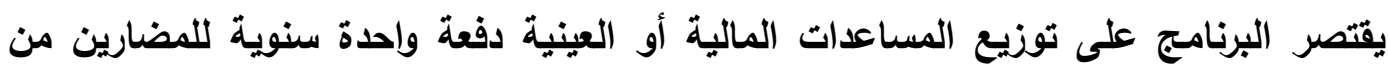

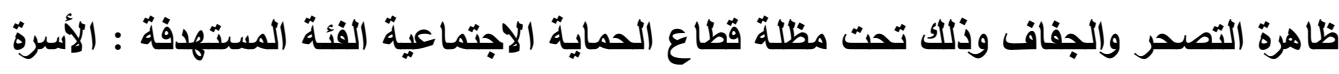

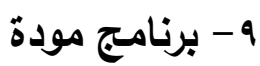

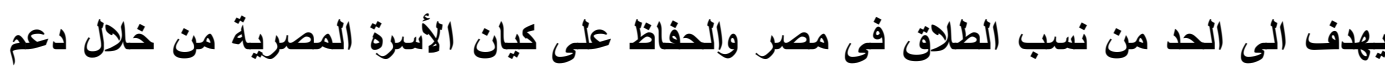

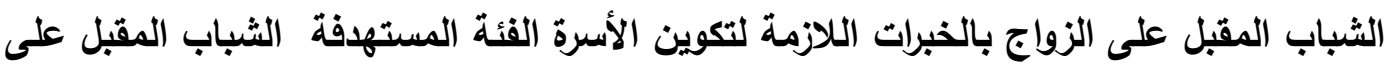

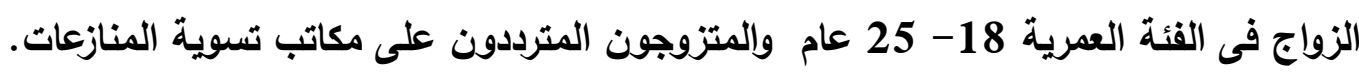
.

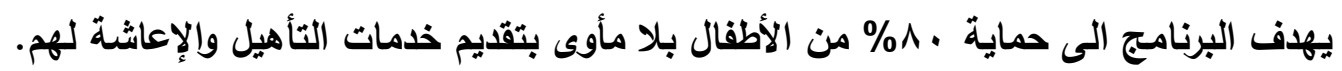

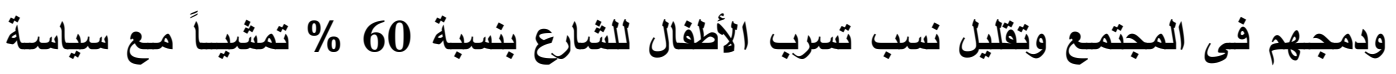

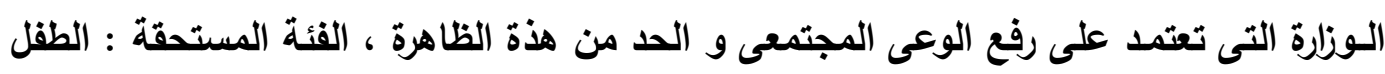

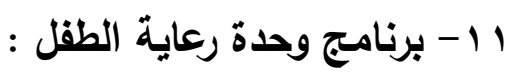

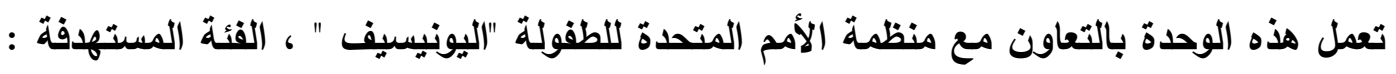

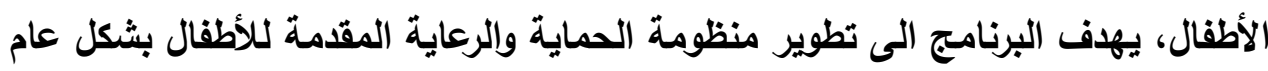

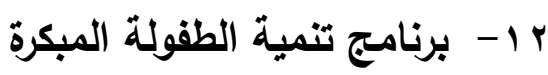

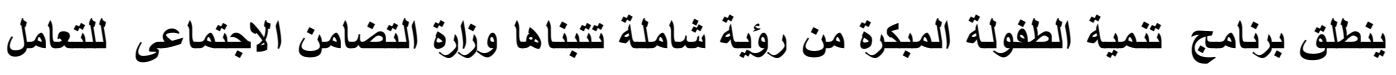

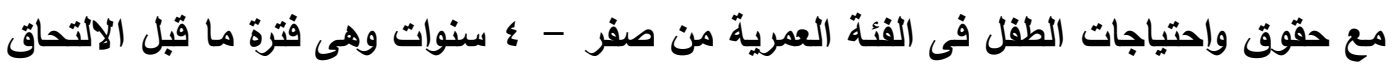

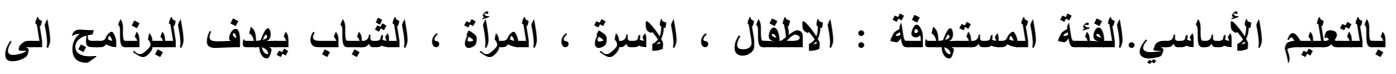

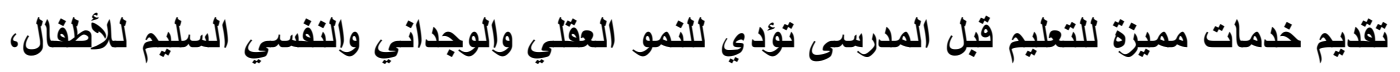

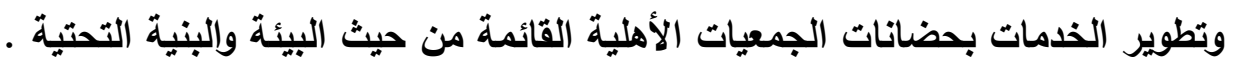

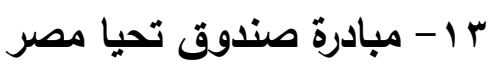

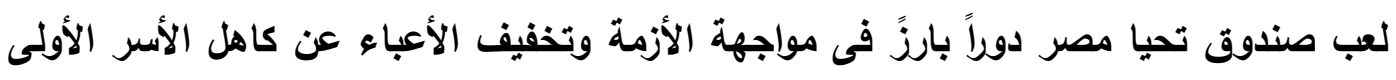

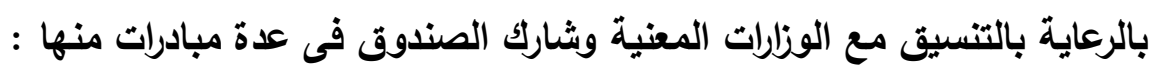

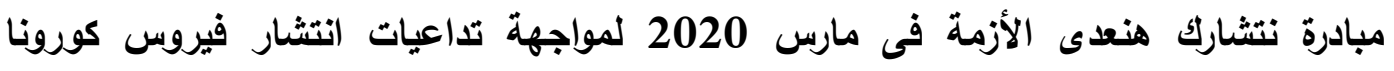
المستجد وخصص الصندوق المساهمات والتبرعات لاعم أنثطة المبادرة من خلال محورى عمل: 
1 - حملة دعم القطاع الطبى فى مواجهة الفيروس لتوفير الاحتياجات والمستلزمات الطبية

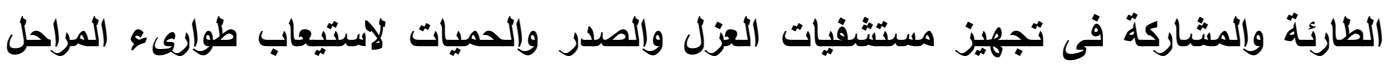
المختلفة لانتثار الفيروس بتوفير اجهزة التنفس الصناعى وغيرة من المستلزمات الطبية.

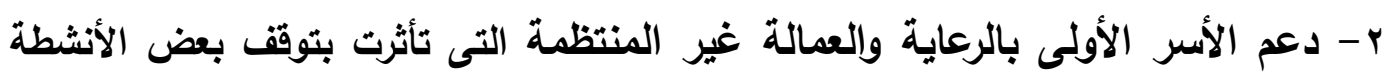

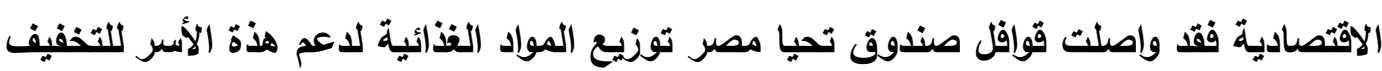

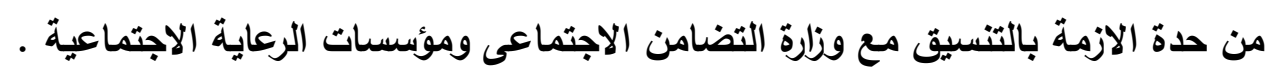

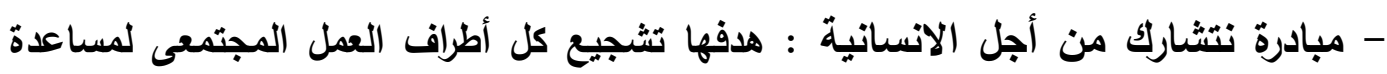

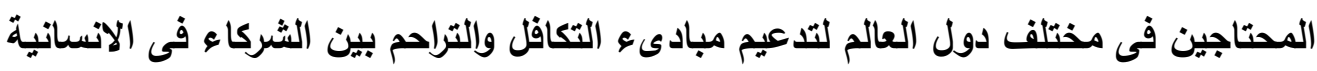

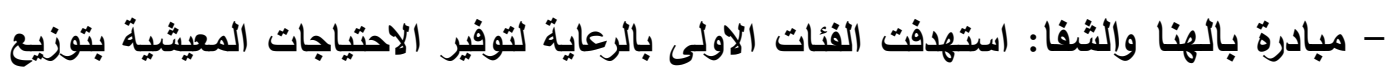

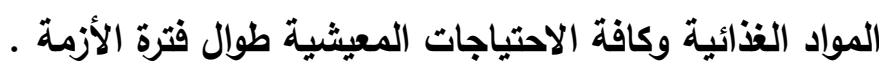

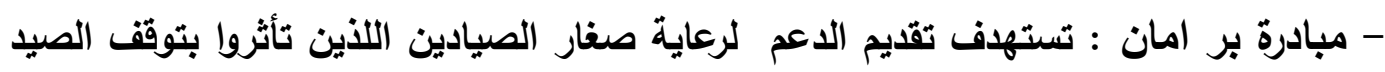

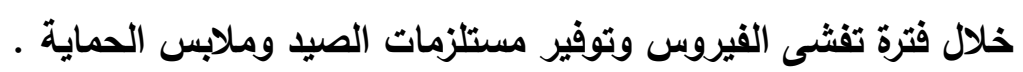

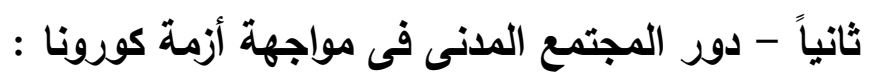

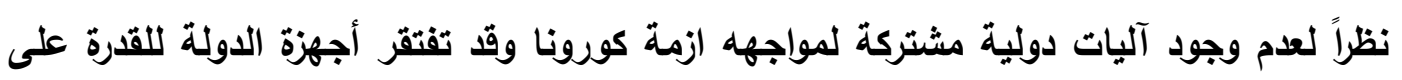

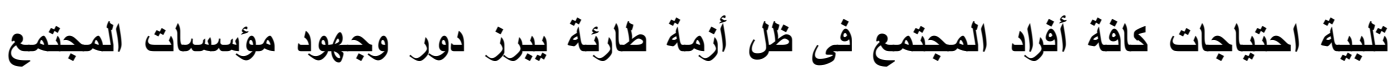

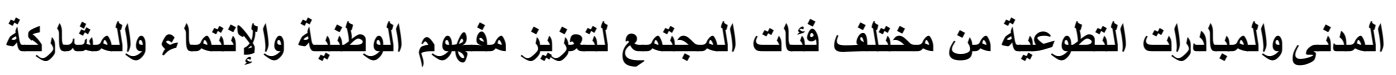

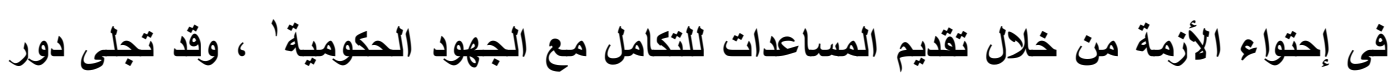

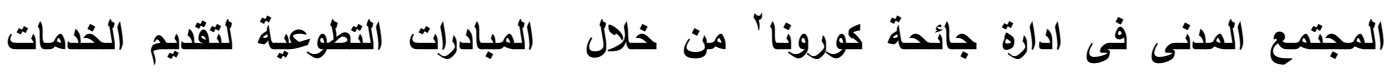

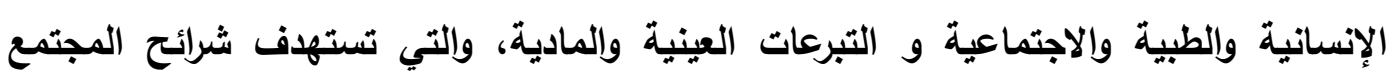

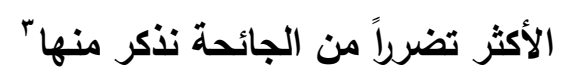

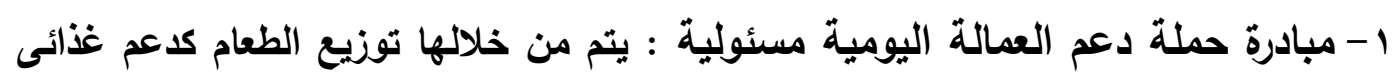

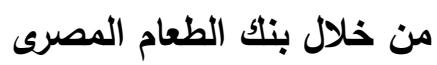

r- مبادرات الدعم الوقائي: من خلالها يتم توفير المستلزمات الطبية التي تحتاجها المستثفيات، ومن بين النماذج دور مؤسسة "مصر الخير"، واسهاماتها في تقايم المستلزمات

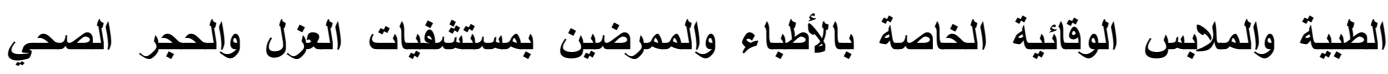
والحميات، على مستوى الجمهورية.

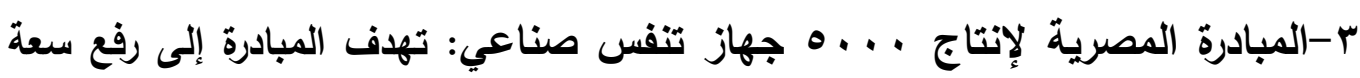

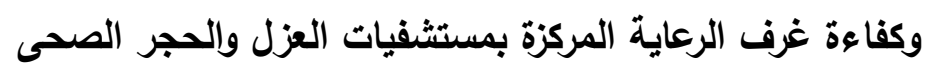

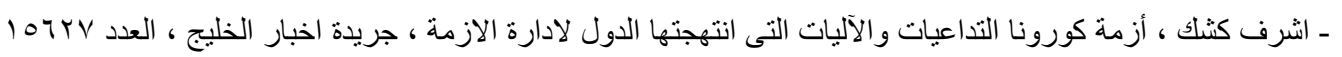

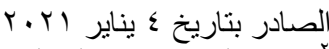

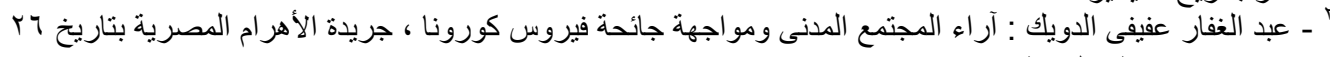

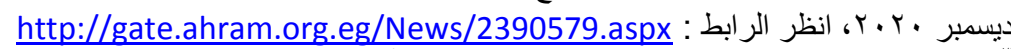
_.Edwards,Michael,Civil Society, $2^{\text {nd }}$ edition,Cambridge,Polity Press.2009,p50 - ${ }^{r}$

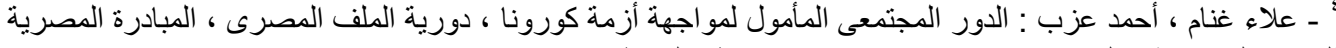

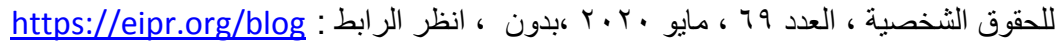


צ - مبادرات تحفيز العمل التطوعي

واجه القطاع الصحي وقت الأزمة عجزاً كبيراً في عدد الأطباء والتمريض قامت وزارة الصحة بفتح باب التطوع للتخصصات العلمية القريبة من مجال الطب للمساهمة في التخفيف من العبء على المنظومة الصحية للقيام بأدوار تكميلية بمستشفيات العزل وإلتقصى والمتابعة الميدانية. ه-تطوع الشباب للعمل المجتمعى فى المحافظات بتعقيم القرى والشوارع وتوزيع الاقتعة الواقية

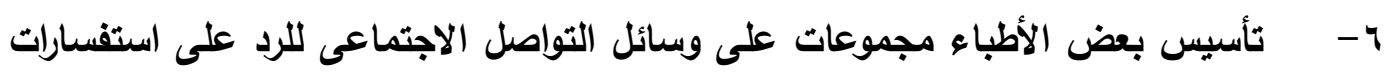
المرضى مجاناً وتوصيل العلاج والغذاء للمرضى المعزولين فى منازلهم والمشاركة في جمع التبرعات المادية والعينية، وتوعية المواطنين بطرق الوقاية وحملات التبرع بالدام

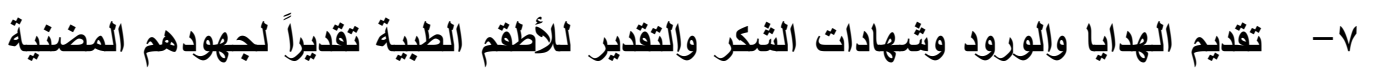
فى ظل الظروف الصعبة لحثهم على بذل المزيد من الجهد للحد من انتشار الفيروس

ثنالثاً - دور القطاع الخاص فى ظل أزمة كورونا التى يمر بها العالم تأتى أهمية القطاع الخاص لمشاركة الحكومة فى احتواء أزمة كورونا باعتباره جزء من المنظومة المجتمعية الأمر الذى يحتم علية تحمل مسئولية المساعدة فى حل فئل

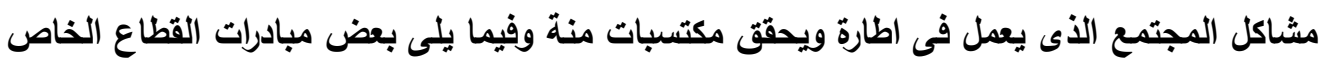

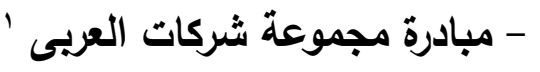
قامت مؤسسة العربى لتنمية المجتمع بامداد مستثفيات الحميات والحجر الصحى بأجهزة لتنقية الهواء كما قامت بتوزيع المساعدات الغذائية فى معظم المحافظات كما وفرت أدوات الوقاية الطبية - مبادرة شركة أورنج للاتصالات تبرعت الشركة بمبلغ 5 ملايين جنية لاعم الأسر التى تضررت من الإجراءات الاحترازية وقامت بتوفير خدمات أورنج كاش لتحويل الأموال التى يستطيع من خلالها العميل دفع فواتير الكهرباء والغاز والمياة كما رفعت سعة التحميل بنسبة 20\% على جميع باقات الإنترنت المنزلى

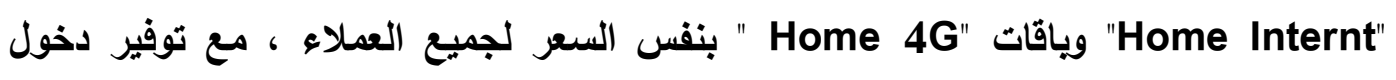
مجانى لطلاب المدارس والجامعات على المواقع التعليمية التابعة لوزارة التربية والتعليم ، - مجموعة طلعت مصطقى تبرعت المجموعة بمبلغ 63 مليون جنية للمساهمة فى احتواء فيروس كورونا ، تم تخصيص التبرعات لشراء أجهزة تنفس صناعى والمستلزمات الطبية لتفطية احتياجات المستثفيات كما ثقدم العديد من رجال الأعمال والثخصيات العامة بالتبرع لدعم صندوق تحيا مصر في

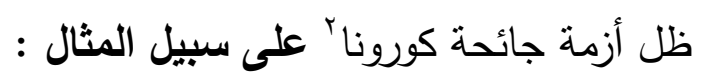
- تبرع رجل الأعمال رامي لكح، لصالح صندوق تحيا مصر، لدعم شراء لقاح كورونا لغير القادرين والفئات المستحقة بمبلغ 30 مليون جنية رلاعية 
- تبرع رجل الأعمال نصيف قزمان بمبلغ 10ملايين جنيه، لدعم صندوق تحيا مصر لتوفير لقاح كورونا لغير القادرين. - تبرع الدكتور أحمد هيكل، رئيس مجلس إدارة شركة القلعة للاستشارات المالية بمبلغ 30 مليون جنية من أجل توفير لقاح فيروس كورونا للفئات المستحقة. - تبرع الدكتور هاني مروان، رئيس شركة الاتحاد للتجارة والصناعة، بمبلغ 5 ملايين جنيه لصندوق تحيا مصر من أجل توفير اللقاح. - تبرع السيد/هشام الخولي، رئيس شركة تطوير عقاري بمبلغ مليوني جنيه، لصندوق تحيا مصر لاعم توفير لقاح كورونا لغير القادرين - تبرع دكتور هاني الناظر رئيس المركز القومى للبحوث الأسبق بمبلغ 50 ألف جنيه لصالح الصندوق للمساهمة في تمويل شراء لقاح كورونا لغير القادرين. - تبرع السيد/ محمد لطفى منصور رئيس مجلس ادارة شرة منصور للسيارات بمبلغ 50 مليون جنية مصرى تخصص لتوفير أدوات الوقاية للأطقم الطبية ، بالإضافة الى أجهزة التنفس

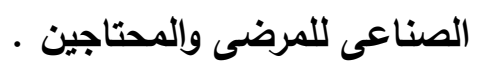
- تبرع السيد/عمر عبد الجواد العضو المنتدب لشركة ابن سيناء فارما بمبلغ 8 مليون جنية

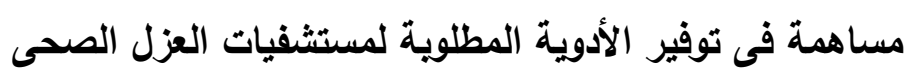
- ساهمت الجمعية المصرية لرجال الأعمال بمبلغ 5 مليون جنية لمتضرية الادوية أزمة فيروس كورونا

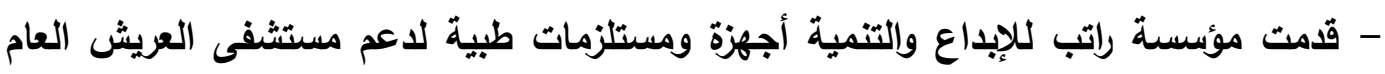

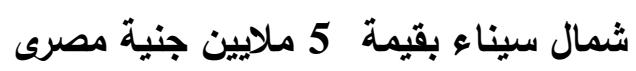
- تبرع العاملين بليوان عام وزارة الخارجية فى القاهرة ، وكذلك بعثات مصر فى الخارج من الابلوماسيين والاداربين بجزء من رواتبهم لصندوق تحيا مصر بقيمة اجمالية 6 مليون وريعمائة ألف جنية مصرى انطلاقاً من المسئولية المجتمعية والتخفيف من حدة التاعيات الاقتصادية

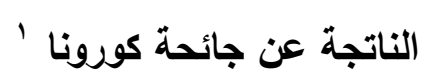

$$
\text { رابعاً- دور المنظمات الدولية في احتواء أزمة كورونَا كونا }
$$

تعاظم دور المنظمات ومؤسسات التمويل الدولية والمؤسسات التابعة لمنظومة الأمم المتحدة فى لتى تقديم التسهيلات الائتمانية والإششادات لمساعدة الدول على احتواء فيروس كورونا المستجد وكان من أهم تلك المنظمات: - منظمة الصحة العالمية : كان لها دور محورى وفعال فى التوجية والإرشاد والمتابعة لكافة دول العالم من أجل احتواء أزمة فيروس كورونا ، والتى تسعى الدول الى معرفة توصياتها 
وتحذيراتها' حيث تتصدر المنظمة التغطيات الإعلامية فى جميع دول العالم محلياً وعالمياً حول

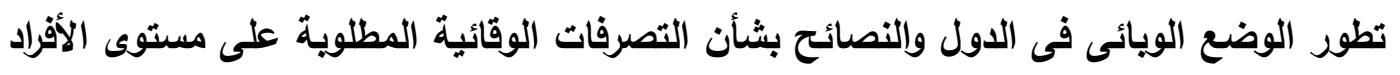

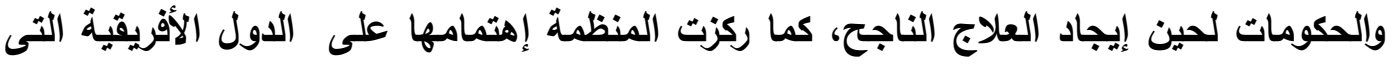

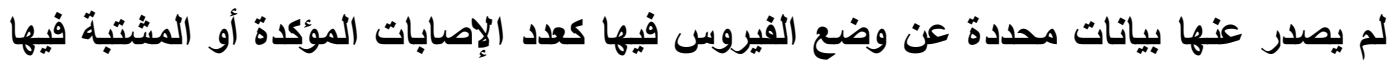

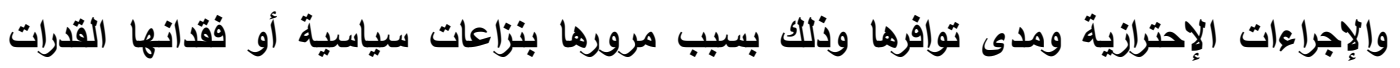

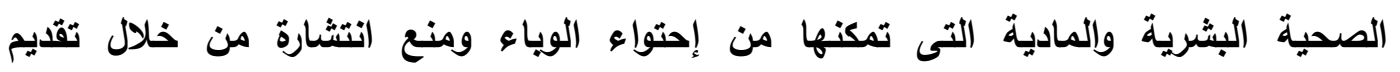

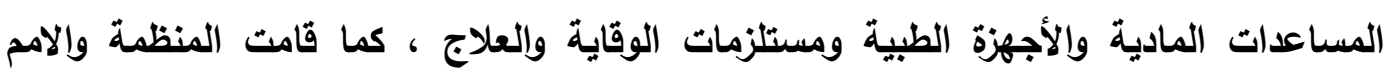

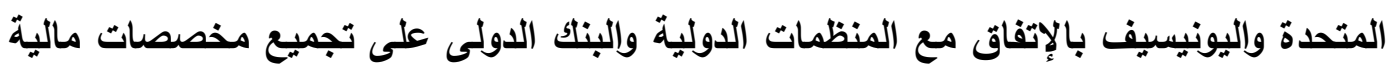
حوالى مليارى دولار لمكافحة وياء كورونا المستجد

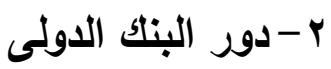

في الوقت الذي تعمل فيه البلان في مختلف أنحاء العالم على احتواء تفشي فيروس كورونا فقد

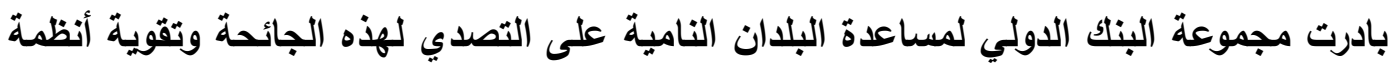

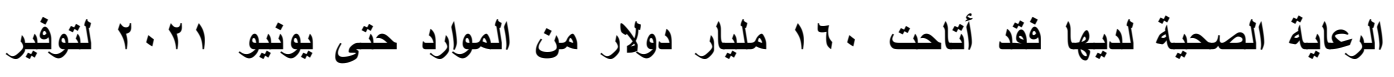

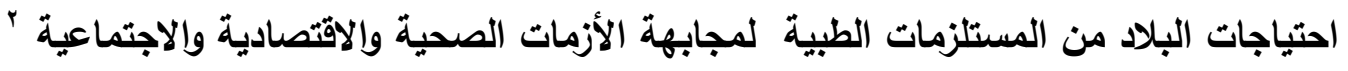

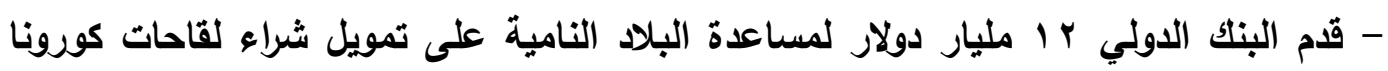

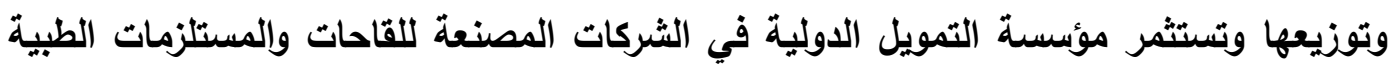

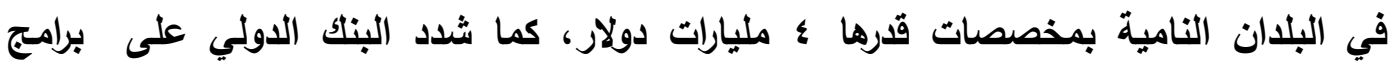

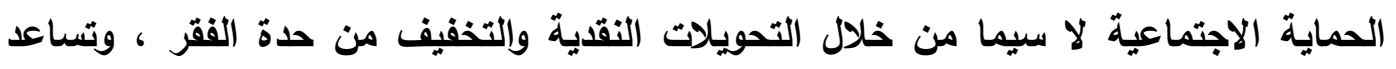

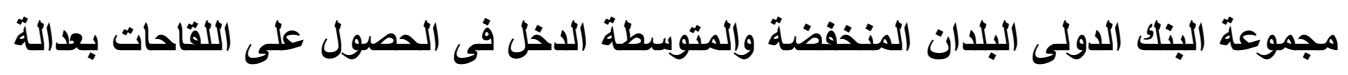

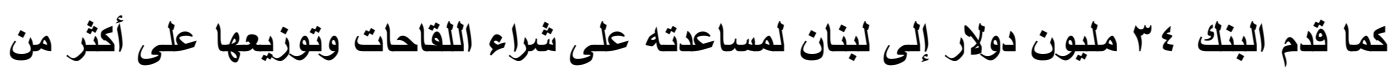

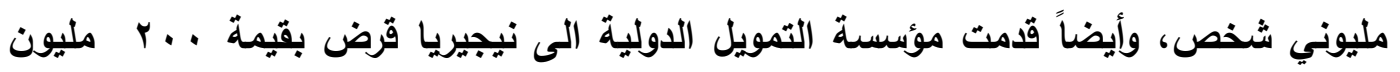

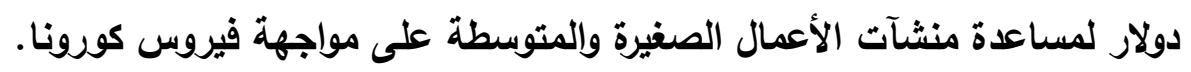

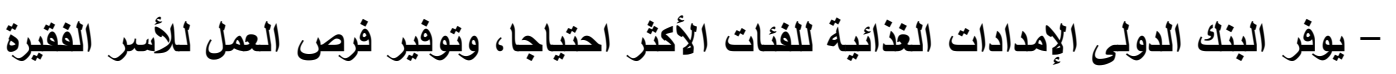

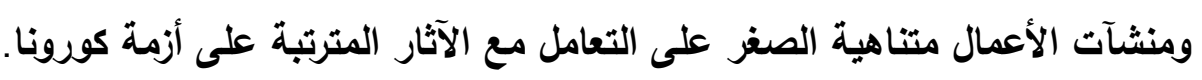

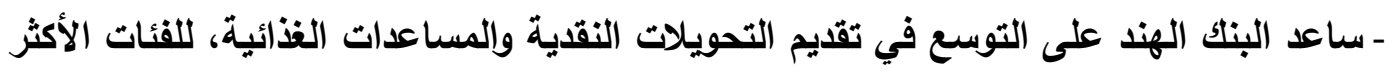

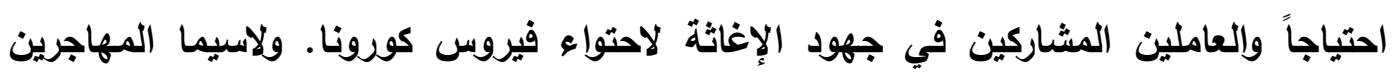
والعاملين غير النظاميين

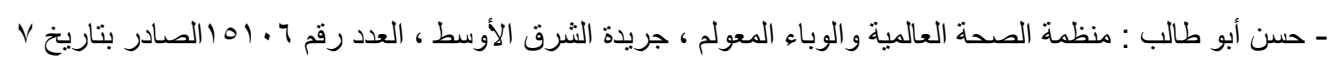

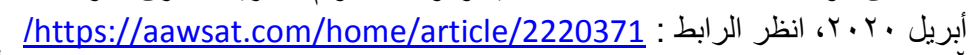

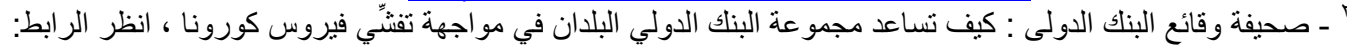
https://www.albankaldawli.org/ar/news/factsheet/2020/02/11/how-the-world-bank-group-is- 
- يساعد البنك البلاد على الاستعداد لتحقيق تعاف قادر على الصمود، من خلال التعاون مع صندوق النقد الدولي فى إدارة الدين العام وتحديد فرص النمو الأخضر والتنمية المستدامة

منخفضة الكريون وذلك أثناء مرحلة إعادة البناء بعد انحسار جائحة كورونا' التهائ r- دور صندوق النقد الدولى فى مساعدة دول العالم لمواجهة جائحة كورونا وافق صندوق النقد الدولى على توفير المساعدات المالية إلي العديد من دول العالم في إطار مختلف تسهيلات الإقراض وتخفيف خدمة الديون لمواجهة الأثر الإتصادي لوياء كورونا فقا بلغ إجمالي المساعدات المالية نحو 87.841 مليار دولار لصالح 80 دولة حتي

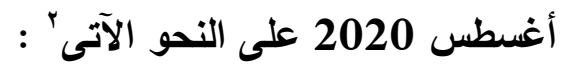
- منطقة آسيا والمحيط الهادي: حصلت علي تمويل قره 1.844 مليار دولار - القارة الأورويية :حصلت على نحو 6.118 مليار دولار - منطقة الثرق الأوسط وآسيا الوسطي : حصلت على تمويل بقيمة 13.548 مليار دولار - منطقة إفريقيا جنوب الصحراء: حصلت علي نحو 15.422 مليار دولار - دول بنصف الكرة الأرضية الغربي : حصلت على نحو 50.907 مليار دولار - رصد صندوق النقد الدولي مساعدات بقيمة . ـ مليار دولار لمكافحة فيروس كورونا بمن خلال تسهيلاته التمويلية في حالات الطوارئ للبلدان منخفضة الاخل ويلدان الأسواق الصاعدة ويتيح الصندوق لأفقر البلان الأعضاء ، 1 مليارات دولار من هذا المبلغ بسعر فائدة صفري

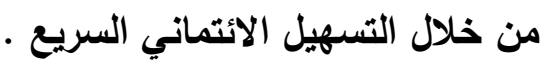

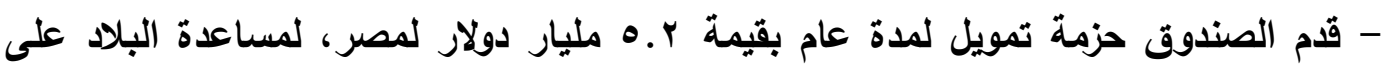
تخفيف الأثر الاقتصادي لوياء فيروس كوروناء جمونه - وافق الصندوق على منح السنغال مساعدة بقيمة 442 مليون دولار بهدف مساعدتها على لئى مواجهة آثار فيروس كوروناء.

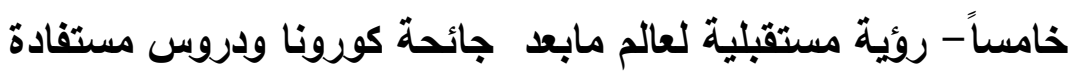
أحثث جائحة كورونا منعطفاً هاماً وفاصلاً فى تاريخ البشرية، وشكلت تحديات صعبة لم تكن حكومات دول العالم على استعداد لمواجهتها ومن ثم يجب على حكومات الدول الاستفادة من دروس الأزمة والعمل على خلق استراتيجية وروئية جديدة للمستقبل قادرة على توجية الجهود ـ البنك الدولى : مجموعة البنك الدولي تزيد استجابتها في مو اجهة فيروس كورونا إلى ـ ا مليار دو لار للمساعدة على دعم

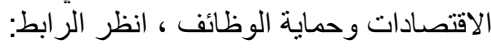
https://www.albankaldawli.org/ar/news/press-release/2020/03/17/world-bank-group-increasescovid-19-response-to-14-billion-to-help-sustain-economies-protect-jobs

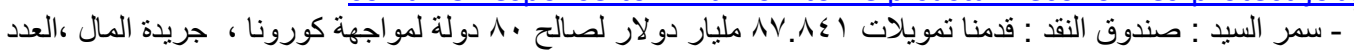

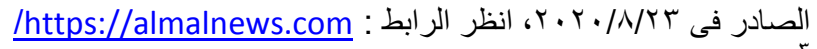
https://www.imf.org/ar/News/Articles/2020/03/04/sp030420-imf-makes-available- : 50-billionh-to-help-address-coronavirus

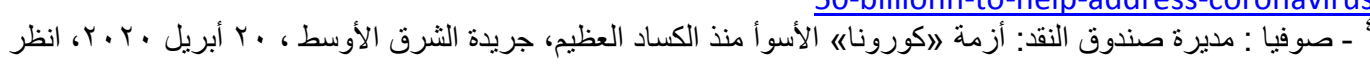

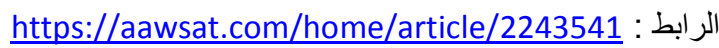

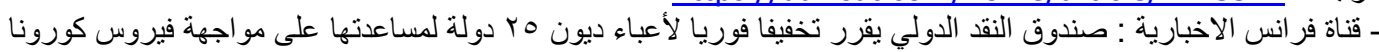

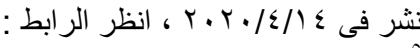
https://www.france24.com/ar/20200414 - 
والمؤسسات نحو التفكير فيما بعد أزمة كورونا باعادة ترتيب أولوياتها برسم السياسات التى تتكيف وتتوائم والواقع والحرص على استكمال مسار التنمية المستدامة' 2030.

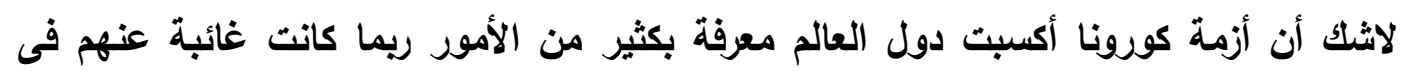

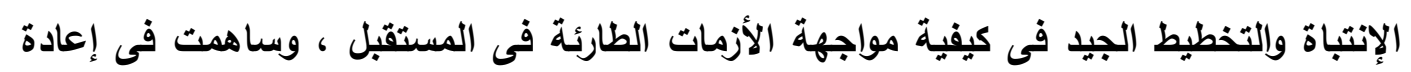

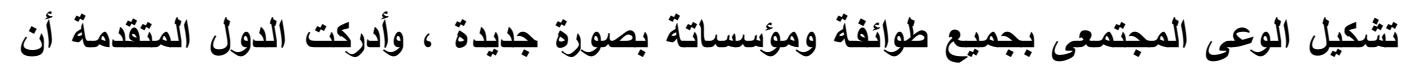
المال والسلطة والقوة ليست ضمانة لحماية الانسان فتلاشت الفوارق بين الدول الفقيرة والغتية، كشفت أزمة كورونا لدول وحكومات العالم عن العديد من الظواهر التى تبعث عن ضرورة اهتمام

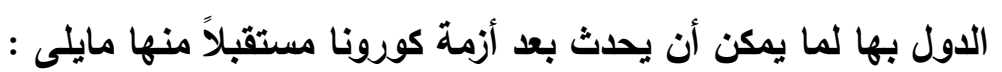

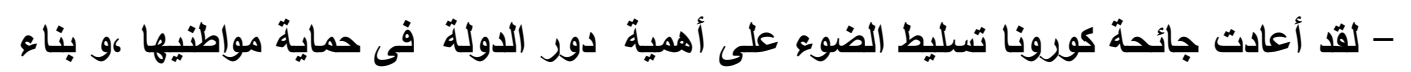
الثقة بين المواطن والحكومة فى ظل عدم قيام المنظمات الدولية والتكتلات الإقليمية بدور فعال أثناء الأزمة ، يقول Stephen Walt " ان أزمة كورونا ستعمل على تقوية دور الدولة وتعزيز

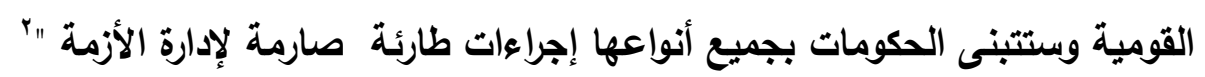

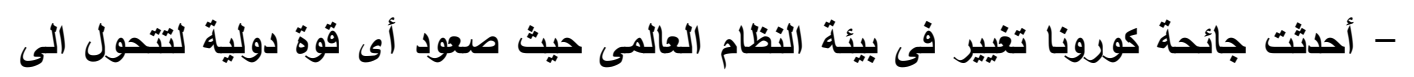
قطب من أقطاب النظام الدولى يتطلب توافر مقومات كان أهمها القوة العسكرية والاقتصادية والتكنولوجية ولكن أزمة كورونا غيرت من شكل تلك المقومات وطرحت مقدرات جديدة للنفوذ مثل ملثمات الرعاية الصحية ، والقدرة على إدارة الأزمات ، وقدرة الاقتصاد على الصمود أمام التحديات

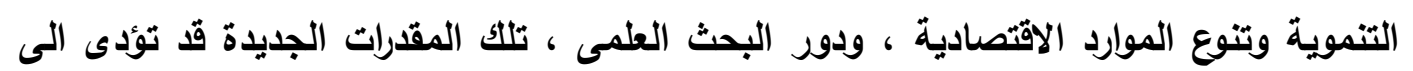

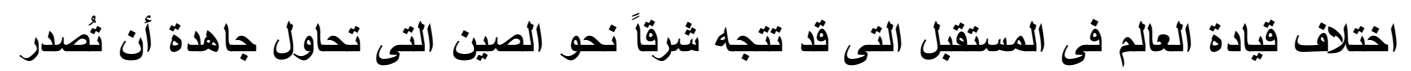

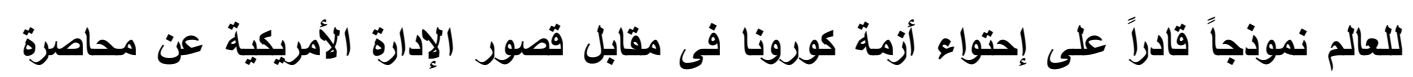
الوياء بسبب عدم التعامل الجاد مع الأزمة - أظهرت جائحة كورونا قدرة بعض المناطق على مواجهة انتشار الفيروس و هشاشة مناطق اخرى فى بعض المجتمعات كانت عرضة للاصابه بالفيروس مثل المحتجزين فى السجون وقاطنى المناطق العشوائية هؤلاء ليس لايهم القدرة على تطبيق إجراعات العزل والتباعد

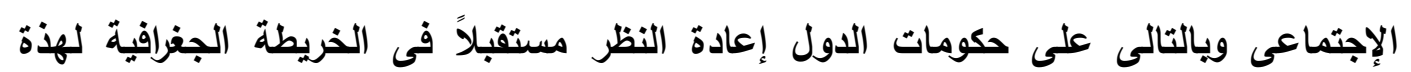

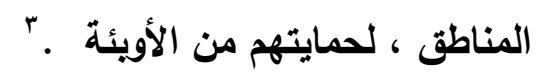
- فى ظل وياء كورونا الذى سيطر على اهتمامات دول العالم تجاهلت وتوققت عن استكمال

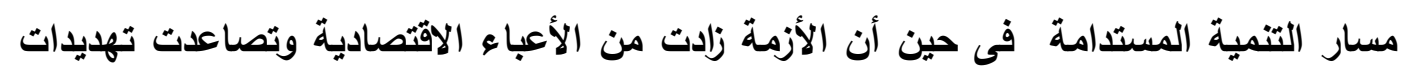

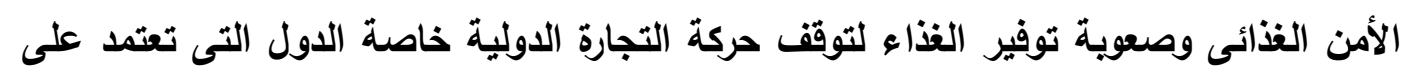
استيراد الأغذية فضلاً عن ازدياد معدلات الفقر والبطالة لفقان العاملين لوظائفهم تلك أهداف نوفي رئيسية فى خطة التنمية المستدامة 2030 نبهت الدول الى مزيد من الاهتمام بها حتى فى ظل الاعلى

-Paulson jr M.Henry:7 Principles for a Post- Corona Virus economy, April 10 ,2020,p.10 -

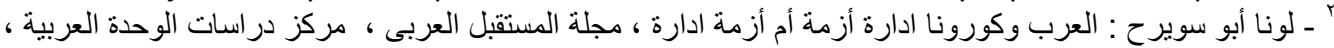

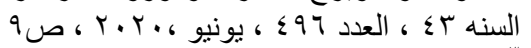

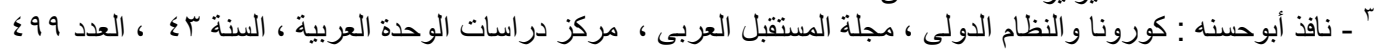


تصاعد الأزمة باعادة ترتيب أولوياتها ورسم سياساتها التى تتواءم والواقع الاقتصادى والأزمات

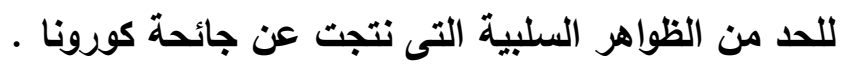
- اظهرت أزمة جائحة كورونا التأثير الكبير فى مصادر النقد الأجنبى الرئيسية مثل السياحة وقناة السويس وتحويلات العاملين بالخارج الأمر الذى يتطلب تغيير مصادر الاخل من النقد الاجنبى بالاعتماد على الصادرات الانتاجية وغير النفية وتطوير صناعات التغذية للحد من استيراد الغذاء وتحقيق الاكتفاء الذاتى • - أحدثت جائحة كورونا صدمة نفسية للمواطنين بسبب الخوف والقلق من الاصابة بالمرض أدت الى البعض بالإنتحار ، ويالتالى يجب على حكومات الدول بتعزيز مستوى الصحة النفسية لاى لون المواطنين وتكريس مجهودات أقسام الصحة النفسية بالجامعات والمستثفيات مستقبلاً'. ممالاثك فية أن التبؤ الدقيق بالمستقبل قضية قـ تكون من الصعوية فى ظل معطيات جائحة كورونا ، وحتى السيناريوهات المستقبلية والتوقعات بمستقبل النظام العالمى لاتستند على معايير

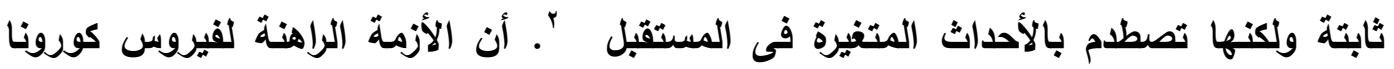
وضعت النظام الاقتصادى العالمى على مشارف مرحلة جديدة تدفع به نحو تغيير الكثير من ثوابت العصر الحديث ويتجة نحو تغيير النظريات الاقتصادية المتعلقة بثروة الأمم وقوتها ، وتجبر الدول على تغيير القواعد التى حكمت منظومة العلاقات الاقتصادية التى تقوم على تحرير التجارة السلعية والخدمية وتحرير حركة البشر و رؤوس الأموال بين الدول . ان مجمل التغيرات التى حدثت والتى سوف تحدث فى المستقبل سوف تعيد صياغة مفهوم العلاقات الاقتصادية بين الدول بحيث يتم تقليص التجارة السلعية التى تتطلب انتقال البشر (التى كانت سبياً فى تفشى الوياء) والتوسع فى تجارة الخدمات ( التجارة الأكترونية ) والاستراع بالتحول الرقمى ونقل التكنولوجيا حيث فرضت ظروف تفشى الوياء نموذجاً جديداً للعولمة يحافظ على قدر من الترابط مع العالم لكنة يبقى على مسافة فاصلة يبنى رويداً رويداً نموذجاً جديداً

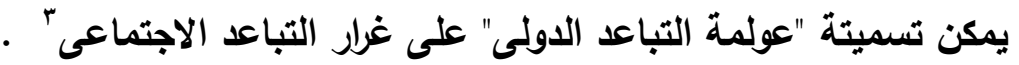
فى ظل هذة التغيرات يجب على الاول استحداث مقدرات جديدة تلائم الواقع وتجعلها قادرة على الصمود لمواجهة الأزمات وتداعياتها فى المستقبل وهذا يتطلب تعزيز الحوكمة الرشيدة والتعامل مع المخاطر على نحو شامل ومتكامل والاستثمار الفعال فى القطاعات الخدمية والعنصر البشرى وتوسيع قاعدة الحماية الاجتماعية لتقليص الفقر من المجتمع وتوظيف البحوث العلمية لتحقيق التنمية المستدامة و إعادة تثكيل الوعى المجتمعى القائم على الإحساس بالمسئولية المشتركة .

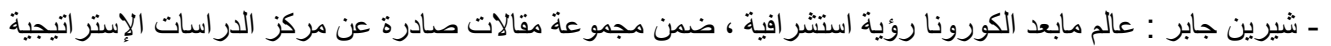

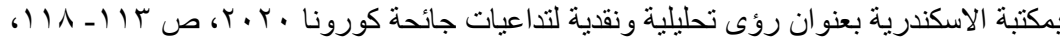

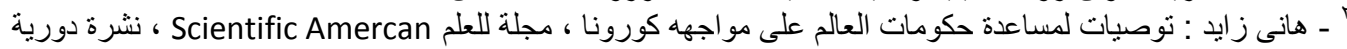

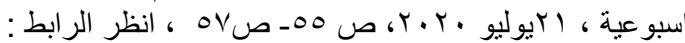
https://www.scientificamerican.com/arabic/articles/news/recommendations-help-governments/to-deal-with-future-pandemics

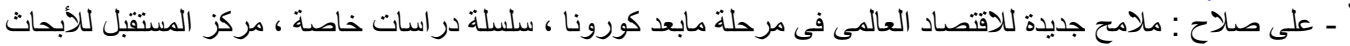

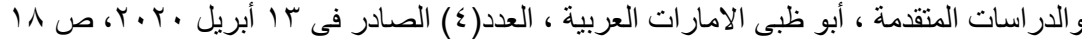


توصلت الاراسة بعد مناقشة وتحليل أهم المحاور والفروض التى تضمنتها الى النتائج الآتية : * أثثتت الاراسة صحة الفرض الأول : أن أزمة كورونا كان لها آثار سلبية على الوضع الاقتصادى والاجتماعى ليس فى مصر وحدها بل أصابت الأزمة جميع دول العالم والاقتصاد العالمى بالركود فقد تسبيث الأزمة فى خسائر قدرث 2.7 ترليون دولار وإنخفض الانتاج العالمى وقدرت منظمة السياحة العالمية حجم الخسائر بنحو 62 مليار دولار لتوقف حركة الطيران بين الدول ، كما قدرت منظمة العمل الدولية زيادة نسبة المتعطلين 25 مليون على مستوى العالم وذلك بفعل الإجراعات الإحترازية ، وانعكست هذة الآثار السلبية على النتائج الإيجابية التى حققها الاقتصاد المصرى بفضل برامج الاصلاح الاقتصادى فتأثز النمو الاقتصادى باعتبارة من أكثر

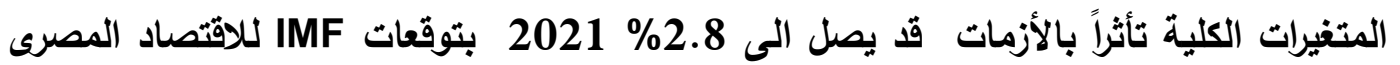
وإنخفت مصادر النقد الاجنبى التى يعتمد عليها الاقتصاد المصرى كمصدر للاخل مثل إيرادات السياحة التى تراجعت فيها الحجوزات بنسبة 80\% وإنخفضت تحويلات العاملين بالخارج بحوالى بهى

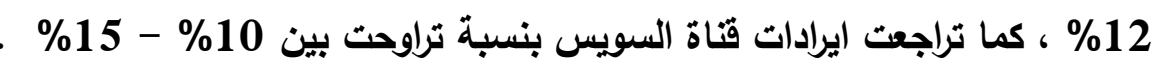
وعلى الجانب الاجتماعى تركت الجائحة أثراً سلبياً على الأسرة المصرية وكان أكثر المتضرين من الأزمة الفئات الفقيرة والمحدودة الاخل والعمالة غير المنتظمة والعاملين بالقطاع السياحى فضلاً عن حظر التجوال والعزل المنزلى الأى الحق الضرر بقطاع كبير من العاملين فى القطاع الخدمى وتوقف مرتباتهم وتسريح البعض لفقدانهم وظائفهم وتزايد معدل البطالة الى 9.6\%. * اثبتت الدراسة صحة الفرض الثانى أن برامج الحماية الاجتماعية والإجراعات التى انتهجتها الحكومة كان لها دور ايجابى الى حد ما فى احتواء آثار أزمة فيروس كورونا فضلاً عن الجهود التى قامت بها وزارة التضامن الاجتماعى بالإشتراك مع الوزارات المعنية فى تفعيل برامج الحماية الاجتماعية وتوسيع قاعدة المستفيدين من برنامج تكافل وكرامة وإتحداث برامج اخرى (برنامج

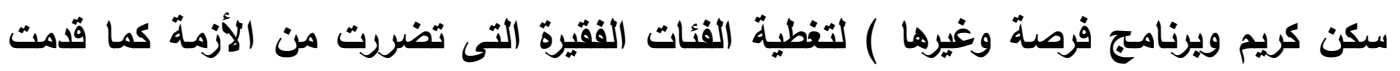
المكومة المساعدات للفئات المتضررة للعمالة غير المنتظمة بمبلغ 500 جنية مع استمرارية صرفة كمعاش دائم الى جانب مبادرات صندوق تحيا مصر بالتعاون مع وزارة التضامن الاجتماعى مثل مبادرة دعم القطاع الطبى لتوفير المستلزمات الطبية ومبادرة دعم الأسر الأولى دأل بالرعاية بالإضافة الى مشاركات المجتمع المدنى والقوات المسلحة فى توزيع الأغذية والسلع الأساسية ومواد التعقيم على الفئات الفقيرة ، وعلى الرغم من كافة الجهود التى بذلت فى هذا لألى الثأن إلا أنه مازال يواجه الحكومة الكثير من التحديات من أجل توسيع قاعدة الحماية

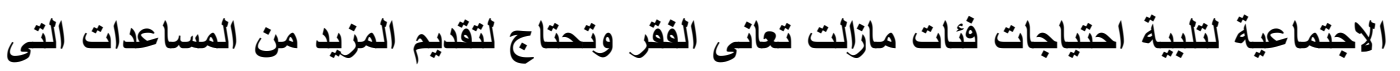
لم تكن كافية لتحقيق حياة معيشية كريمة . * أثبتت الاراسة عدم صحة الفرض الثالث أن برامج الحماية الاجتماعية التى انتهجتها الحكومة خلال أزمة فيروس كورونا لم تساهم فى تحقيق أهداف التنمية المستدامة الـ17 خاصة الأهداف ذات الأولوية فى خطة التنمية المستدامة 2030 على الرغم من تقدم مصر فى بعض 
المؤشرات قبل الجائحة ، وذلك لأن الحكومة وجهت كافة الموارد المالية لإحتواء الفيروس وتوفير

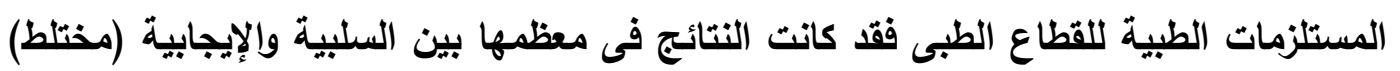

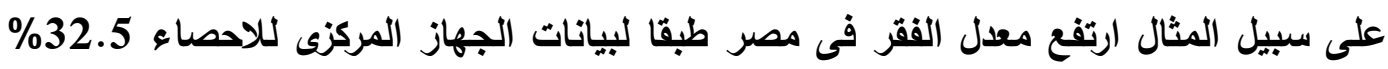

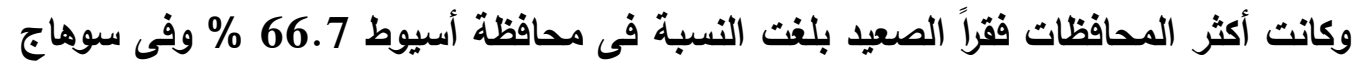

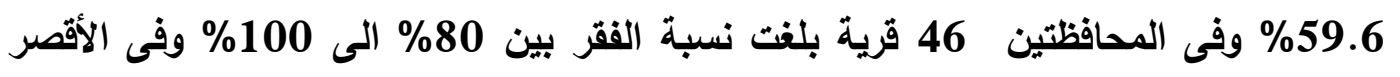
نحو55.3\% فى المنيا 54 \% وقنا 41 \% \% وفى بيان للبنك الدولى صدر فى مايو 2020 و 2020 أن

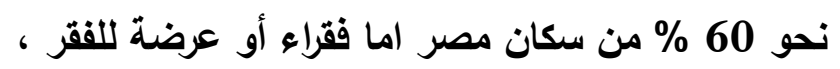

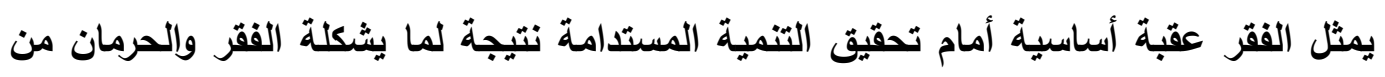

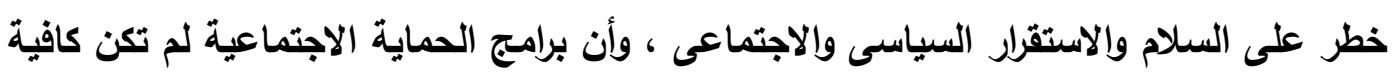

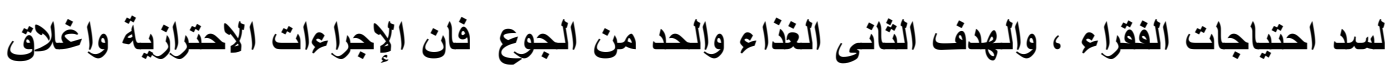

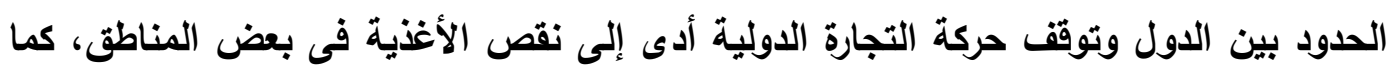

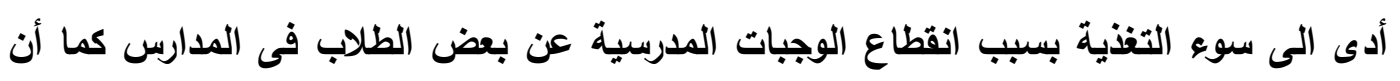

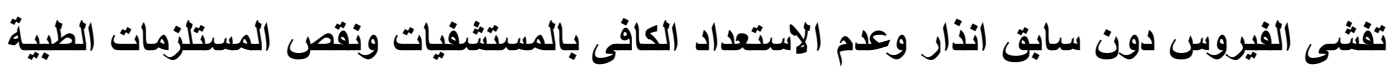

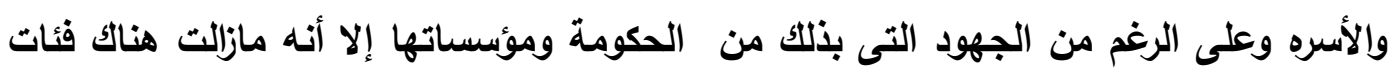

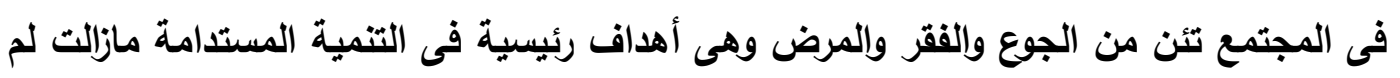

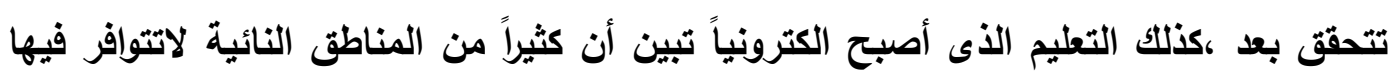

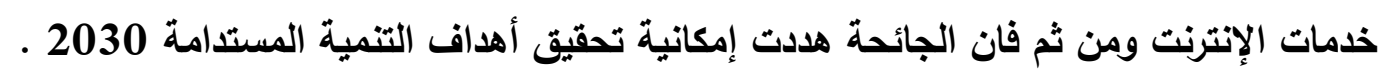

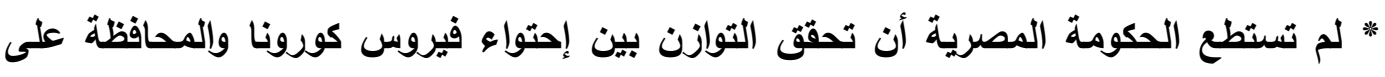

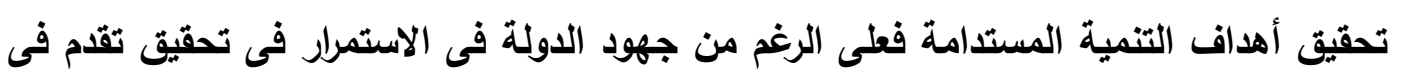

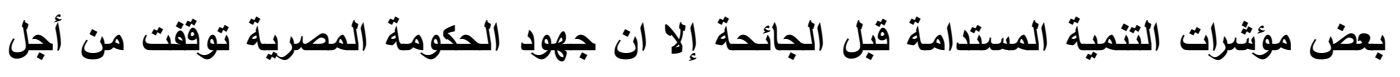

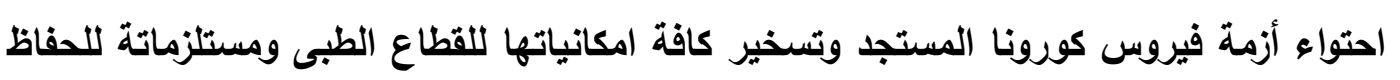
على صحة المواطنين ليس فى مصر وحدها بل في جميع دول العالم.

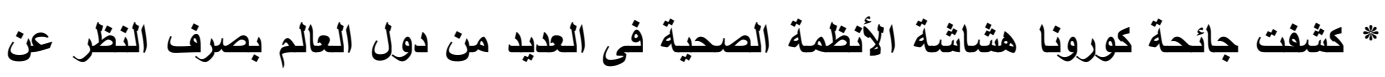

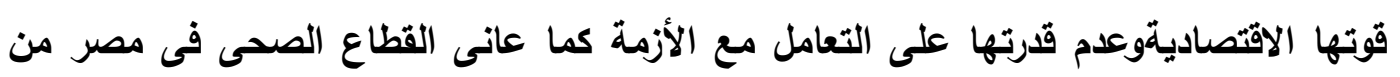

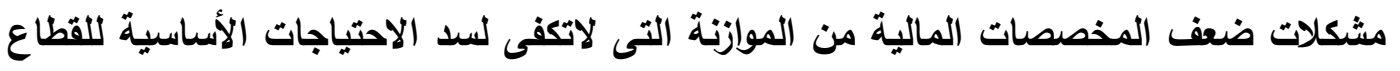

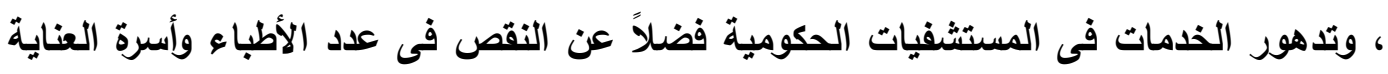

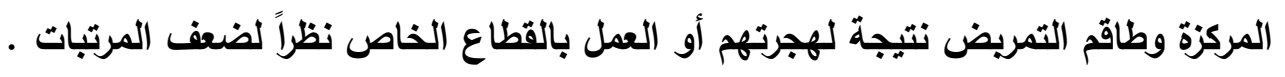

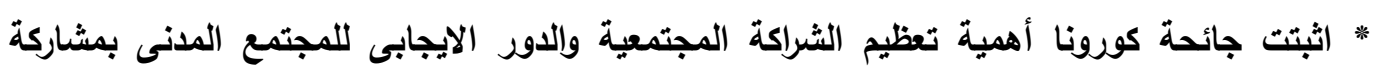

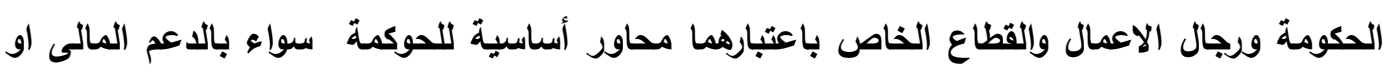

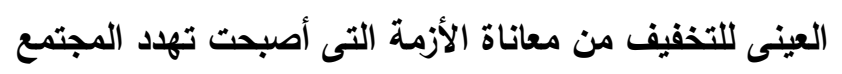

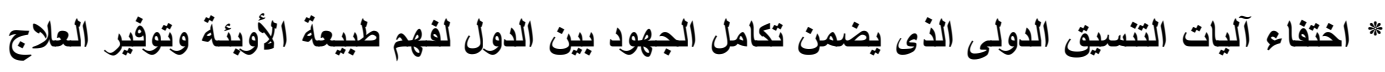

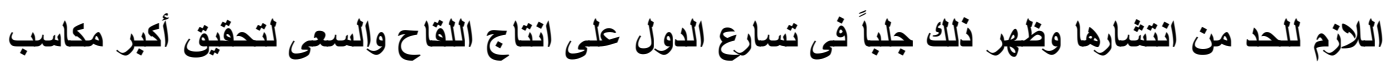


من أجل استكمال مسارات وخطط التتمية الاقتصادية والمستدامة ومواجهة الأزمات فى المستقبل

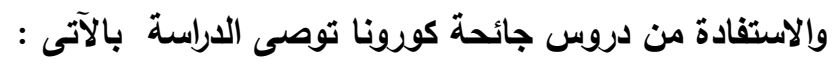

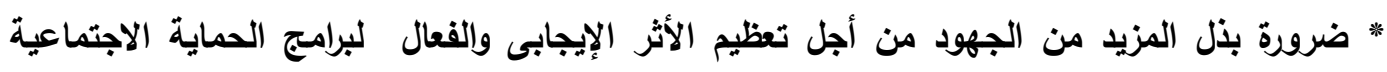

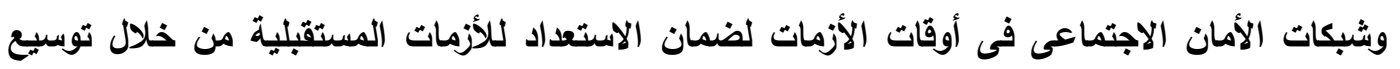

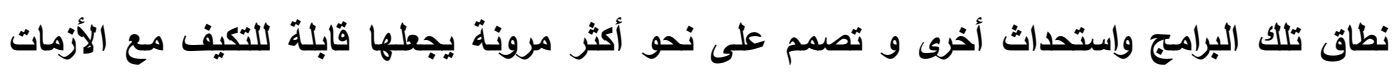

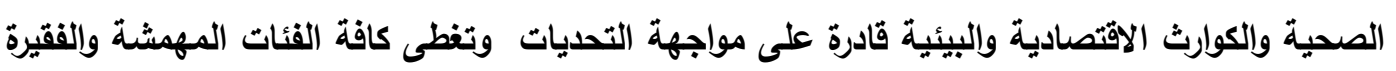

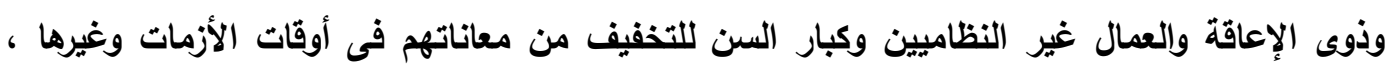

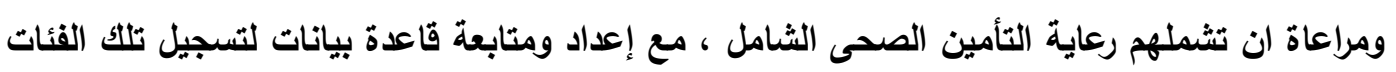

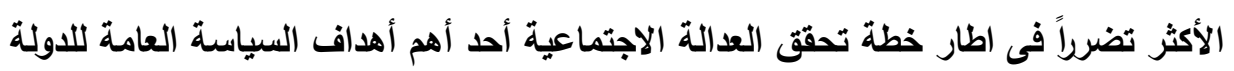

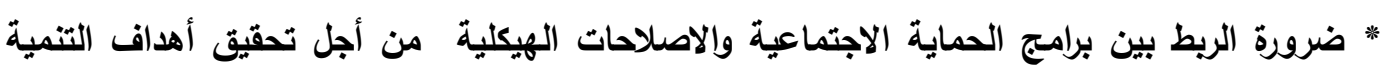

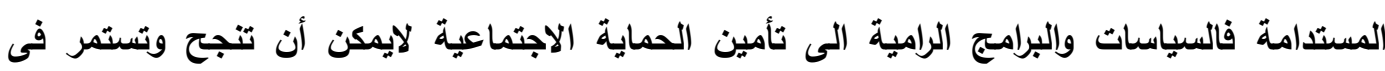

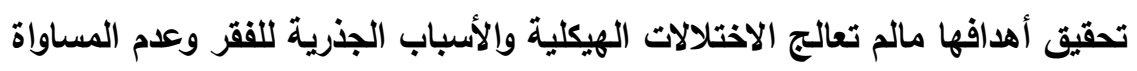

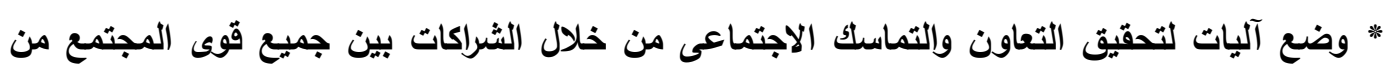

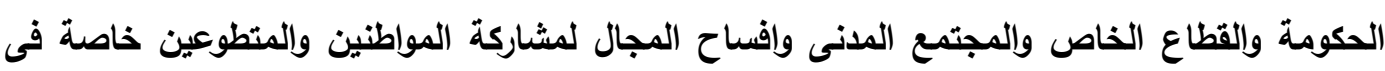

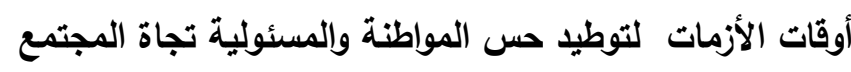

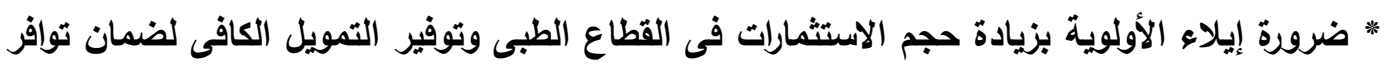

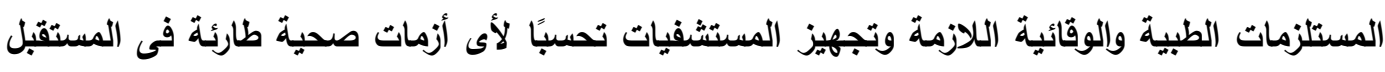

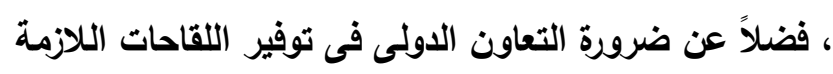
* يجب العمل على زيادة مجالات الاستثمار فى العنصر البثرى واستغلال الطاقات الثبابية المعطلة

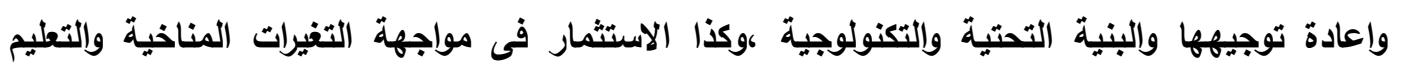

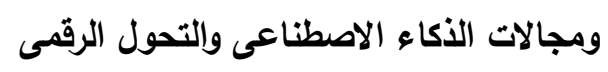
* دعم الثركات والمشروعات الصغيرة والمتوسطة وتقاءيم التسهيلات الإئتمانية بهـف تحفيز الاقتصاد

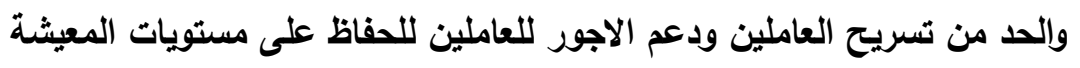

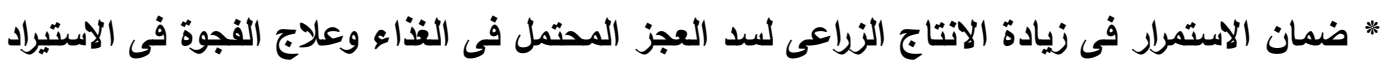

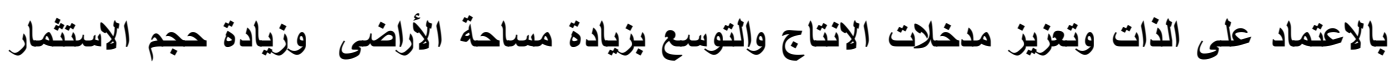

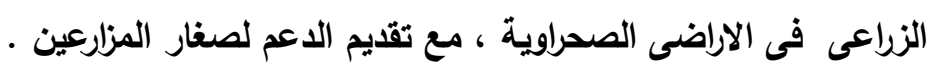

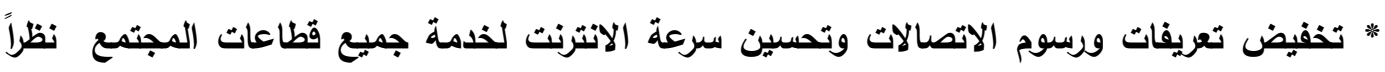

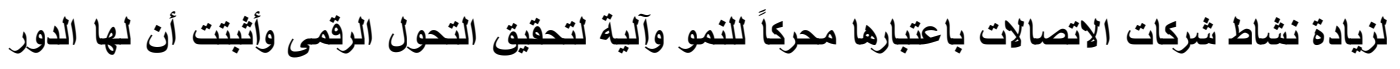
المحورى خلال جائحة كورونا والعزل المنزلى فى الاعتماد الكامل على استخدام تكنولوجيا الاتصالات وازالة العقبات أمام التجارة الإكترونية لتعاظم دورها فى توفير احتياجات المواطنين.

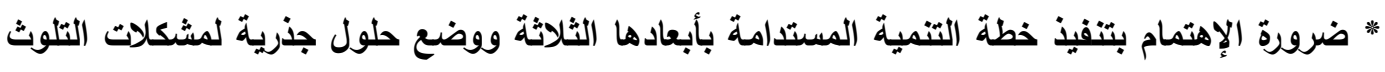

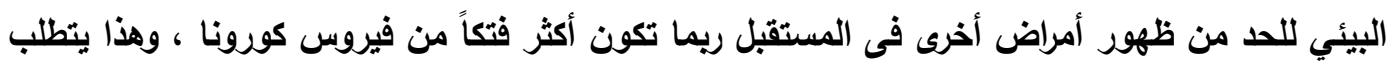

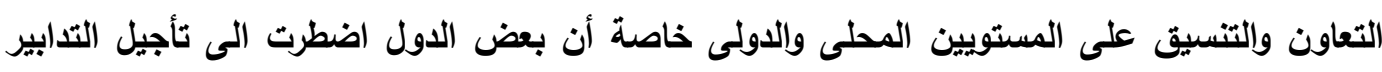

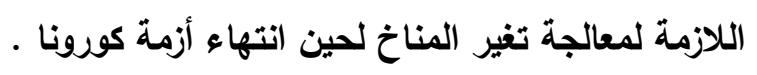




\section{قائمة المراجع :}

$$
\text { المراجع العربية : }
$$

- أثرف محمد كثك : أزمة كورونا : التداعيات والآليات التى انتهجتها الدول لإدارة الأزمة ،جريدة

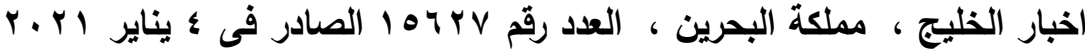
- 1 - لجهاز المركزى للتعبئة العامة والاحصاء ، دراسة بعنوان أثر فئر فيروس كورونا على الاسرة المصرية

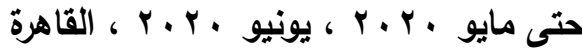
- الجهاز المركزى للتعبئة العامة والاحصاء :التقرير الاحصائى الوطنى لمتابعة مؤشثرات أهداف للتنمية

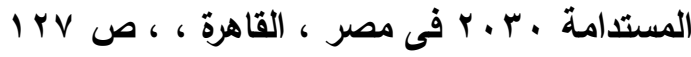
- الجهاز المركزى للتعيئة العامة والاحصاء : التقرير الاحصائى الوطنى لمتابعة أهداف التنمية

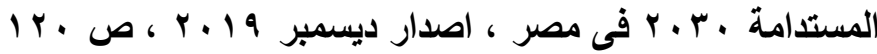

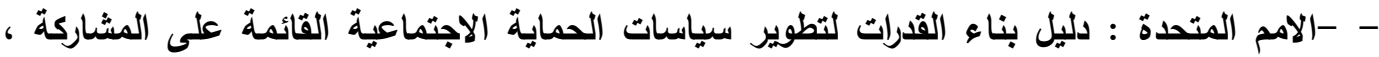

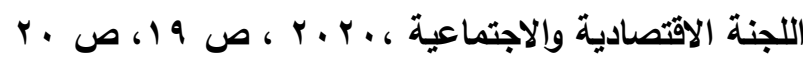

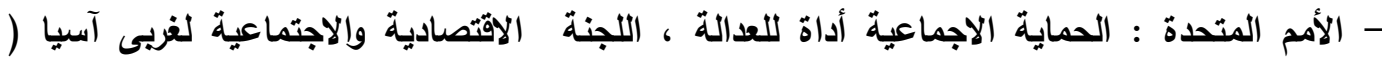

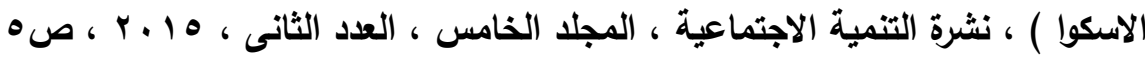
- الأمم المتحدة : ليل إدماج مبادئ العدالة الاجتماعية في السياسات الإنمائية ، اللجنة الإقتصادية

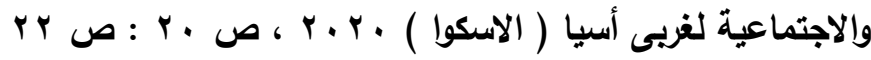

- الأمم المتحدة : اصلاح نظم الحماية الاجتماعية فى البلان العربية العيبة ، اللجنة الاقتصادية والاجتماعية

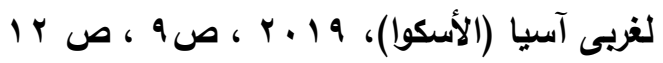
- الأمم المتحدة : التقرير العربى للتنمية المستدامة .r.r.r. ، لجنة الأمم المتحدة الاقتصادية

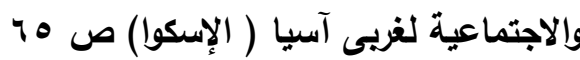

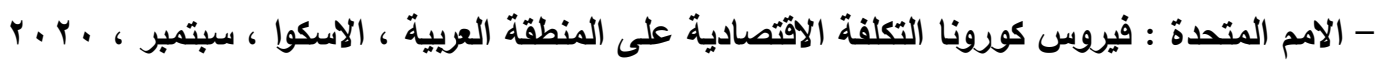

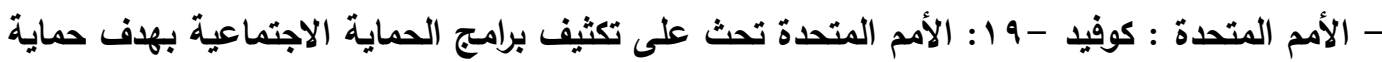

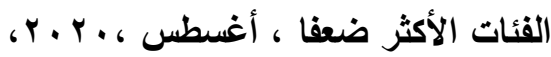
- الامم المتحدة : التقرير العربى للتتمية المستدامة ، لجنة الامم المتحدة الاقتصادية والاجتماعية لغربى

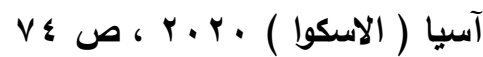
- المنظمة العربية للتربية والثقافة والعظوم: جائحة كورونا revid-19 وتداعياتهاعلى أهداف التنمية

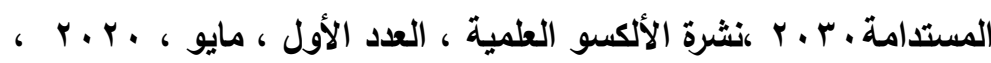

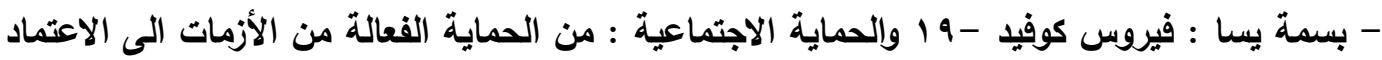

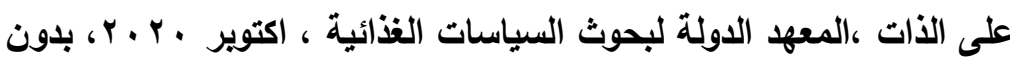

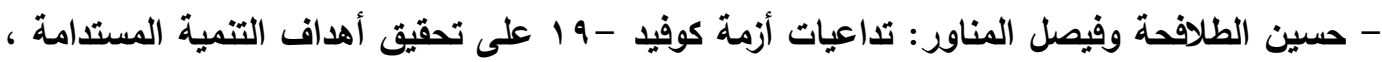

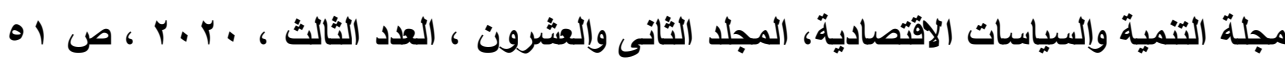

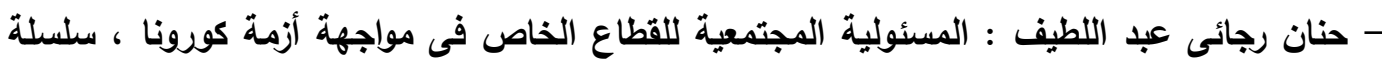

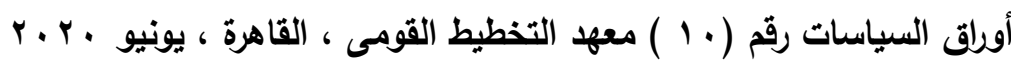

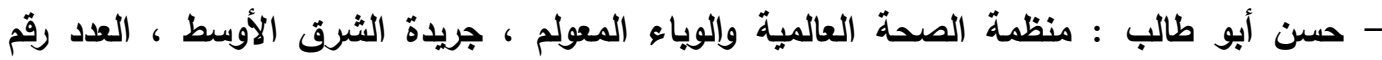

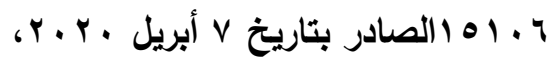


- دعاء عبد المنعم : أثر كورونا على الدول النامية ، جريدة الأهرام اليومية ، مؤسسة الأهرام ، القاهرة

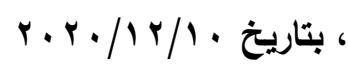
- عبد الغفار عفيفى الدويك : آراء المجتمع المدنى ومواجهة جائحة فيروس كورونا ، جريدة الأهرام

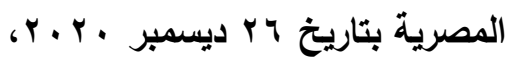
- علاء غنام ، أحمد عزب : الدور المجتمعى المأمول لمواجهة أزمة كورونا ، دورية المبلف المبادية المصرى ،

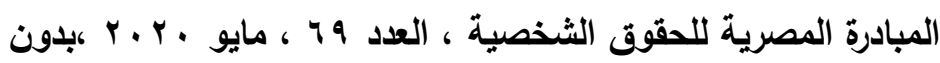

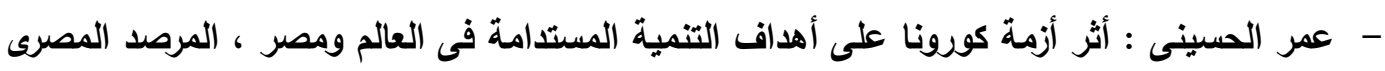

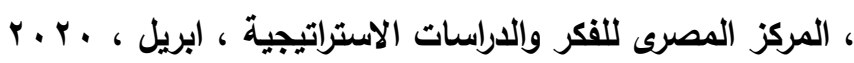

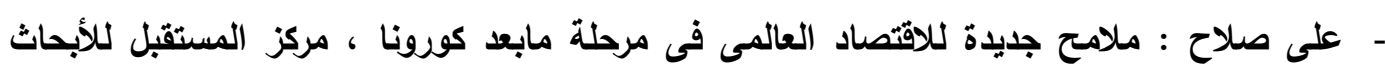

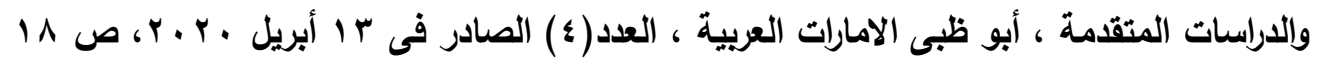

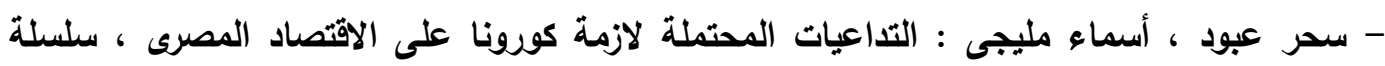

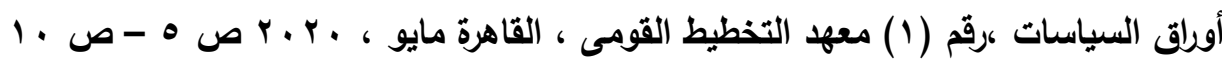

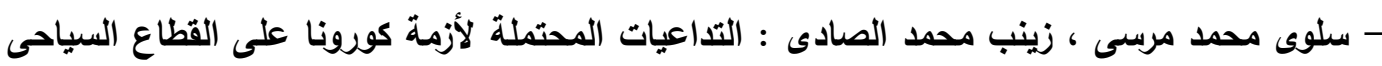

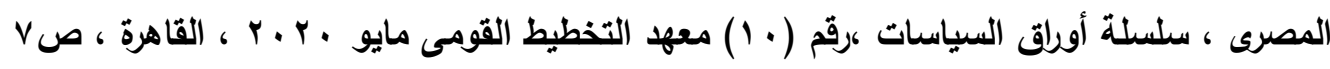

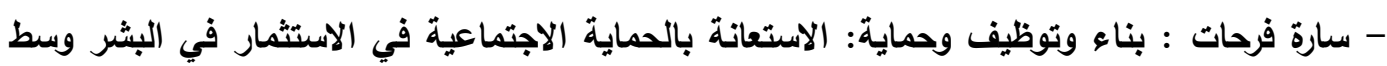

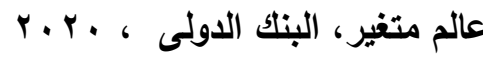

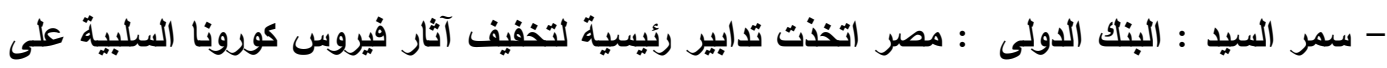

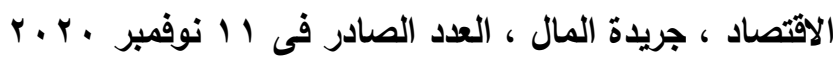

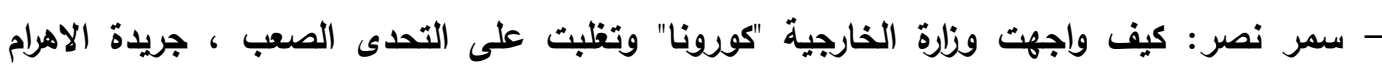

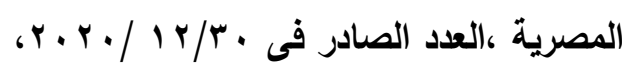
- شيرين جابر : عالم مابعد الكورونا روئة استشرافية ، مقالات صادرة عن مركز الدراسات الإستراتيجية

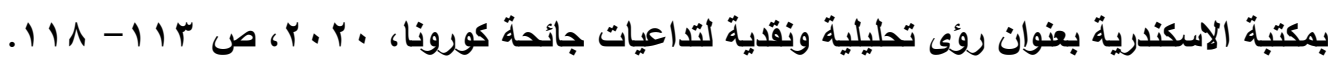

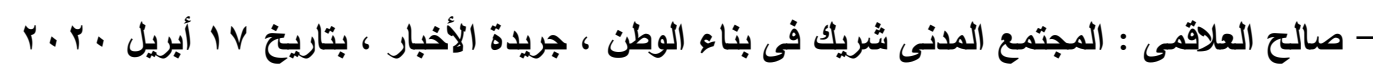

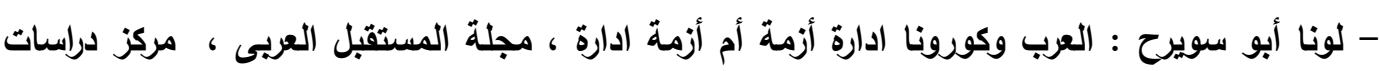

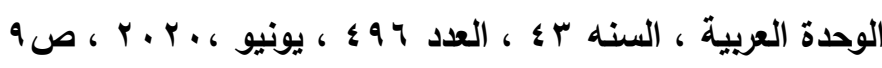

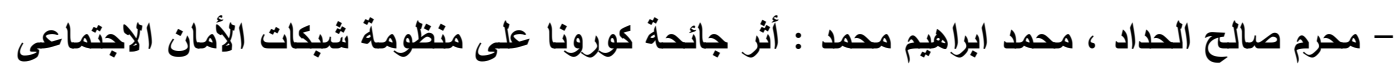

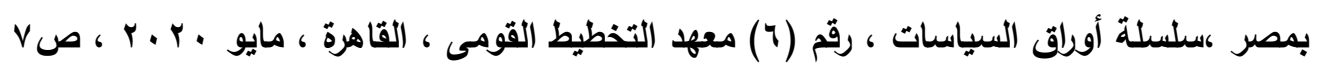

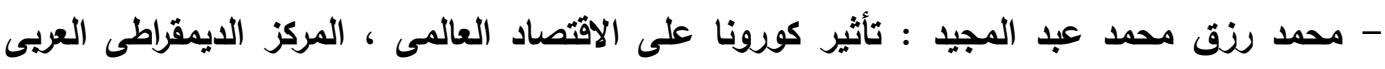

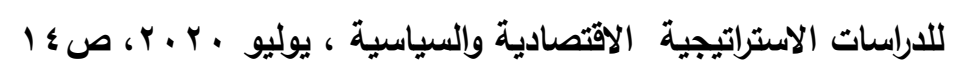

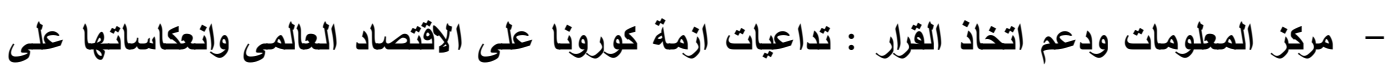

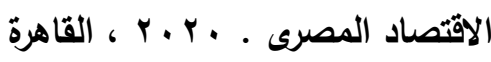
- ماجدة شاهين :الاقتصاد المصرى وأزمة فيروس كورونا المستجد كوفيد 9 ، ، المجلس المصرى للثئون الخارجية ، بدون ماهن - محمود محي الدين : أزمـة كورونا آثارها ايجابية على اقتصاد مصر على المدى المتوسط ، جريدة

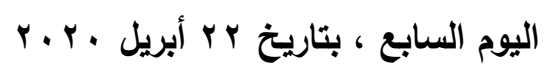


- منار رمضان : كورونا تلقى بظلالها على اهداف التنمية المستدامة فهل ستعيد ترتيبها ، مركز الإعلام

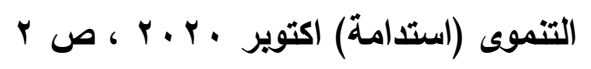

- محمود عبدالله : خبراء: نجاح الدولة فى مواجهة كورونا وراء اثلادة المؤسسات الدولية بالاقتصاد

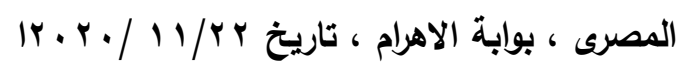

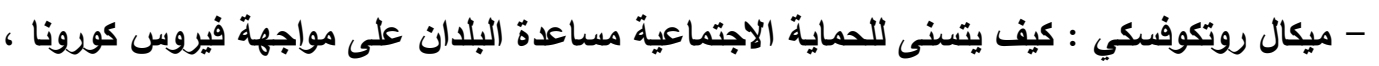

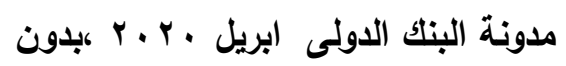

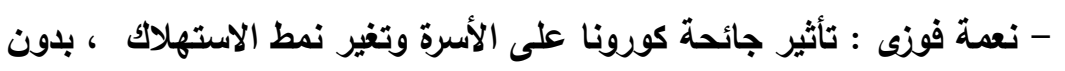

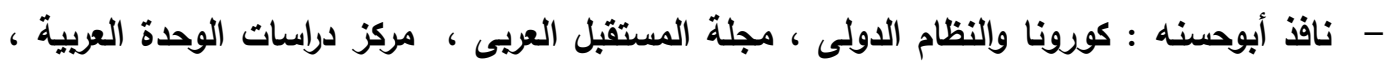

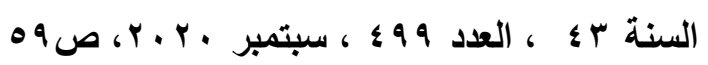

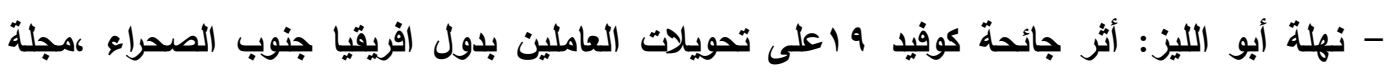

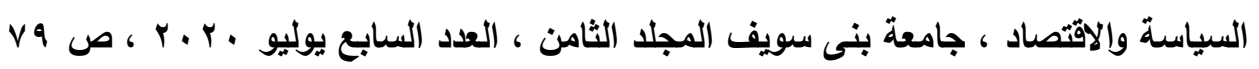

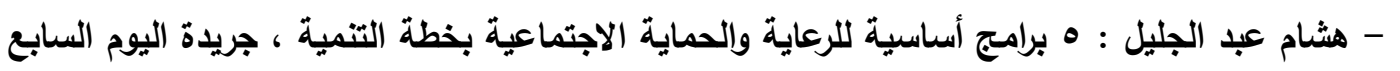

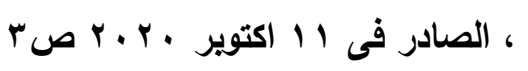

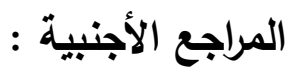

-United Nation Research Institute for Social Development (UNRISD) Combating Poverty and Inequality: Structural change, Social Policy and Politics, 2010, p: 135

-World bank, COVID-19 Crisis Through a Migration Lens, Migration and Development, Brief no. 32 , world bank Washington D.C., April 2020, p.8 -Paulson jr M.Henry:7 Principles for a Post- Corona Virus economy, April $10,2020, p .10$

-Alondra Nelson: Covid-19 and the Social sciences society After Pandemie, April ,23,2020

-United Nation : Social Protection responses to the Covid-19 Crisis in the MENA,Arab Sstates region,(BC-SP), July.2020

-World Tourism Organization,UNWTO:International Tourism Arrivals Could Fall By 20-30\% in 2020 ,newsrelease,27 March,2020,p.21

-World Health Organization: Consideration for implementing and adjusting public health and social measures in the context of Covid-19,

4November,2020 .p.3

- The Sustainable Development Goals Report- 2019 Arabic

-World Health Organization:Covid-19: Occupational health and safety for health workers,2February 2021

-World Tourism Organization, UNWTO: International Tourism Arrivals

Could Fall By 20-30\% in 2020 ,news release,27 March,2020 ,p.21 
- world bank, COVID-19 Crisis Through a Migration Lens, Migration and Development, Brief no. 32 , world bank Washington D.C., April 2020), p.8 -UNICEF MEAN: The Impact of Covid-19 on Cheeldren on the Middle East ، .and North Africa,November2020

- Ishac Diwan, Nadim Houry and Others: Egypt after the Coronavirus:

Back to Square One,26 August, 2020

-Vinay Sharma: COVID-19 Challenges and Response: How

procurement underpins the World Bank's response to the pandemic, World Bank, 15 APRIL, 2020

$$
\text { مواقع الكترونية : }
$$

- https://www.arab-reform.net/publication/egypt-after-the-coronavirushttps://blogs.worldbank.org/voices/covid-19-challenges-and-responsehow-procurement-underpins-world-banks-response-pan

-https://www.albankaldawli.org/ar/news/factsheet/2020/02/11/how-theworld-bank-group-is-helping-countries-with-covid-19-coronavirus -https://www.imf.org/ar/News/Articles/2020/03/04/sp030420-imf-makesavailable-50-billionh-to-help-address-coronavirus https://www.scientificamerican.com/arabic/articles/news/recommendations -help-governments-to-deal-with-future-pandemics http://repository.inp.edu.eg/bitstream/handle/123456789/4876/10.pdf? ue https://www.moss.gov.eg/ar-eg/Pages/programs-listing.aspx https://enterprise.press/issues/2020/08/11/poll-sees-cbe-leaving-rateshold-inflation-july

https://www.albankaldawli.org/ar/news/immersive-story/2019/07/29/buildemploy-and-protect-using-social-protection-to-invest-in-people-in-achanging-world

https://blogs.worldbank.org/ar/voices/how-social-protection-can-helpcountries-cope-covid-19

https://asdr.unescwa.org/sdgs/pdf/ar/ASDR2020-Final-Online.pdf http://www.alecso.org/nsite/images/pdf/corona-final1.pdf https://www.eg.undp.org/content/egypt/ar/home/ourwork/sustainable development/overview.html https://www.imf.org/ar/News/Articles/2020/07/09/na070920-egypt-takesproactive-approach-to-limit-the-pandemics-fallou https://arabic.cnn.com/business/article/2020/08/18/egypt-unemployment- 